\title{
Genetische Analyse von Heterosis im jüngsten Stadium einer Pflanze, als Embryo, am Beispiel der Fababohne (Vicia faba L.)
}

Dissertation zur Erlangung des Doktorgrades der

Fakultät für Agrarwissenschaften der Georg-August-Universität Göttingen

vorgelegt von Susanne Dieckmann geb. Voges

geboren in Hannover

Göttingen, im April 2007 
D 7

1. Referent: Prof. Dr. Wolfgang Link

2. Korreferent: Prof. Dr. Bernward Märländer

Tag der mündlichen Prüfung: 20.04.2007 


\section{Inhaltsverzeichnis}

\section{EINLEITUNG}

1.1 Heterosis 1

1.2 Heterosis des Samens am Beispiel der Ackerbohne (Vicia faba L.) 2

$\begin{array}{lll}1.3 & \text { ZIELSETZUNG } & 4\end{array}$

$\underline{2}$ MATERIAL UND METHODEN

2.1 Pflanzenmaterial $\quad 6$

$\begin{array}{lll}2.2 & \text { STANDORT } & 7\end{array}$

2.3 VERSUCHSDURCHFÜHRUNG

2.4 ERTRAgSPHYSIOLOGISCHE StUdien 9

2.5 EXPERIMENT 1: DialleLANALYSE

2.5.1 FREILANDVERSUCHE 10

2.5.2 BIOMASSEVERSUCHE 12

2.5.3 DATENANALYSE 13

2.6 EXPERIMENT 2: KONKURRENZ 14

2.6.1 VERSUCHSDURCHFÜHRUNG 14

2.6.2 DATENANALYSE 16

2.7 EXPERIMENT 3: TROCKENSTRESS

2.7.1 VERSUCHSDURCHFÜHRUNG 16

$\begin{array}{ll}2.7 .2 & \text { DATENANALYSE } \\ & 17\end{array}$

2.8 EXPERIMENT 4: NATÜRLICHE Befruchtung 18

2.8.1 VERSUCHSDURCHFÜHRUNG 18

2.8.2 DATENANALYSE 20

2.9 EXPERIMENT 5: CMS VERSUCH 20

2.9.1 VERSUCHSDURCHFÜHRUNG 20

2.9.2 DATENANALYSE 22

$\underline{3}$ ERGEBNISSE $\quad 23$

3.1 ERTRAGSPHYSIOLOGISCHE StUdIEN 23

3.2 EXPERIMENT 1: DialLeLANALYSE 25

3.2.1 FREILANDVERSUCHE

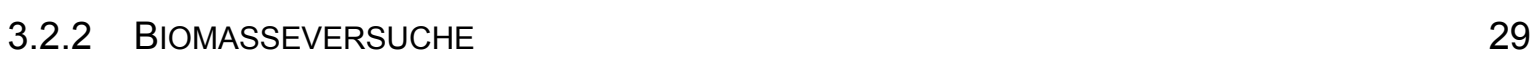


3.3 EXPERIMENT 2: KONKURRENZ

3.4 EXPERIMENT 3: TROCKENSTRESS

3.5 EXPERIMENT 4: NATÜRLICHE BEFRUCHTUNG 36

3.6 EXPERIMENT 5: CMS VERSUCH

4.1 METHODENKRITIK

4.1.1 PFLANZENMATERIAL

4.1.2 ERTRAGSPHYSIOLOGISCHE STUDIEN

4.1.3 NAH-INFRAROT-REFLEXIONS-SPEKTROSKOPIE (NIRS)

4.2 SAMENHETEROSIS 49

4.3 Heterosis der Biomasse 52

4.4 KONKURRENZ UM RESSOURCEN 54

4.5 VerWANDTSChAFT UND SAMENGRÖßE 58

4.6 ERTRAgSWIRKUNG 61

4.7 SCHLUßBETRACHTUNG

6 SUMMARY 
Abkürzungsverzeichnis

$\% \quad$ Prozent

${ }^{\circ} \mathrm{C} \quad$ Grad Celsius

A Österreich

$A_{i / j} \quad$ Additiveffekt der Allele i bzw. $j$

Abb. Abbildung

AFLP Amplified Fragment Length Polymorphism

Am maternaler Additiveffekt

bzw. Beziehungsweise

C Zytoplasmatischer Effekt

CMS Zytoplasmatisch männliche steril

CZ Tschechische Republik

D Deutschland

$D_{i / j} \quad$ Dominanzeffekt der Allele i bzw. j

d.h. Das heißt

Dm maternaler Dominanzeffekt

DNS/ DNA Desoxyribonukleinsäure

EM Elternmittel

F Frankreich

g Gramm

GD Grenzdifferenz

$\mathrm{H} \quad$ Heterosis über das Elternmittel. $H=D_{\mathrm{ij}}-1 / 2\left(D_{\mathrm{ii}}+D_{\mathrm{ji}}\right)$

HP Hedin/2 x Pietranera

Hy Hybridüberlegenheit über den selbstbefruchteten Samen

m Meter

mg Milligramm

MxCE Minica $x$ Canner Express

NIRS Nah- Infrarot- Reflexions- Spektroskopie

NS Nicht signifikant

$r \quad$ Korrelationskoeffizient

Tab. Tabelle

TKG Tausendkorngewicht

vs. Versus (im Vergleich zu)

z.B. Zum Beispiel 
Tabellenverzeichnis

Tab. 1 Übersicht über die verwendeten Genotypen 6

Tab. 2 Temperatur und Niederschläge der Jahre 2004 bis 2006 am Stand- 8 ort Reinshof, Göttingen (http://www.wetterstation-goettingen.de)

Tab. 3 Verwendete Genotypen für ertragsphysiologische Studien 9

Tab. 4 Übersicht über die in Experiment 1 verwendeten Genotypen, deren 10 Samengrößen und Verwandtschaftskoeffizienten (f)

Tab. 5 Samengenerationen mit Reziproken $(R)$ des diallelen Kreuzungs- 11 schemas in Anlehnung an Dani und Kohel (1989)

Tab. 6 Zerlegung des genotypischen Wertes der Samen in genetische Ef- 12 fekte, nach Zhu and Weir (1994)

Tab. 7 Übersicht über die in Experiment 2 verwendeten Genotypen 14

Tab. 8 Übersicht über die verwendeten Genotypen in Experiment $3 \quad 16$

Tab. 9 Übersicht über die verwendeten Genotypen im Experiment 4, deren 18 Samengröße und Verwandtschaftskoeffizient (f)

Tab. 10 Übersicht über die in Experiment 5 verwendeten Genotypen 21

Tab. 11 Anzahl Hülsen/Pflanze, Samen/Pflanze und mittlere Samengewich- 23 te der untersuchten Genotyopen

Tab. 12 Komponenten der genetischen Varianz der Diallelanalyse und de- 26 ren Standardfehler

Tab. 13 Zerlegung des genotypischen Wertes und Darstellung der Heterosis 27 in Experiment 1, in Anlehnung an Zhu and Weir (1994)

Tab. 14 Heterosis $(\mathrm{H})$ der Kreuzungen des Diallels in $\mathrm{mg}$ und in Prozent über das Elternmittel

Tab. 15 Genetische Varianzen der Biomasseversuche, deren Standardfehler 29 und Signifikanzen

Tab. 16 Vergleich der Heterosis $(\mathrm{H})$ der Samengewichte und der Biomasse 29 der Kreuzungen des Diallels in mg

Tab. 17 Auszug aus der Varianzanalyse des Experimentes 2. Merkmal: Sa- 30 mengewicht (mg)

Tab. 18 Zerlegung des genotypischen Wertes und Darstellung der Hybridüberlegenheit bezogen auf die Mutter (Hy) in Experiment 2, in Anlehnung an Zhu (1997)

Tab. 19 Mittlere Samengewichte (mg) in den Konkurrenzsituationen und 
Behandlungen im Mittel über Mutter- und Vatergenotypen

Tab. 20 Mittlere Samengewichte (mg) und Hybridüberlegenheit (Hy, \% nach Gleichung 4, Tab.18), realisiert auf den Muttergenotypen, in Abhängigkeit von Konkurrenzsituation, Vatergenotyp und Behandlung

Tab. 21 Mittlere Samengewichte $(\mathrm{mg})$ über Vatergenotypen und Behandlun- 33 gen im Mittel über beide Muttergenotypen

Tab. 22 Mittlere Samengewichte $(\mathrm{mg})$ der fremd- und selbstbefruchteten 34 Samen des Experimentes 3 und Hybridüberlegenheiten $(\mathrm{Hy}, \%)$ in Abhängigkeit von Jahr und Stressvariante. Mittel über Kreuzungen und Varianten

Tab. 23 Mittlere Samengewichte $(\mathrm{mg})$ der fremd- und selbstbefruchteten 35 Samen des Experimentes 3 in Abhängigkeit von der Variante, Mittel über Kreuzungen, Jahre und Stressvarianten

Tab. 24 Auszug aus der Varianzanalyse des Experimentes 3. Merkmal: Sa- 35 mengewicht (mg)

Tab. 25 Mittlere Samengewichte $(\mathrm{mg})$ der fremdbefruchteten Samen über die Mutter- und Vatergenotypen des Experimentes 4, Mittelwerte über Jahre

Tab. 26 Mittlere Samengewichte der Muttergenotypen über beide Behandlungen und Hybridüberlegenheit $(\mathrm{Hy}, \%)$, Mittel über Väter und Jahre

Tab. 27 Auszug aus der Varianzanalyse des Genotyps L2 (MxCE) im Expe- 39 riment 4

Tab. 28 Auszug aus der Varianzanalyse der Genotypen Gloria/5 und Gobo- 39 il1 im Experiment 4

Tab. 29 Auszug aus der Varianzanalyse des Genotyps Troy/1 im Experiment 4

Tab. 30 Auszüge aus der Varianzanalyse des Experimentes 5

Tab. 31 Einzelpflanzenertrag (g) der Muttergenotypen in Abhängigkeit von der Behandlung

Tab. 32 Anzahl Samen pro Pflanze und Anzahl Hülsen pro Pflanze in Abhängigkeit von Muttergenotyp und Behandlung

Tab. 33 Tausendkorngewicht (mg) der Muttergenotypen in Abhängigkeit von der Behandlung

Tab. 34 Reziprokendifferenzen in verschiedenen Generationen (Melchinger et al., 1984)

Tab. 35 Genetische Ähnlichkeiten für Samengröße und Restgenom der 
Abbildungsverzeichnis

Abb. 1 Typen der Nährstoffspeicherung, verändert nach Jacob und Jäger (1987). 1: Nährstoffspeicherung mit Endosperm (Beispiel: Ricinus communis). 2: Nährstoffspeicherung mit Speicherkotyledonen (Beispiel: Vicia faba). $\mathrm{E}=$ Endosperm, Em= Embryo

Abb. 2 Ackerbohnenzuchtgarten 2004. Isolierhäuser zum Ausschluss von bestäubenden Insekten

Abb. 3 Schematische Darstellung der Behandlungen im Experiment 215

Abb. 4 Beispielhafte Darstellung einer Wiederholung des Experimentes 4. 1-4= Vatergenotypen, A-E= Muttergenotypen (siehe Tab. 9)

Abb. 5 Schematische Darstellung einer Parzelle des Experimentes 5

Abb. 6 Mittleres Samengewicht (mg) der sechs Genotypen in Abhängig- 23 keit von der Anzahl Samen pro Hülse

Abb. 7 Mittleres Samengewicht (mg) der sechs Genotypen in Abhängigkeit von der Samenposition in der Hülse

Abb. 8 Mittleres Samengewicht (mg) in Abhängigkeit von der Position der Infloreszenz auf der Mutterpflanze. Mittel über Genotypen

Abb. 9 Heterosis im Vergleich über die reziproken Kreuzungsrichtungen 28 und die Samengröße der jeweiligen Mutter, Heterosisgleichungen [1] \&[3] siehe Tab.13

Abb. 10 Reziprokenspezifische Heterosis der einzelnen Kreuzungen des Diallels in Abhängigkeit von dem $\mathrm{F}_{1}$ Samengewicht, Heterosisgleichungen [1+3], siehe Tab.13

Abb. 11 Hybridüberlegenheit ( $\mathrm{Hy}, \%$ und $\mathrm{mg}$ ) der fremdbefruchteten Samen über die mütterlichen Selbstungssamen in den Kreuzungen des Experimentes 4. GD1: Grenzdifferenz $(0,05)$ für $\mathrm{Hy}(\mathrm{mg})$ der Kreuzungen mit Gobo-il1 und Gloria/5. GD2: Grenzdifferenz $(0,05)$ für $\mathrm{Hy}(\mathrm{mg})$ der Kreuzungen mit Troy/1. M= Klassifizierung wurde mit morphologischen Markern durchgeführt.

Abb. 12 Vergleich der reziprokenspezifischen Heterosis $(H,[1]$ siehe

Tab.13) der Samengewichte und der Biomasse der Kreuzungen des Diallels in Experiment 1 in Abhängigkeit von der mütterlichen Samengröße und Verwandtschaft zwischen den Kreuzungseltern in $\mathrm{mg}$ 


\section{$1 \quad$ Einleitung}

\subsection{Heterosis}

Heterosis, die Mehrleistung der Hybride über das Mittel ihrer homozygoten Eltern, wurde erstmals von Shull (1908) beschrieben. Das Phänomen tritt bei höheren Pflanzen und Tieren gleichermaßen auf und wird bei hochgradig heterozygoten Genotypen beobachtet. Heterosis manifestiert sich neben einer höheren Ertragsleistung und Ertragsstabilität auch in erhöhter Fertilität und Resistenz gegenüber Krankheiten und Schädlingen (Birchler et al., 2003). Mit Ausnahme der Linienzüchtung ist Heterosis von bedeutendem Einfluß auf den Ertrag in allen Züchtungskategorien (Schnell, 1982). Bei fremdbefruchtenden Arten wie Mais, Roggen und Sonnenblumen kann Heterosis zu Ertragssteigerungen von über 200\% über das homozygote Elternmittel führen (Gallais, 1988; Becker, 1993).

Mit mindestens drei Hypothesen wird versucht, das genetische Phänomen Heterosis zu erklären. Die (1) Dominanzhypothese sagt, dass rezessive Allele mit negativem Einfluß in der heterozygoten Hybride durch dominante Allele verdeckt werden (Meyer et al., 2006). Die (2) Überdominanzhypothese sagt, dass der heterozygote Genotyp in seiner phänotypischen Leistung beiden entsprechenden homozygoten Genotypen überlegen ist (Uzarowska et al., 2006). Die (3) Epistasiehypothese sagt, dass die Heterosis überwiegend das Ergebnis von epistatischen Wechselwirkungen zwischen verschiedenen Genen ist (Becker, 1993). Trotz der wirtschaftlichen Relevanz dieses Phänomens sind die genetischen Ursachen der Heterosis bisher weitgehend ungeklärt. Verschiedene klassisch- genetische Studien versuchten die unterschiedlichen Gen- Wirkungsweisen in ihrer Bedeutung für die Heterosis zu untersuchen, so konnten Fu und Dooner (2002) anhand von DNA-Sequenzierungsdaten die Dominanzhypothese erweitern. Sie fanden heraus, dass sich möglicherweise fehlende funktionale Gene einer Maislinie bei Vorhandensein in der zweiten Elternlinie in der Hybride komplementieren und eine heterotische Wirkung induzieren. Der Einfluß der Überdominanz auf die Heterosis ist nicht vollständig geklärt, biometrische Analysen haben aber angedeutet, dass die Überdominanz im Vergleich zur Dominanz eine untergeordnete Rolle spielt (Gallais, 1988). Auch epistatische Effekte sind nur in Ausnahmefällen für die Erklärung von Heterosis von Bedeutung (Becker, 1993). Mit der Einführung molekularer Marker in den späten 1980er können detaillierte Studien zur genetischen Architek- 
tur komplexer quantitativer Merkmale durchgeführt werden. QTL- Analysen zur Aufklärung der genetischen Ursachen der Heterosis sind Gegenstand der aktuellen Züchtungsforschung (Reif et al., 2005; Lippmann and Zamir, 2006). Verschiedene physiologische und molekulare Mechanismen, die dem Phänomen Heterosis zugrunde liegen sollen bzw. es auch nur begleiten, wurden vorgeschlagen (Meyer et al., 2004). Tsaftaris et al. (1995) führten Untersuchungen zum Methylierungsgrad genomischer DNA durch, um einen möglichen Einfluß der DNA- Methylierung auf die Unterdrückung von Genaktivitäten zu analysieren. Genexpressionsstudien zum Vergleich von Hybriden und Linien sollen genetische Grundlagen der Heterosis klären (Meyer et al., 2006).

Aufgrund der phänotypischen Komplexität der Heterosis ist bisher wenig über die fundamentalen Prozesse bekannt, die zur Heterosis führen. Besonders die Identifizierung von heterosisrelevanten Genen und deren Interaktionen ist bis heute ein weitgehend ungeklärter aber wichtiger Bereich, um die genetische Basis von Heterosis detailliert zu analysieren (Lippmann and Zamir, 2006).

\subsection{Heterosis des Samens am Beispiel der Ackerbohne (Vicia faba L.)}

Heterosis ist ein bekanntes Phänomen, insbesondere für Merkmale wie Ertrag und Biomasse, und wird üblicherweise an Merkmalen der Pflanze oder des Pflanzenbestandes gemessen. Sie kann aber auch schon im frühesten Stadium der Pflanze, am Embryo oder Samen, untersucht werden. Wenn Hybridpflanzen größer und wüchsiger sind als ihre ingezüchteten Eltern, so könnte auch der Hybridsame in seinem Samengewicht einem vergleichbaren homozygoten Samen überlegen sein. Nach Davies (1975) zeigen heterozygote Samen eine erhöhte AssimilatAneignung, sie sind für Assimilate stärkere Senken als homozygote Samen. Duc et al. (2001) konnten an drei Ackerbohnenlinien in offener Bestäubungssituation eine gewichtsmäßige Überlegenheit der Hybridsamen über die Selbstungssamen finden, die sie mit einer erhöhten Zellzahl in den Hybrid- Kotyledonen erklären konnten. Darüber hinaus fanden sie einen Zusammenhang zwischen dem heterotischen Effekt auf die Samengröße und der Heterosis der Biomasseproduktion der $F_{1}$ - Pflanzen, die aus diesen Samen erwachsen, was darauf schließen lässt, dass die Heterosis des Samens und die Heterosis der $F_{1}$ - Pflanze eine ähnliche genetische Basis haben. Duc und Rowland (1990) konnten zeigen, dass es unter abioti- 
schem Stress bevorzugt zu einer Abstoßung der Selbstungssamen kommt, während die Hybridsamen von der Mutterpflanze eher weiter ernährt werden.

Der wachsende und reifende Same verbindet zwei Generationen: er ist Bestandteil des Phänotyps der Mutter in Merkmalen wie dem Kornertrag, er kann seinen eigenen Phänotyp für bestimmte Merkmale ausbilden (Xenien), und er repräsentiert die nächste Generation. Dabei kann er sich genetisch auf zweierlei Weise vom Genotyp seiner Mutterpflanze unterscheiden: in seiner allelischen Komposition und in seinem Inzuchtstatus. Eine zu untersuchende Frage ist, ob ein heterozygoter, nicht ingezüchteter Same (Hybridsame) Heterosis für sein Gewicht bei Reife zeigt und dabei insbesondere einem homozygoten Geschwister- Same (Selbstungssame) überlegen ist. Darüber hinaus bleibt unter anderem zu beantworten, welchen Einfluß Gene der Mutter bzw. des Vaters für Samengröße auf das Gewicht der auf ihr wachsenden bzw. von ihm befruchteten Samen haben. Die Ackerbohne eignet sich für diese Studien besonders gut, weil sie zu den partiell allogamen Kulturarten zählt und damit natürlicherweise Fremd- und Selbstbefruchtung stattfinden. Dabei liegt die Fremdbefruchtungsrate zwischen 38,4\% und 72,5\% mit einem Mittel von 53,7\% (Link et al., 1994). Darüber hinaus findet sich eine große genetische Variation für das Merkmal Samengröße in gut adaptiertem Material.

Die Ackerbohne gehört zu den Kulturen, deren Nährstoffspeicherung im Samen mittels Speicherkotyledonen durchgeführt wird. Der Endospermanteil im Samen ist deshalb sehr niedrig (Jacob und Jäger, 1987), und ein Einfluß eines triploiden Endosperms (durch doppelte Befruchtung) auf das reife Samengewicht ist weitestgehend auszuschließen (siehe Abb.1).

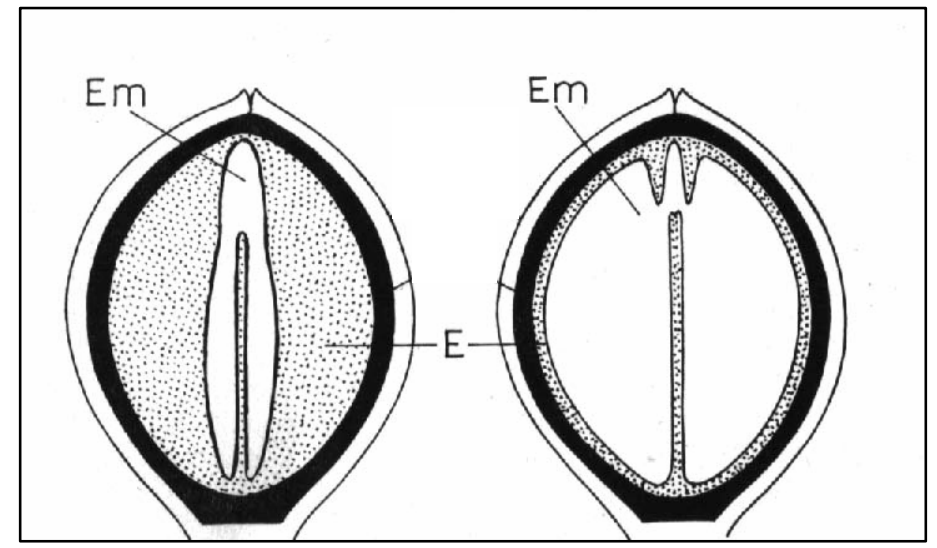

Abb. 1: Typen der Nährstoffspeicherung, verändert nach Jacob und Jäger (1987). 1: Nährstoffspeicherung mit Endosperm (Beispiel: Ricinus communis). 2: Nährstoffspeicherung mit Speicherkotyledonen (Beispiel: Vicia faba). E= Endosperm, Em= Embryo 
Der Ackerbohnensame setzt sich aus maternalem und embryonalem Gewebe zusammen. Deren Entwicklung vollzieht sich nacheinander, erst wird das maternale Gewebe ausgebildet, im Anschluß folgen die embryonalen Organe (Embryo und Endosperm). Diese differenzieren sich später zu hoch spezialisierten Speicherorganen. Die Differenzierung ist ein andauernder Prozess von Zellteilung, Zellwachstum, Zuckereinlagerung und durch photosynthetische Aktivität bedingte Einlagerung von Speicherprodukten, der histologisch in verschiedene Phasen eingeteilt wird. Die Samenentwicklung ist genetisch kodiert und kann in Verbindung gesetzt werden mit Konzentrationsveränderungen verschiedener Stoffwechselprodukte. Während der Differenzierung der Speicherkotyledonen von Vicia faba konnten Veränderungen der Glukosekonzentrationen nachgewiesen werden, die in direkter Verbindung zur mitotischen Aktivität stehen. Auch die Saccharosekonzentration in verschiedenen Zellen der Speicherkotyledonen verändert sich während der Differenzierung und konnte mit dem Transkriptionsniveau verschiedener Enzyme der Stärkebiosynthese in Verbindung gebracht werden. In Leguminosenembryonen wird die Komposition und Konzentration der Zucker im Endosperm durch die Samenschale gesteuert. Das bestätigt einen großen Einfluß des maternalen Gewebes auf die Zellentwicklung des Embryos und auf die Samengröße (Borisjuk et al., 2004).

\subsection{Zielsetzung}

Ziel dieser Arbeit ist der Vergleich von fremd- und selbstbefruchteten Samen in ihrem Samengewicht zur Reifezeit und die damit verbundene Analyse der Heterosis des Samengewichtes. Zusätzlich soll die Samenheterosis in ihrer Abhängigkeit von Umwelten und elterlicher Kombination detailliert studiert werden. In Feld- und Gewächshausversuchen sollen Genotypen verschiedener Verwandtschaftsbeziehungen und Samengrößen miteinander angepaart werden. Das Samengewicht von fremd- und selbstbefruchteten Samen soll in verschiedenen Konkurrenz- und Stresssituationen untersucht werden. Zusätzlich soll ein möglicher Zusammenhang zwischen der Samenheterosis und der Heterosis für Biomasse von Jungpflanzen untersucht werden. Der Einfluß der Samenheterosis auf den Einzelpflanzenertrag soll ebenfalls studiert werden. Eine Methode zur Detektierung von fremd- vs. selbstbefruchteten Samen soll für die unter natürlicher Bestäubungssituation wachsenden Samen anhand von Spektraldaten entwickelt werden. 
Die zu untersuchenden Hypothesen lauten:

1. Fremdbefruchtete Samen werden größer als selbstbefruchtete Samen.

2. Der heranwachsende Same hat einen signifikanten genetischen Einfluß auf seine eigene Samengröße.

3. Die Heterozygotie des Samens ist entscheidend für den heterotischen Effekt auf seine Größe.

4. Es besteht ein enger Zusammenhang zwischen der Genetik der Samenheterosis und der klassischen Heterosis für Biomasse.

5. Direkte Assimilat- Konkurrenz zwischen fremd- und selbstbefruchteten Samen innerhalb einer Infloreszenz bzw. in einer Hülse erhöht den heterotischen Kontrast im Samengewicht.

6. Unter abiotischem Stress erhöht sich ebenfalls der heterotische Kontrast im Samengewicht.

7. Der Ertrag einer Pflanze ist größer wenn die auf ihr wachsenden Samen heterozygot sind, als wenn sie homozygot sind. 


\section{Material und Methoden}

\subsection{Pflanzenmaterial}

Das untersuchte Pflanzenmaterial umfasste 17 Genotypen verschiedener Herkunft und Samengrößen (siehe Tab. 1)

Tabelle 1: Übersicht über die verwendeten Genotypen

\begin{tabular}{|c|c|c|c|c|}
\hline Genotyp & Herkunft & Varietät & $\mathrm{TKG}^{3}$ & Generation $^{1}$ \\
\hline Gloria/5 & SZ Gleisdorf & minor & 350 & $\mathrm{~F}>20$ \\
\hline $\mathrm{L} 2\left(\mathrm{MxCE}^{4}\right)$ & Göttingen (D) & major & 980 & $\mathrm{~F}>20$ \\
\hline Hedin/2 & Franck SHA (D) & minor & 300 & $\mathrm{~F}>20$ \\
\hline Troy/1 & NPZ (D) & minor & 350 & $\mathrm{~F}>20$ \\
\hline Gobo-il1 & Göttingen (D) & minor & 430 & $\mathrm{BC}_{2}$ \\
\hline HP58 ${ }^{2}$ & Göttingen (D) & major & 1300 & $\mathrm{~F}_{13}$ \\
\hline HP69 ${ }^{2}$ & Göttingen (D) & minor & 500 & $\mathrm{~F}_{13}$ \\
\hline Maya/2 & Serasem $(F)$ & minor & 430 & $\mathrm{~F}>20$ \\
\hline Merkur/2 & Selgen (CZ) & minor & 390 & $\mathrm{~F}>20$ \\
\hline MarisBead-il1 & Göttingen (D) & minor & 300 & $\mathrm{BC}_{2}$ \\
\hline CMS199 & Göttingen (D) & minor & 300 & $\mathrm{~F}>20$ \\
\hline CMS350 & Rennes (F) & minor & 600 & $\mathrm{~F}>20$ \\
\hline $\mathrm{F}_{1}(\mathrm{CMS199xHF22)}$ & Göttingen (D) & minor & 320 & $\mathrm{~F}>20$ \\
\hline Afg187 & IPK (D) & minor & 300 & $\mathrm{~F}>20$ \\
\hline G58 & Rennes (F) & minor & 600 & $\mathrm{~F}>20$ \\
\hline$F_{1}(A f g 187 x H F 22)$ & Göttingen (D) & minor & 280 & $\mathrm{~F}_{1}$ \\
\hline $\mathrm{F}_{1}[$ Merkur/2xL1(MxCE)] & Göttingen (D) & minor & 700 & $\mathrm{~F}_{1}$ \\
\hline
\end{tabular}

${ }^{1}$ Frühjahr 2004

${ }^{2} \mathrm{HP}=$ Hedin $/ 2 \times$ Pietranera

${ }^{3}$ Aus vorangegangenen Projekten

${ }^{4} \mathrm{MxCE}=$ Minica $\times$ Canner Express

Einige Genotypen stehen in verwandtschaftlichem Verhältnis zueinander, so sind HP58 und HP69 Kreuzungsnachkommen kontrastierender Samengröße aus der Kreuzung Hedin/2 (minor, mit einem TKG von etwa 350g) und Pietranera (major, mit einem TKG von etwa 1800g). Die aus der Kreuzung hervorgegangenen Nachkommen wurden ab der $\mathrm{F}_{2}$-Generation auf das Merkmal Samengröße selektiert, der jeweils kleinste und größte $F_{2}$-Same wurde bis zur Generation $F_{13}$ weiterge- 
führt. Ziel hier war der Einsatz von Genotypen mit kontrastierender Samengröße bei ansonsten ähnlichem genetischen Hintergrund, um den Einfluß der Samengröße auf die untersuchte Samenheterosis einschätzen zu können. Des Weiteren war die Sorte Troy Mutter für die Sorte Maya; aus den jeweiligen Sorten stammen die Linien Troy/1 und Maya/2.

Die Genotypen Gobo-il1 und MarisBead-il1 sind mit einem besonderen Merkmal ausgestattet: ihre homozygot grüne Kotyledonenfarbe, eine metabolische Störung im Chlorophyllabbau des reifenden Samens, wurde von Duc et al. (1999) gefunden und dient in dieser Arbeit als morphologischer Marker zur Detektierung von Fremd- vs. Selbstbefruchtung. Als monogenes, rezessives Merkmal führt es zu einer Veränderung der Kotyledonenfarbe vom üblichen gelb zu grün und erlaubt damit in den vorliegenden Experimenten eine Erkennung des Inzuchtstatus des Samens direkt bei seiner Reife. Ein weiteres Merkmal in diesem Zusammenhang ist die rein weiße Blütenfarbe des Genotyps Gloria/5; als pleiotropes, rezessives Merkmal tritt es stets gemeinsam auf mit fehlendem Tannin in der Samenschale und mit einem Fehlen des schwarzen Punktes am Nektarium, der bei den üblichen, bunt blühenden Ackerbohnen deutlich vorhanden ist. In dieser Arbeit diente die rein weiße und bunte Blütenfarbe bzw. das Vorhandensein vs. Fehlen des schwarzen Punktes ebenfalls als morphologischer Marker zur Detektierung von Selbstbefruchtung gegenüber Fremdbefruchtung.

\subsection{Standort}

Alle Feldversuche wurden auf der Versuchsstation der Universität Göttingen, dem Reinshof, durchgeführt. Der Reinshof liegt 165m über NN. Die vorliegenden Böden sind lößbürtige Parabraunerden, die vorherrschende Bodenart Lehm mit durchschnittlich 80 Bodenpunkten. Der langjährige Durchschnitt der Niederschläge beträgt $645 \mathrm{~mm}$, die Jahresdurchschnittstemperatur beträgt $8,7^{\circ} \mathrm{C}$. In allen drei Jahren waren die Temperaturen im Mittel ähnlich (siehe Tab. 2). Die Monate Juni und Juli waren im Jahr 2006 wärmer als in den Vorjahren. Die Niederschlagsmengen waren im Jahr 2006 überdurchschnittlich hoch, im August 2006 fielen deutlich mehr Niederschläge als im August der vorigen Jahre. 
Tabelle 2: Temperatur und Niederschläge der Jahre 2004 bis 2006 am Standort Reinshof, Göttingen (http://www.wetterstation-goettingen.de)

\begin{tabular}{ccccccc}
\hline & \multicolumn{3}{c}{ Temperatur $\left({ }^{\circ} \mathrm{C}\right)$} & \multicolumn{3}{c}{ Niederschlag $(\mathrm{mm})$} \\
\cline { 2 - 7 } $\begin{array}{c}\text { Mahat } \\
\text { Jahr }\end{array}$ & 2004 & 2005 & 2006 & 2004 & 2005 & 2006 \\
\hline März & 4,5 & 4,6 & 2,2 & 27 & 27 & 63 \\
April & 9,1 & 9,3 & 7,8 & 33 & 34 & 58 \\
Mai & 11,0 & 12,2 & 12,5 & 88 & 83 & 97 \\
Juni & 14,9 & 15,1 & 16,3 & 63 & 50 & 95 \\
Juli & 16,1 & 17,9 & 21,7 & 93 & 70 & 83 \\
August & 18,5 & 18,5 & 18,0 & 85 & 63 & 101 \\
September & 13,9 & 15,1 & 16,6 & 48 & 35 & 13 \\
\hline & 12,6 & 13,2 & 13,6 & 437 & 362 & 510 \\
\hline
\end{tabular}

\subsection{Versuchsdurchführung}

Die Experimente wurden im Freiland und im Gewächshaus durchgeführt. Ein Teil der Freilandversuche wurde unter natürlichen Bestäubungsverhältnissen, andere Experimente im Freiland wurden unter kontrollierten Bestäubungsverhältnissen durchgeführt. Um die natürlichen Bestäuber (Bienen und Hummeln) auszuschließen, wurden die Pflanzen in Isolierhäusern angebaut (siehe Abb.2). Die Häuser waren je $3 \mathrm{~m} \times 20 \mathrm{~m} \times 3 \mathrm{~m}$ groß, ein Netzgewebe $\left(2 \times 2 \mathrm{~mm}^{2}\right)$ verhinderte das Eindringen von bestäubenden Insekten. Die Pflanzen wurden mit ca. $10 \mathrm{~cm}$ Abstand innerhalb der Reihen ausgelegt, der Reihenabstand betrug $60 \mathrm{~cm}$ zwischen Doppelreihen und $20 \mathrm{~cm}$ innerhalb einer Doppelreihe.
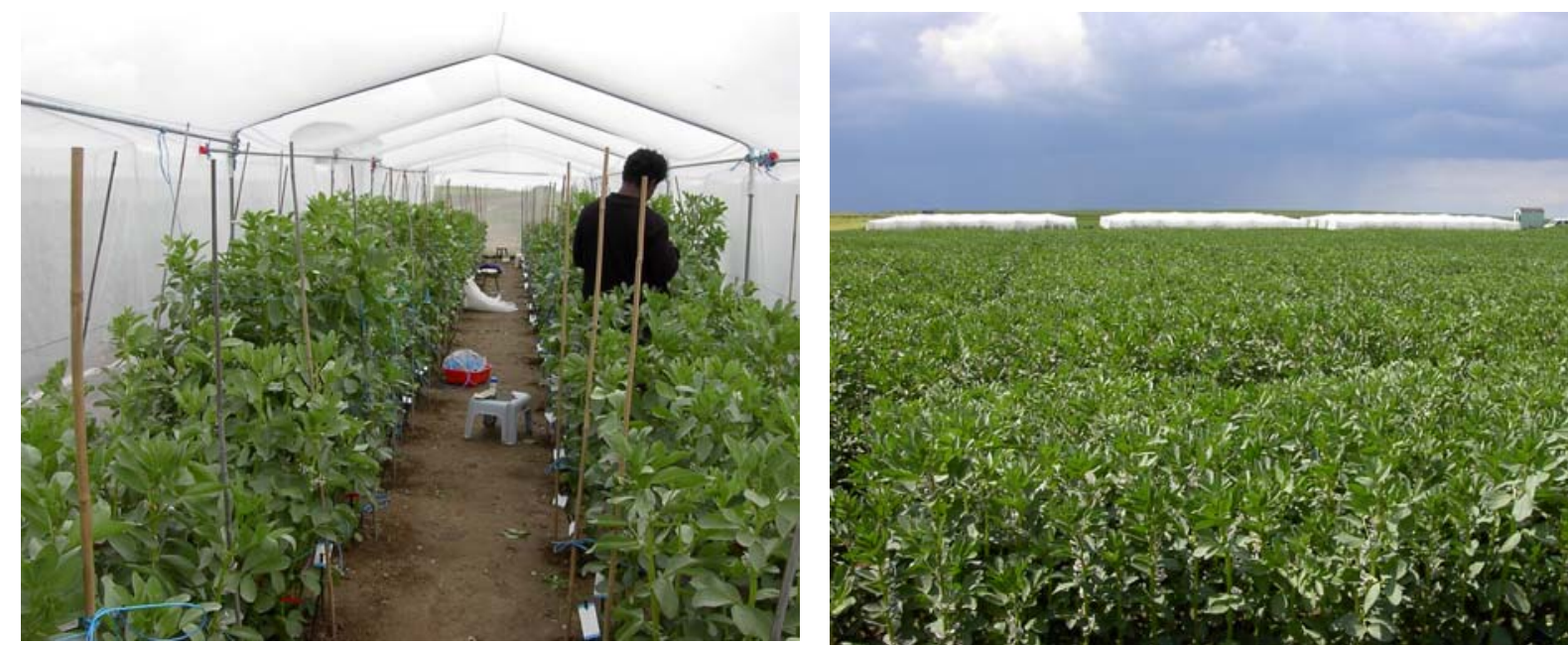

Abbildung 2: Ackerbohnenzuchtgarten 2004. Isolierhäuser zum Ausschluss von bestäubenden Insekten 
Die in den Isolierhäusern gewachsenen Pflanzen wurden in ihrer Ertragsstruktur normiert, indem jede Pflanze auf ihren Haupttrieb und darin auf acht Hülsen mit je einer Hülse pro Nodium (d.h. pro Blütenstand) reduziert wurde. Dazu wurden überzählige Hülsen frühest möglich abgeschnitten, maximal 14 Tage nach dem Aufblühen. Um mögliche Positionseffekte auf die Entwicklung der Samen zu reduzieren, wurden ausschließlich Hülsen der zweiten oder dritten Position in der Infloreszenz zur Weiterentwicklung belassen.

\subsection{Ertragsphysiologische Studien}

Um einen möglichen Einfluß der Samenposition, Hülsenposition und Samenzahl pro Hülse auf das Samengewicht untersuchen zu können, wurden im Jahr 2005 sechs Linien im Freiland unter kontrollierten Bestäubungsverhältnissen angebaut (siehe Tab. 3). Alle Pflanzen wurden in ihrer Ertragsstruktur normiert (siehe Kap. 2.3).

Tabelle 3: Verwendete Genotypen für ertragsphysiologische Studien

\begin{tabular}{ccc}
\hline Genotyp & Varietät & TKG \\
\hline HP58 & major & 1300 \\
HP69 & minor & 500 \\
Gobo-il1 & minor & 430 \\
Gloria/5 & minor & 350 \\
MarisBead-il1 & minor & 320 \\
Hedin/2 & minor & 300 \\
\hline
\end{tabular}

Es wurden je sieben Individuen pro Reihe angebaut, wobei nur die fünf Pflanzen aus der Reihenmitte untersucht wurden, während die weiteren Pflanzen als Randpflanzen eingesetzt wurden. In zwei Isolierhäusern wurden jeweils zwei Reihen angebaut. Alle Blüten einer Pflanze wurden manuell selbstbefruchtet. Die ertragsphysiologischen Untersuchungen wurden einzelpflanzenweise durchgeführt. Für die Faktoren Anzahl Samen pro Hülse, Samenposition in der Hülse und Position der Infloreszenz an der Pflanze wurden jeweils einzelne Varianzanalysen durchgeführt. 


\subsection{Experiment 1: Diallelanalyse}

\subsubsection{Freilandversuche}

Das Experiment 1 wurde im Freiland unter kontrollierten Bestäubungsverhältnissen (siehe Kap. 2.3) in drei aufeinander folgenden Jahren (2004 bis 2006) ausgeführt. Im Jahr 2004 wurde aufgrund von Saatgutknappheit nur eine Wiederholung, in den Jahren 2005 und 2006 wurde Experiment 1 in je zwei Wiederholungen angebaut. Die Wiederholungen wuchsen in separaten Isolierhäusern. Es wurden vier teilweise miteinander verwandte Genotypen verwendet (siehe Tab.4).

Tabelle 4: Übersicht über die in Experiment 1 verwendeten Genotypen, deren Samengrößen und Verwandtschaftskoeffizienten ( $f$ )

\begin{tabular}{llll}
\hline Nummer & Genotyp & Varietät & Verwandtschaftskoeffizient \\
\hline 1 & Hedin/2 & minor & $\mathrm{f}=0,5$ zu 2 und 3 \\
2 & HP58 & major & $\mathrm{f}=0,5$ zu 1 und 3 \\
3 & HP69 & minor & $\mathrm{f}=0,5$ zu 1 und 2 \\
4 & Gobo-il1 & minor & $\mathrm{f}=0,0$ zu 1 und 2 und 3 \\
\hline
\end{tabular}

Die vier Genotypen und alle ihre sechs möglichen $\mathrm{F}_{1}$ - Hybriden wurden durch Handkreuzungen im Diallel (inklusive Reziproke) nach einem speziellen Kreuzungsschema in Anlehnung an Dani und Kohel (1989) angepaart. Die daraus erwachsenden Samen befinden sich dadurch in verschiedenen Inzuchtstadien bzw. Generationen (siehe Tab.5). Selbstungssamen wachsen entweder auf der Mutterpflanze und gehören der Generation $P$ an, oder sie wachsen auf einer $F_{1}$ - Pflanze und gehören somit der Generation $F_{2}$ an. Kreuzungssamen können der $F_{1}$ - Generation angehören, nämlich wenn sie auf der Mutterpflanze wachsen, oder sie gehören einer der Rückkreuzungsgenerationen an wenn sie auf einer $F_{1}$ - Pflanze wachsen. Ziel ist die Untersuchung von heterotischen Unterschieden im Samengewicht. Dazu wird der einzelne Same als Prüfglied und das Samengewicht bei Reife als Merkmal untersucht. 
Tabelle 5: Samengenerationen mit Reziproken $(R)$ des diallelen Kreuzungsschemas in Anlehnung an Dani und Kohel (1989) für die Kreuzung i x j

\begin{tabular}{cccccc}
\hline \multirow{2}{*}{$\begin{array}{c}\text { Kreuzungs- } \\
\text { kombination }\end{array}$} & \multicolumn{5}{c}{ Generation } \\
\cline { 2 - 6 } i x j & $\mathrm{P}_{\mathrm{i}} / \mathrm{P}_{\mathrm{j}}$ & $\mathrm{F}_{1} / \mathrm{RF}_{1}$ & $\mathrm{~F}_{2} / \mathrm{RF}_{2}$ & $\mathrm{BC}_{\mathrm{i}} / \mathrm{BC}_{\mathrm{j}}$ & $\mathrm{RBC}_{\mathrm{i}} / \mathrm{RBC}_{\mathrm{j}}$ \\
\hline Anzahl pro Kreuzung & $\mathrm{i}$ & $(\mathrm{ixj})$ & $(\mathrm{ixj})$ & $(\mathrm{ixj}) \mathrm{xi}$ & $\mathrm{ix}(\mathrm{ixj})$ \\
\hline Anzahl im Diallel & $\mathrm{j}$ & $(\mathrm{jxi})$ & $(\mathrm{jxi})$ & $(\mathrm{ixj}) \mathrm{xj}$ & $\mathrm{jx}(\mathrm{ixj})$ \\
\hline Anzahl insgesamt & 4 & 2 & 2 & 2 & 2 \\
\hline
\end{tabular}

Der genotypische Wert eines Samen- Genotypes in einer bestimmten Generation lässt sich mittels eines linearen Modells in verschiedene Effekte untergliedern. Diese Effekte sind die statistischen Effekte oder Durchschnittseffekte von Allelen, die in der klassischen quantitativen Genetik zum Beispiel dem Zuchtwert zugrunde liegen. Dabei sind $A_{i}$ und $A_{j}$ die sogenannten direkten Additiveffekte der von den Eltern geerbten Allele i und j, wie sie im Samen auf das Samengewicht wirken, $D_{i i}$ und $\mathrm{D}_{\mathrm{jj}}$ sind die direkten Dominanzeffekte der Allele der Eltern $\mathrm{i}$ und $\mathrm{j}$, und $\mathrm{D}_{\mathrm{ij}}$ ist der direkte Dominanzeffekt der Kombination ixj. Die Parameter $C_{i}$ und $C_{j}$ beschreiben die zytoplasmatischen Effekte der Eltern i bzw. j. Mit $A m_{i}$ und $A m_{j}$ werden die additiv maternalen Effekte der Eltern i und $\mathrm{j}$ bezeichnet, $\mathrm{Dm}_{\mathrm{ii}}$ und $\mathrm{Dm}_{\mathrm{jj}}$ sind die dominant maternalen Effekte der Elternlinien $\mathrm{i}$ und $\mathrm{j}$ und $\mathrm{Dm}_{\mathrm{ij}}$ ist der dominant maternale Effekt der elterlichen Hybride ixj (Zhu,1997; siehe Tab. 6). Um Samen aller aufgeführten Generationen produzieren zu können, wurden die vier Elternlinien in neun Reihen mit je acht Pflanzen pro Isolierhaus und die sechs $F_{1}$ - Hybriden in je zwei Reihen mit je acht Pflanzen pro Isolierhaus angebaut. Um Randeffekte zu minimieren, wurde jede Reihe von zwei Randpflanzen begrenzt. Um Samengewichte von fremd- und selbstbefruchteten Samen auf einer Mutterpflanze direkt vergleichen zu können, wurde abwechselnd nach Nodium eine fremdbefruchtete Hülse und eine selbstbefruchtete Hülse produziert. Die fremdbefruchteten Hülsen wurden durch manuelle Kastration und anschließende manuelle Bestäubung hergestellt, die selbstbefruchteten Hülsen wurden durch manuelle Selbstbestäubung (Trippen) hergestellt. Die Pflanzen wurden einzelhülsenweise beerntet, das Erntegut wurde vier Wochen bei Raumtemperatur und gleichen Bedingungen gelagert. Anschließend wurden die Ertragsstrukturen der Pflanzen und die Einzelsamengewichte ihres Ertrages detailliert untersucht und festgehalten. 
Tabelle 6: Zerlegung des genotypischen Wertes der Samen in genetische Effekte, nach Zhu and Weir (1994)

Genetische Effekte und ihre Koeffizienten

\begin{tabular}{|c|c|c|c|c|c|c|c|c|c|c|c|c|c|}
\hline \multirow[t]{2}{*}{ Samengeneration } & \multicolumn{6}{|c|}{ Direkte Effekte } & \multicolumn{2}{|c|}{$\begin{array}{c}\text { Zy- } \\
\text { toplasm. } \\
\text { Effekte }\end{array}$} & \multicolumn{5}{|c|}{ Maternale Effekte } \\
\hline & $A_{i}$ & $A_{j}$ & $D_{i j}$ & $D_{i i}$ & $\mathrm{D}_{\mathrm{jj}}$ & $D_{i j}$ & $\mathrm{C}_{\mathrm{i}}$ & $\mathrm{C}_{\mathrm{j}}$ & $A m_{i}$ & $A m_{j}$ & $\mathrm{Dm}_{\mathrm{ij}}$ & $\mathrm{Dm}_{\mathrm{ii}}$ & $\mathrm{Dm}_{\mathrm{j}}$ \\
\hline$P_{i}(z . B$. Hedin/2) & 2 & & & 1 & & & 1 & & 2 & & & 1 & \\
\hline$P_{j}(z . B$. Gobo-il1) & & 2 & & & 1 & & & 1 & & 2 & & & 1 \\
\hline P Mittel & 1 & 1 & & 0,5 & 0,5 & & 0,5 & 0,5 & 1 & 1 & & 0,5 & 0,5 \\
\hline $\begin{array}{ll}F_{1} & \left(P_{i} x P_{j}\right)\end{array}$ & 1 & 1 & 1 & & & 1 & 1 & & 2 & & & 1 & \\
\hline $\mathrm{RF}_{1} \quad\left(\mathrm{P}_{\mathrm{j}} \mathrm{X} \mathrm{P}_{\mathrm{i}}\right)$ & 1 & 1 & 1 & & & 1 & & 1 & & 2 & & & 1 \\
\hline$F_{2} \quad\left(P_{i} x P_{j}\right)$ & 1 & 1 & 0,5 & 0,25 & 0,25 & 0,5 & 1 & & 1 & 1 & 1 & & \\
\hline $\mathrm{RF}_{2} \quad\left(\mathrm{P}_{\mathrm{j}} \mathrm{x} \mathrm{P}_{\mathrm{i}}\right)$ & 1 & 1 & 0,5 & 0,25 & 0,25 & 0,5 & & 1 & 1 & 1 & 1 & & \\
\hline$B C_{i}\left(P_{i} \times P_{j}\right) \times P_{i}$ & 1,5 & 0,5 & 0,5 & 0,5 & & 0,5 & 1 & & 1 & 1 & 1 & & \\
\hline$B C_{i}\left(P_{j} \times P_{i}\right) \times P_{i}$ & 1,5 & 0,5 & 0,5 & 0,5 & & 0,5 & & 1 & 1 & 1 & 1 & & \\
\hline$B C_{j}\left(P_{i} \times P_{j}\right) \times P_{j}$ & 0,5 & 1,5 & 0,5 & & 0,5 & 0,5 & 1 & & 1 & 1 & 1 & & \\
\hline$B C_{j}\left(P_{j} \times P_{i}\right) \times P_{j}$ & 0,5 & 1,5 & 0,5 & & 0,5 & 0,5 & & 1 & 1 & 1 & 1 & & \\
\hline $\mathrm{RBC}_{\mathrm{i}} \mathrm{P}_{\mathrm{i}} \mathrm{x}\left(\mathrm{P}_{\mathrm{i}} \mathrm{X} \mathrm{P}_{\mathrm{j}}\right)$ & 1,5 & 0,5 & 0,5 & 0,5 & & 0,5 & 1 & & 2 & & 1 & & \\
\hline $\mathrm{RBC}_{\mathrm{i}} \mathrm{P}_{\mathrm{i}} \mathrm{x}\left(\mathrm{P}_{\mathrm{j}} \mathrm{x} \mathrm{P}_{\mathrm{i}}\right)$ & 1,5 & 0,5 & 0,5 & 0,5 & & 0,5 & 1 & & 2 & & 1 & & \\
\hline $\mathrm{RBC}_{\mathrm{j}} \mathrm{P}_{\mathrm{j}} \mathrm{x}\left(\mathrm{P}_{\mathrm{i}} \mathrm{xP} \mathrm{P}_{\mathrm{j}}\right)$ & 0,5 & 1,5 & 0,5 & & 0,5 & 0,5 & & 1 & & 2 & 1 & & \\
\hline$R B C_{j} P_{j} \times\left(P_{j} \times P_{i}\right)$ & 0,5 & 1,5 & 0,5 & & 0,5 & 0,5 & & 1 & & 2 & 1 & & \\
\hline
\end{tabular}

\subsubsection{Biomasseversuche}

Ziel des Experimentes ist der Vergleich zwischen der Heterosis im Samengewicht und der Heterosis der Biomasse der Pflanze im Jungpflanzenstadium. Ein möglicher Zusammenhang zwischen der Heterosis des Samens (eigenes Gewicht) und der Heterosis der Jungpflanze ist hier im Fokus. Dazu wurden die Genotypen des Experimentes 1 zwischen November 2006 und Januar 2007 in zwei Durchgängen in ihrer oberirdischen Biomasseproduktion im Gewächshaus untersucht. Das Zustandekommen der 76 Genotypen, die als Nachkommen aus dem in Kapitel 2.5.1 beschriebenen Kreuzungsschema hervorgingen, wird in Tabelle 5 erläutert. Um gewissen Unterschieden in Temperatur- und Lichtverteilung im Gewächshaus Rechnung zu tragen, wurde das Experiment in zwei Wiederholungen als vollständig randomisierte Blockanlage ausgeführt. Der erste Durchgang wurde am 
1.11.2006, der zweite am 12.12.2006 ausgelegt. Ein Durchgang bestand jeweils aus acht Tischen der Größe $200 \mathrm{~cm}$ x $126 \mathrm{~cm}$, wobei jeder Tisch in fünf Blöcke unterteilt war, die jeweils mit den 76 Genotypen bestückt waren. Die Aussaat erfolgte in 7x7 cm Töpfen, die mit Fruhstorfer Erde Typ „T 25 (fein)“ gefüllt waren. Je Topf wurde ein Same ausgelegt. Um Randeffekte zu minimieren, wurde um jede Wiederholung außen eine Reihe Töpfe der Sorte Merkur/2 gepflanzt. Der Versuch wurde einmal wöchentlich im Anstauverfahren bewässert. Hierzu wurden die Tische für drei Stunden 3-4 cm hoch mit Wasser befüllt. Zusätzlich zum Tageslicht wurden die Tische für 15 Stunden täglich mit Natriumdampflampen der Firma Philips (Typ SON-T-Agro, 400 Watt) beleuchtet. Nach 27 Tagen wurden die Pflanzen geerntet (Durchgang 1: 28.11.2006, Durchgang 2: 8.1.2007), indem sie direkt über der Erdoberfläche abgeschnitten und in der Frischmasse gewogen wurden. Die Trockenmasse wurde nach 24 Stunden Trocknung bei $60^{\circ} \mathrm{C}$ und anschließend 12 Stunden Trocknung bei $105^{\circ} \mathrm{C}$ bestimmt.

\subsubsection{Datenanalyse}

Die Einzelsamengewichte der fremdbefruchteten, ebenso wie der selbstbefruchteten Samen, wurden jeweils erst über die Mutterpflanze und anschließend über die Reihe dieser Mutter einer Wiederholung gemittelt. Diese Mittelwerte wurden mit der Software zur Auswertung quantitativ genetischer Studien (QGA Station Version 1.0, entwickelt von Guobo Chen und Jun Zhu, 2003) nach dem folgenden genetischen Modell analysiert:

$Y_{h i j k l}=\mu+E_{h}+G_{i j k}+G E_{h i j k}+B_{h l}+e_{h i j k l}$

Wobei $\mu=$ Populationsmittel, $E_{h}=$ Umwelt Effekt, $G_{i j k}=$ Genotypischer Effekt, $\mathrm{GE}_{\mathrm{hijk}}=$ Genotyp x Umwelt Interaktionseffekt, $\mathrm{B}_{\mathrm{hl}}=$ Blockeffekt und $\mathrm{e}_{\mathrm{hijk}}=$ Fehler. Die weitere Aufteilung des genotypischen Effektes nach dem Modell für diploide Samen wird hier beispielhaft für die Samengenerationen $F_{1}$ aufgeführt (vergl. Tab. 6 und zugehörigen Text):

\section{Samengeneration $\mathbf{F}_{1}$ :}

$G_{i j 1}=A_{i}+A_{j}+D_{i j}+C_{i}+2 A m_{i}+D m_{i i}$ 
Die Versuchsjahre wurden als Umwelten in das Modell aufgenommen, von jeder Pflanzenreihe wurde das mittlere Kreuzungssamengewicht sowie das mittlere Selbstungssamengewicht dem entsprechenden Block und der gegebenen Wiederholung zugeordnet. Die Schätzung der Varianzkomponenten wird von QGA Station mit Hilfe der MINQUE (0/1)-Methode durchgeführt (Searle, 1995).

Die Auswertung der Biomasseversuche erfolgte ebenso, hier wurden pro Durchgang die Einzelpflanzengewichte eines Genotyps über einen Tisch gemittelt und ausgewertet, wobei die zwei Durchgänge als zwei Umwelten und die acht Tische pro Durchgang als acht Blöcke in das statistische Modell aufgenommen wurden.

\subsection{Experiment 2: Konkurrenz}

\subsubsection{Versuchsdurchführung}

Ziel des Experiments ist die Untersuchung der Samenheterosis in verschiedenen Konkurrenzsituationen. Dazu wurden die in Tabelle 7 aufgestellten Genotypen im Freiland in kontrollierter Bestäubungssituation (siehe Kap.2.3) angepaart.

Tabelle 7: Übersicht über die in Experiment 2 verwendeten Genotypen

\begin{tabular}{lllll}
\hline Elter & Genotyp & Kotyledonenfarbe & Blütenfarbe & Varietät \\
\hline Mutter & MarisBead-il1 & Grün & Bunt & minor \\
Mutter & Gloria/5 & Gelb & Weiß & minor \\
Bestäuber & Hedin/2 & Gelb & Bunt & minor \\
Bestäuber & L2(MxCE) & Gelb & Bunt & major \\
\hline
\end{tabular}

Das Experiment wurde in drei aufeinander folgenden Jahren (2004 bis 2006), im Jahr 2004 aufgrund von Saatgutknappheit in nur einer Wiederholung, in den Jahren 2005 und 2006 in zwei Wiederholungen, angebaut. Die Wiederholungen wuchsen in separaten Isolierhäusern. Innerhalb einer Wiederholung wurden die Pflanzen drei verschiedenen Behandlungen unterzogen (siehe auch Abb.3):

1. Fremd- und selbstbefruchtete Samen wuchsen auf derselben Pflanze in abwechselnder Reihenfolge am Nodium.

2. Fremd- und selbstbefruchtete Samen wuchsen gemeinsam in einer Hülse.

3. Fremd- und selbstbefruchtete Samen wuchsen auf getrennten Pflanzen.

Es wurden je zwölf Pflanzen pro Behandlung, Mutter x Vater-Kombination und Isolierhaus angebaut. Um Randeffekte zu minimieren, wurden die Reihen mit Rand- 
pflanzen begrenzt. Um in Behandlung 2 fremd- und selbstbefruchtete Samen gemeinsam in einer Hülse wachsen zu lassen, wurde nach Kastration der Blüte eine Pollenmischung von Mutter- und Vatergenotyp auf die Narbe aufgebracht.

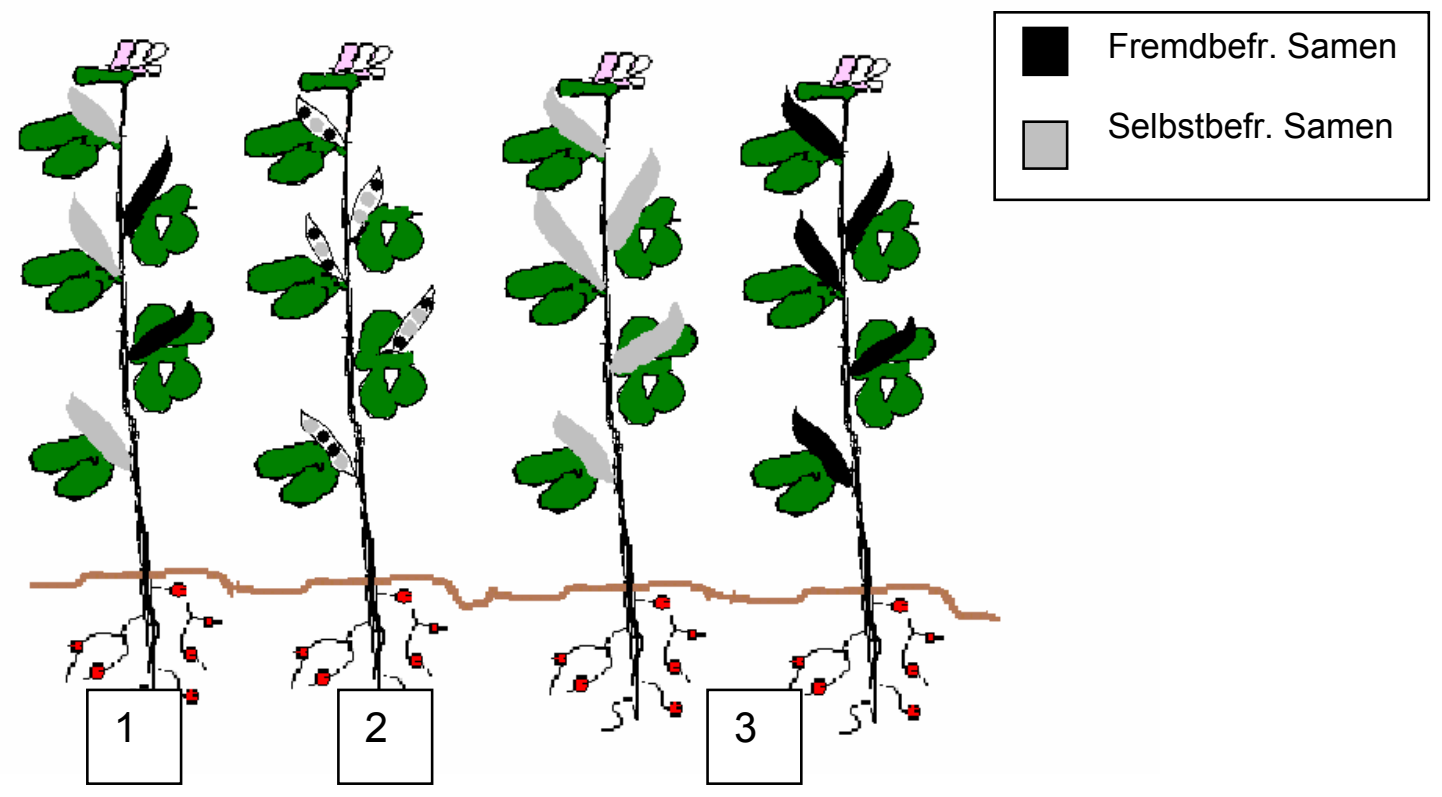

Abbilung 3: Schematische Darstellung der Behandlungen im Experiment 2

Nach der Ernte wurden die Pflanzen bei Raumtemperatur und gleichen Bedingungen vier Wochen gelagert. Anschließend wurde die Ertragsstruktur der Pflanzen erfasst und die Samen einzeln gewogen. In Behandlung 2 wurde der fremdbefruchtete Same vom selbstbefruchteten Samen mittels morphologischer Marker (grüne Kotyledonenfarbe, weiße Blütenfarbe, siehe Kapitel 2.1) unterschieden. Hierzu wurde nach dem Wiegen die Samenschale der auf MarisBead-il1 geernteten Samen angeschnitten, um die Kotyledonenfarbe zu sehen, wobei grüne Kotyledonenfarbe selbstbefruchtete und gelbe Kotyledonenfarbe fremdbefruchtete Samen zeigte. Die auf Gloria/5 geernteten Samen wurden nach dem Wiegen im Gewächshaus angezogen und die Jungpflanzen nach ca. 30 Tagen bonitiert, wobei das Vorhandensein des schwarzen Punktes am Nektarium einen fremdbefruchteten Samen anzeigte und das Fehlen des schwarzen Punktes einen selbstbefruchteten. 


\subsubsection{Datenanalyse}

Die Einzelsamengewichte der fremdbefruchteten, ebenso wie der selbstbefruchteten Samen, wurden jeweils erst über die Mutterpflanze und anschließend über die Reihe der Mutterpflanzen einer Wiederholung gemittelt. Das Experiment wurde im Wesentlichen als Split- Plot- Anlage mit dem Programm Plabstat (Utz, 1996) analysiert. Allerdings gibt es auf der Ebene des Großteilstückfaktors die gekreuzten Faktoren Muttergenotyp und Vatergenotyp, ebenso wie es auf der Ebene der Kleinteilstückfaktoren die gekreuzten Faktoren Konkurrenzsituation und Behandlung gibt. Die drei- und vierfachen Interaktionen wurden gepoolt (http://www.gseis.ucla.edu).

\subsection{Experiment 3: Trockenstress}

\subsubsection{Versuchsdurchführung}

Ziel des Experimentes ist die Untersuchung des Kontrastes im Samengewicht von fremd- und selbstbefruchteten Samen, wenn die Mutterpflanze der Samen in abiotischer Stresssituation wächst. Das Experiment wurde im Freiland in offener Bestäubungssituation in drei aufeinander folgenden Jahren (2004 bis 2006) durchgeführt. Eine Übersicht über die verwendeten Genotypen findet sich in Tabelle 8.

Tabelle 8: Übersicht über die verwendeten Genotypen in Experiment 3

\begin{tabular}{lllll}
\hline Elter & Genotyp & Kotyledonenfarbe & Blütenfarbe & Varietät \\
\hline Mutter & MarisBead-il1 & Grün & Bunt & minor \\
Mutter & Gobo-il1 & Grün & Bunt & minor \\
Mutter & Gloria/5 & Gelb & Weiß & minor \\
Bestäuber & Elitelinien $(\mathrm{N}=15)$ & Gelb & Bunt & minor \\
\hline
\end{tabular}

Die drei Muttergenotypen wurden von einer Pollenmischung von N=15 unverwandten Elitelinien bestäubt. Die Pflanzen wuchsen in sogenannten Trockenstresshäusern (Abdelmula et al., 1999). Diese Häuser sind 3m x 20m x 3m groß und mit wasserdichter Folie überspannt. Der durch die Folie verursachte Strahlungsverlust betrug in 2006 ca. 30-35\%. Die Temperatur unter der Folie war im Juni 2006 maximal $5^{\circ} \mathrm{C}$ wärmer als außerhalb (Lüpken, 2006). Die Pflanzen wuchsen in verschiedenen Stressvarianten: 
Stressvariante 1: Aufwuchs im Trockenstresshaus mit kontrollierter Bewässerung (ohne Trockenstress)

Stressvariante 2: Aufwuchs im Trockenstresshaus ohne Bewässerung (Trockenstress)

Es wurden je zwei Trockenstresshäuser pro Stressvariante angebaut. In Stressvariante 1 wurde wöchentlich mit $20 \mathrm{Liter} / \mathrm{m}^{2}$ bewässert. Dazu wurden neun Bewässerungsschläuche $(30 \mathrm{~cm}$ Lochabstand) eingesetzt, die nach der Aussaat zwischen den in Stressvariante 1 wachsenden Pflanzen ausgelegt worden waren. Um eine zusätzliche Wasserzufuhr durch Spritzwasser und seitlich eintretendes Oberflächenwasser zu minimieren, wurden an den Stirn- und Randseiten jedes Hauses je zwei Reihen Ackerbohnen als Rand gepflanzt. Die Prüfglieder wuchsen in einem Mittelstreifen von 1,5 m Breite. Innerhalb einer Stressvariante wurden die Pflanzen zwei Varianten unterzogen:

Variante1: Normierung der Ertragsstruktur auf eine Hülse pro Nodium Variante 2: Keine Normierung der Ertragsstruktur Pro Genotyp, Variante und Trockenstresshaus wurden je neun Reihen mit je zwei Pflanzen pro Reihe untersucht. Der Samenabstand innerhalb der Reihe betrug ca. $10 \mathrm{~cm}$, der Reihenabstand lag bei $33 \mathrm{~cm}$. Um Randeffekte zu minimieren, wurde jede Reihe von zwei Randpflanzen begrenzt. Die Ertragsnormierung wurde wöchentlich von Hand durchgeführt, indem jeweils die zweite oder dritte Hülse am Nodium stehen gelassen wurde, während die restlichen Hülsen eines Nodiums entfernt wurden. Die Pflanzen wurden einzelhülsenweise geerntet und bei Raumtemperatur und gleichen Bedingungen vier Wochen gelagert. Anschließend wurden die Ertragsstruktur und die Einzelsamengewichte der Pflanzen detailliert untersucht. Die fremd- und selbstbefruchteten Samen wurden anhand morphologischer Marker detektiert (siehe Kap. 2.1).

\subsubsection{Datenanalyse}

Die Einzelsamengewichte der fremd- und selbstbefruchteten Samen wurden erst über die Mutterpflanze und dann über die Reihe der Mutterpflanzen gemittelt. Das Experiment wurde mit dem Programm Plabstat (Utz, 1996) als Split- Plot mit den gekreuzten Faktoren Muttergenotyp, Stressvariante und Variante auf der Ebene des Großteilstückfaktors und mit der Behandlung auf der Ebene des Kleinteilstückfaktors ausgewertet. 


\subsection{Experiment 4: Natürliche Befruchtung}

\subsubsection{Versuchsdurchführung}

Das Experiment wurde im Freiland in offener Bestäubungssituation in drei aufeinander folgenden Jahren (2004 bis 2006) als zweifaktorielle Spaltanlage in drei Wiederholungen durchgeführt. Es wurden neun teilweise miteinander verwandte Genotypen verwendet (siehe Tab. 9).

Tabelle 9: Übersicht über die verwendeten Genotypen im Experiment 4, deren Varietät und Verwandtschaftskoeffizient (f)

\begin{tabular}{|c|c|c|c|}
\hline Bezeichnung & Genotyp & Varietät & $\begin{array}{c}\text { Verwandtschafts- } \\
\text { koeffizient }\end{array}$ \\
\hline \multicolumn{4}{|c|}{ Mutter } \\
\hline$A$ & L2(MxCE) & major & $f=0$ \\
\hline$B$ & Gloria/5 $5^{\mathrm{a}}$ & minor & $f=0$ \\
\hline C & Hedin/2 & minor & $f=0,5$ zu 1 und 2 \\
\hline $\mathrm{D}$ & Troy/1 & minor & $f=0,5$ zu 3 \\
\hline$E$ & Gobo-il1 $^{b}$ & minor & $f=0$ \\
\hline \multicolumn{4}{|c|}{ Bestäuber } \\
\hline 1 & HP58 & major & $f=0,5$ zu C und 2 \\
\hline 2 & HP69 & minor & $\mathrm{f}=0,5 \mathrm{zu} C$ und 1 \\
\hline 3 & Maya/2 & minor & $f=0,5 \mathrm{zu} D$ \\
\hline 4 & Merkur/2 & minor & $f=0$ \\
\hline
\end{tabular}

${ }^{a}$ weiße Blütenfarbe, ${ }^{b}$ grüne Kotyledonenfarbe

Um die Mutterpflanzen mit einem konkreten Bestäubergenotyp anzupaaren, wurden die Bestäuber als Großparzelle in einem Verhältnis von 1:5 (Mutterpflanze : Bestäuber) und mit einer räumlichen Distanz zur nächsten Großparzelle ausgesät. Das Experiment bestand aus vier solchen Großparzellen pro Wiederholung. Die außen stehenden Parzellen waren als Randparzelle ausschließlich mit Bestäubersaatgut bestückt. Eine Großparzelle war in fünf vierreihige Kleinparzellen von 1,5 $\mathrm{m}$ Breite untergliedert (siehe Abb.4). Eine Kleinparzelle war $6 \mathrm{~m} \times 9 \mathrm{~m}$ groß und mit einer Saatstärke von 180 Samen ausgesät. Die vier Reihen einer Kleinparzelle teilten sich in jeweils zwei äußere Reihen des Bestäubergenotyps und zwei innere Reihen auf, welche mit je 15 Samen Muttergenotyp und 30 Samen Bestäubergenotyp pro Reihe bestückt waren. 


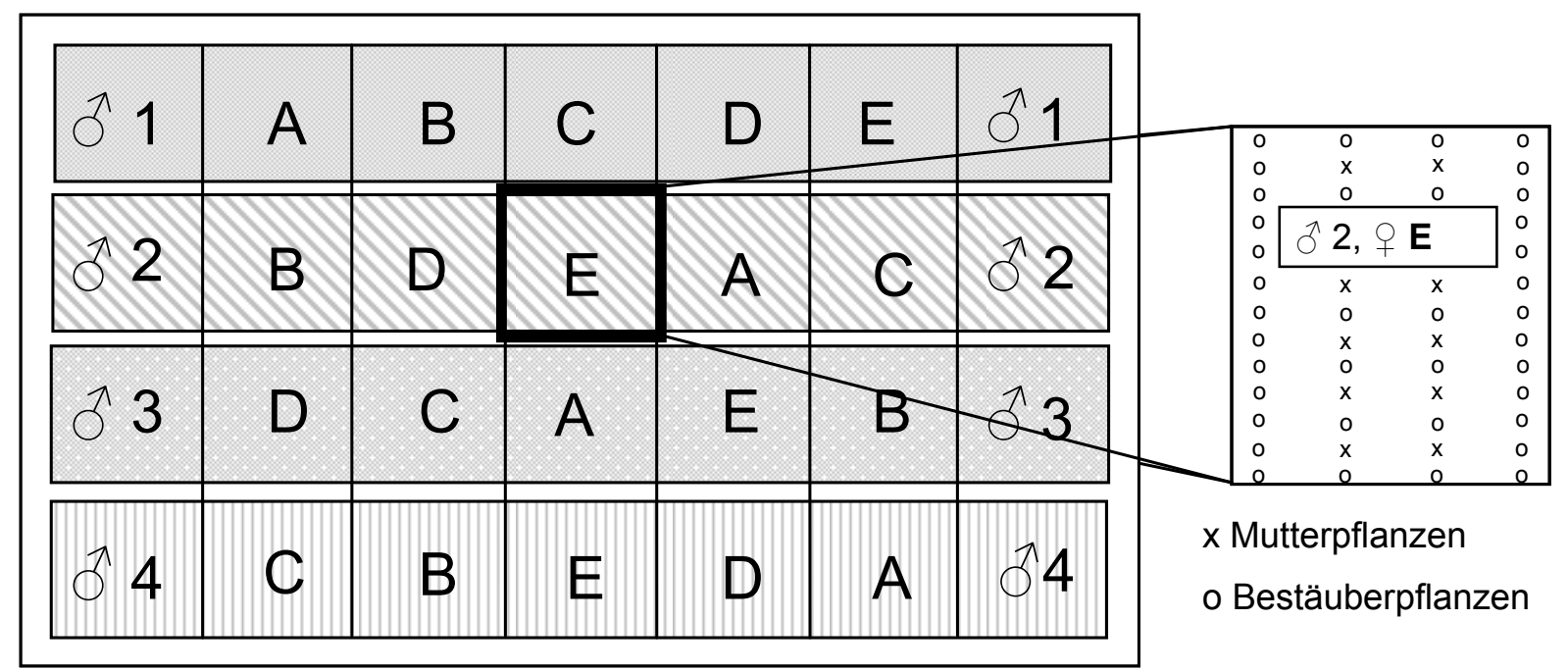

Abbildung 4: Beispielhafte Darstellung einer Wiederholung des Experimentes 4. $1-4=$ Vatergenotypen, $A-E=$ Muttergenotypen (siehe Tab. 9)

Während der Blüte wurden die Mutterpflanzen anhand ihrer Morphologie identifiziert und markiert. Um Unterschiede in der Blühzeit zwischen Mutter- und Bestäuberpflanzen auszugleichen, wurden die Pflanzen parzellenweise in der Blühzeit synchronisiert, indem bei den früher blühenden Pflanzen die untersten Infloreszenzen entfernt wurden.

Fünf zufällig ausgewählte Pflanzen aus den 30 Mutterpflanzen einer Parzelle wurden einzelhülsenweise geerntet, das Erntegut wurde bei Raumtemperatur und gleichen Bedingungen vier Wochen aufbewahrt. Anschließend wurde die Ertragsstruktur detailliert festgehalten und die Samen einzeln gewogen. Die Detektierung der fremd- vs. selbstbefruchteten Samen wurde bei Gloria/5 und Gobo-il1 mit Hilfe morphologischer Marker (siehe Kap. 2.1) vorgenommen. In den restlichen Mutter $x$ Bestäuber- Kombinationen standen keine morphologischen Marker zur Verfügung. In Vorarbeiten hatten Abel und Link (2004) fremd- und selbstbefruchtete Samen anhand von Spektraldaten in einer Diskriminanzanalyse unterscheiden können. Mit Bezug darauf wurden die im Freiland geernteten Samen einzeln in der NahInfrarot-Reflexions-Spektroskopie (NIRS, Gerät: 6500 VOSS) mit Hilfe eines Sondenaufsatzes (SmartProbe 060) untersucht. Gemessen wurden die Absorptionsspektren im Bereich des Infrarots bei Wellenlängen von 400 - 2500 nm. Zusätzlich wurden jeweils 40 von Hand gekreuzte $F_{1}$-Samen aus den Jahren 2005 und 2006 der untersuchten Genotypen und dazugehörige 40 selbstbefruchtete Samen im NIRS gemessen, um für die Diskriminanzanalyse als Referenzspektren zu dienen. 


\subsubsection{Datenanalyse}

Unter Nutzung des Programms WinISI II (Infrasoft International LLC, Analysis, calibration and network computer software Version 1.0) wurden die Spektraldaten in einer Diskriminanzanalyse analysiert. Basierend auf den Referenzspektren wurde jedes Spektrum der im Freiland geernteten Samen einer der beiden Gruppen der Referenzspektren (Fremd- oder Selbstbefruchtung) zugeordnet, indem ein Ähnlichkeitswert ermittelt wurde. Ein Spektrum, d.h. ein Same, wurde einer der beiden Gruppen zugeordnet wenn einer der beiden Ähnlichkeitswerte über 1,55 lag. Spektren, die zu beiden Gruppen Ähnlichkeitswerte über 1,55 oder zu beiden Gruppen unter 1,55 aufwiesen, wurden keiner Gruppe zugeordnet und galten als fehlende Werte.

Die Samengewichte der so als fremdbefruchtet, ebenso wie der als selbstbefruchtet gefundenen Samen, wurden erst jeweils über die Mutterpflanze und anschließend über die fünf Mutterpflanzen einer Parzelle gemittelt. Die Analyse der Daten erfolgte für die Mütter $A$ und $E$ als Serie über Jahre in zweifaktorieller Spaltanlage mit dem Programm Plabstat (Utz, 1996). Die Mütter B, C und D wurden aufgrund mangelnder Vollständigkeit der Daten in einzelnen Varianzanalysen als zweifaktorieller Versuch in vollständig randomisierter Blockanlage ebenfalls mit dem Programm Plabstat (Utz, 1996) analysiert.

\subsection{Experiment 5: CMS Versuch}

\subsubsection{Versuchsdurchführung}

Das Experiment wurde im Freiland unter offener Bestäubungssituation in zwei aufeinander folgenden Jahren (2005 und 2006) als randomisierter Blockversuch in drei Wiederholungen durchgeführt. Es wurden drei Genotypen mit zytoplasmatisch männlicher Sterilität (CMS, Link et al., 1997) und deren isogene Bestäuber, sowie ein unverwandter Bestäubergenotyp verwendet (siehe Tab. 10). Eine Wiederholung bestand aus acht Parzellen, die jeweils 5,4m x 6m groß waren und jeweils eine Mutter x Bestäuber- Kombination beinhalteten. Die Mutterpflanzen wuchsen in zwei verschiedenen Behandlungen:

1. Mutterpflanzen wuchsen umgeben von ihrem isogenen Bestäuber, diese Fremdbestäubung entspricht genetisch einer Selbstbefruchtung. 
2. Mutterpflanzen wuchsen umgeben von einem unverwandten Bestäuber (Bestäuber 7, siehe Tab.10), was zur Fremdbefruchtung führte.

Tabelle 10: Übersicht über die in Experiment 5 verwendeten Genotypen

\begin{tabular}{|c|c|c|c|c|}
\hline Nummer & Genotyp & Pollensteril & Varietät & $\begin{array}{c}\text { Isogener/ } \\
\text { unverwandter } \\
\text { Bestäuber }\end{array}$ \\
\hline \multicolumn{5}{|c|}{ Mutter } \\
\hline 1 & CMS199 & $\mathrm{Ja}$ & minor & \\
\hline 2 & CMS350 & $\mathrm{Ja}$ & minor & \\
\hline 3 & $\mathrm{~F}_{1}(\mathrm{CMS199xHF22)}$ & $\mathrm{Ja}$ & minor & \\
\hline \multicolumn{5}{|c|}{ Bestäuber } \\
\hline 4 & Afg187 & Nein & minor & Isogen zu 1 \\
\hline 5 & G58 & Nein & minor & Isogen zu 2 \\
\hline 6 & $\mathrm{~F}_{1}(\mathrm{Afg} 187 x \mathrm{HF} 22)$ & Nein & minor & Isogen zu 3 \\
\hline 7 & $\mathrm{~F}_{1}[$ Merkurx L1(MxCE)] & Nein & minor & $\begin{array}{c}\text { Unverwandt zu } \\
1,2,3\end{array}$ \\
\hline
\end{tabular}

Wegen Pollensterilität der CMS- Mütter lag die zu erwartende Fremdbefruchtungsrate bei $100 \%$. Die Parzellen waren von je vier Reihen à 30 Bestäuberpflanzen umrandet. In der Mitte befanden sich zweimal drei Reihen Mutterpflanzen, von denen nur die 40 Mutterpflanzen der innersten Reihe geerntet wurden. Die beiden äußeren Reihen waren mit jeweils 20 Mutterpflanzen bestückt. Zwischen den mütterlichen Reihen befanden sich vier Reihen mit je 30 Bestäuberpflanzen (siehe Abb.5). Der Reihenabstand betrug $30 \mathrm{~cm}$, die innerste Mutterreihe wurde mit 10 cm Samenabstand innerhalb der Reihe, die restlichen Reihen mit jeweils $20 \mathrm{~cm}$ Samenabstand ausgelegt.

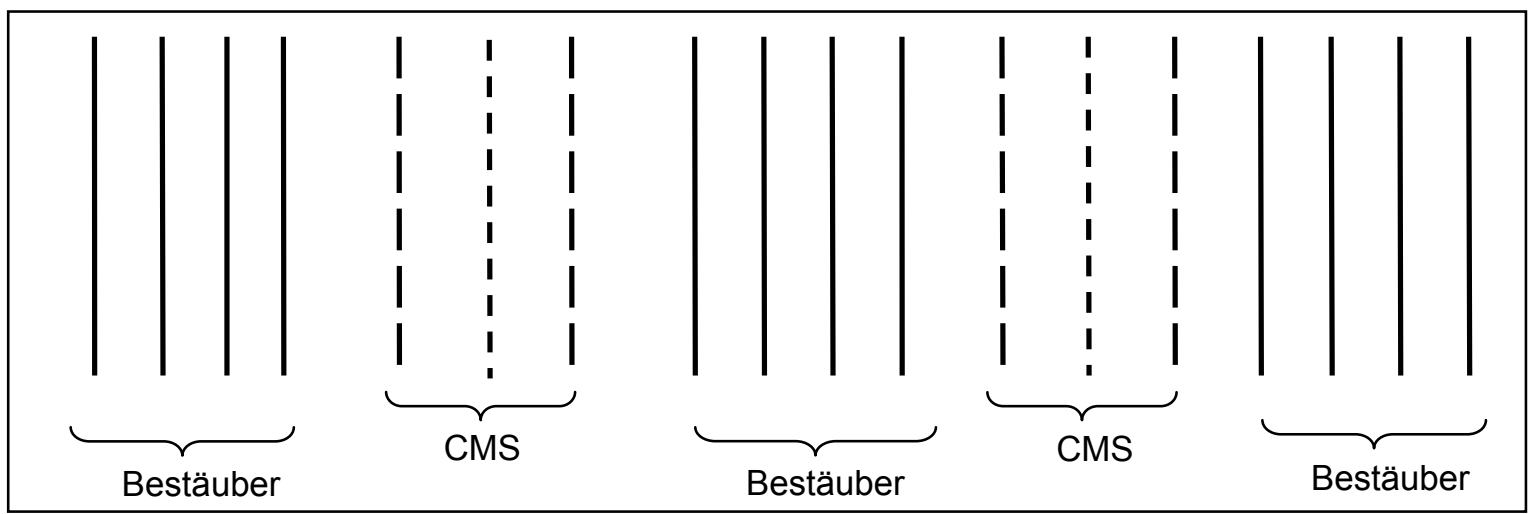

Abbildung 5: Schematische Darstellung einer Parzelle des Experimentes 5 
Da die CMS- Linien erfahrungsgemäß (Link et al., 1997) nicht zu 100\% steril sind, wurden während der Blüte alle Mutterpflanzen auf Sterilität geprüft und etwaige fertile Pflanzen wurden von der Ernte ausgeschlossen.

Die 40 Mutterpflanzen der inneren Mutterreihen wurden geerntet und vier Wochen bei Raumtemperatur und gleichen Bedingungen gelagert. Anschließend wurde der Einzelpflanzenertrag, das Tausendkorngewicht (TKG), die Anzahl Samen pro Pflanze und Anzahl Hülsen pro Pflanze ermittelt.

\subsubsection{Datenanalyse}

Es wurde ein Vergleich der Erträge in beiden Behandlungen vorgenommen, dazu wurde das Experiment als zweifaktorieller Versuch in vollständig randomisierter Blockanlage mit dem Programm Plabstat (Utz, 1996) ausgewertet. 


\section{Ergebnisse}

\subsection{Ertragsphysiologische Studien}

Mit Ausnahme von HP58 konnte bei allen Genotypen eine Anzahl von acht Hülsen pro Pflanze erreicht werden. Die mittlere Anzahl Samen pro Hülse lag zwischen 2,96 und 3,99, die mittleren Samengewichte lagen zwischen 584,70 mg und $1634,80 \mathrm{mg}$ (siehe Tab. 11).

Tabelle 11: Anzahl Hülsen/Pflanze, Samen/Pflanze und mittlere Samengewichte der untersuchten Genotypen

\begin{tabular}{cccc}
\hline Genotyp & $\begin{array}{c}\text { Mittlere Anzahl } \\
\text { Hülsen/Pflanze }\end{array}$ & $\begin{array}{c}\text { Mittlere Anzahl } \\
\text { Samen/Hülse }\end{array}$ & $\begin{array}{c}\text { Mittleres Samen- } \\
\text { gewicht }(\mathrm{mg})\end{array}$ \\
\hline Hedin/2 & 8,00 & 3,99 & 584,70 \\
MarisBead-il1 & 8,00 & 3,17 & 729,00 \\
Gloria/5 & 8,00 & 3,01 & 748,90 \\
Gobo-il1 & 8,00 & 3,06 & 814,10 \\
HP69 & 8,00 & 3,76 & 818,90 \\
HP58 & 6,48 & 2,85 & 1634,80 \\
\hline
\end{tabular}

Die geringere Anzahl Hülsen pro Pflanze als auch der geringere Samenansatz des Genotyps HP58 sind auf seine markante Großsamigkeit zurückzuführen. Auch die Besetzung der Samenpositionen innerhalb der Hülsen von HP58 ist dementsprechend anders als bei den anderen Genotypen (siehe Abb.6).

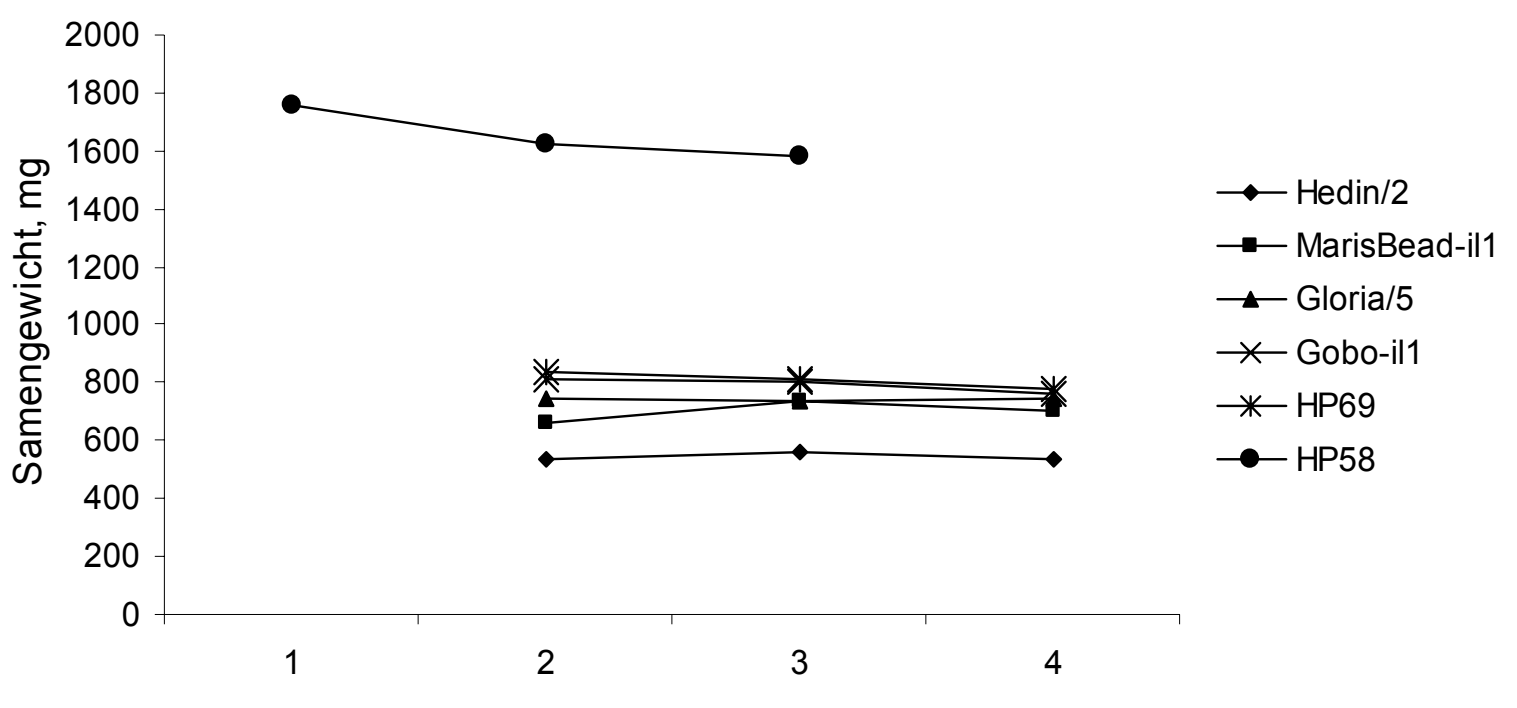

Anzahl Samen/ Hülse

Abbildung 6: Mittleres Samengewicht [mg] der sechs Genotypen in Abhängigkeit von der Anzahl Samen pro Hülse 
Das mittlere Samengewicht verändert sich nicht signifikant (Varianzanalyse nicht gezeigt) mit der Anzahl Samen pro Hülse (siehe Abb.6). Untersucht sind hier, mit Ausnahme von HP58, ausschließlich zwei- bis viersamige Hülsen, da Hülsen mit weniger als zwei und mehr als vier Samen selten auftraten.

Auch in Abhängigkeit von der Samenposition in der Hülse fanden sich keine signifikanten Unterschiede im mittleren Samengewicht (siehe Abb.7, Varianzanalyse nicht gezeigt). Vergleichbare viersamige Hülsen treten für den Genotyp HP58 zu wenig auf und sind daher nicht dargestellt.

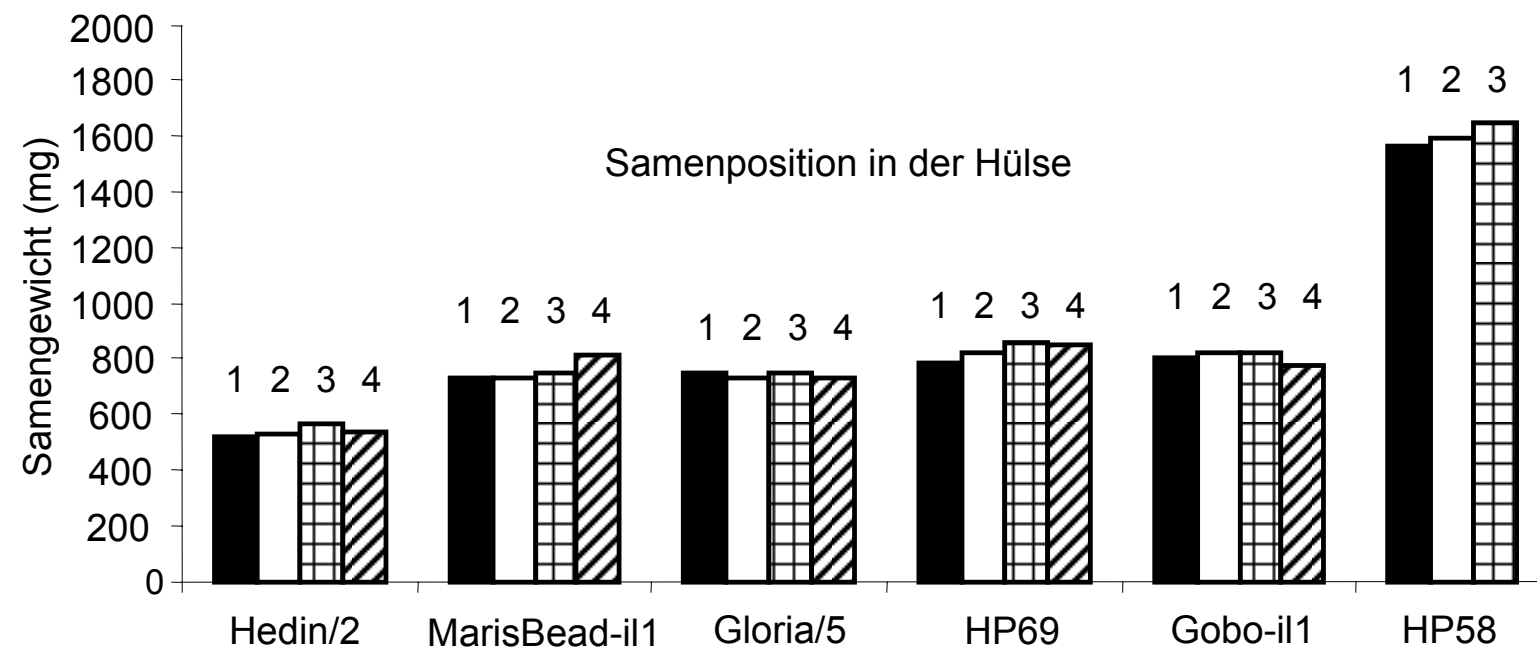

Abbildung 7: Mittleres Samengewicht [mg] der sechs Genotypen in Abhängigkeit von der Samenposition in der Hülse

Die Position der Infloreszenz auf der Pflanze war von signifikantem Einfluß auf das Samengewicht (siehe Abb.8, Varianzanalyse nicht gezeigt). Die mittleren Samengewichte waren in der Infloreszenz 4, also in der Mitte der Pflanzen, mit 897 mg am größten und sanken mit zunehmender Infloreszenzposition, also zur Sprossspitze hin, auf ein Minimum von 802 mg (Infloreszenz 8) ab. 


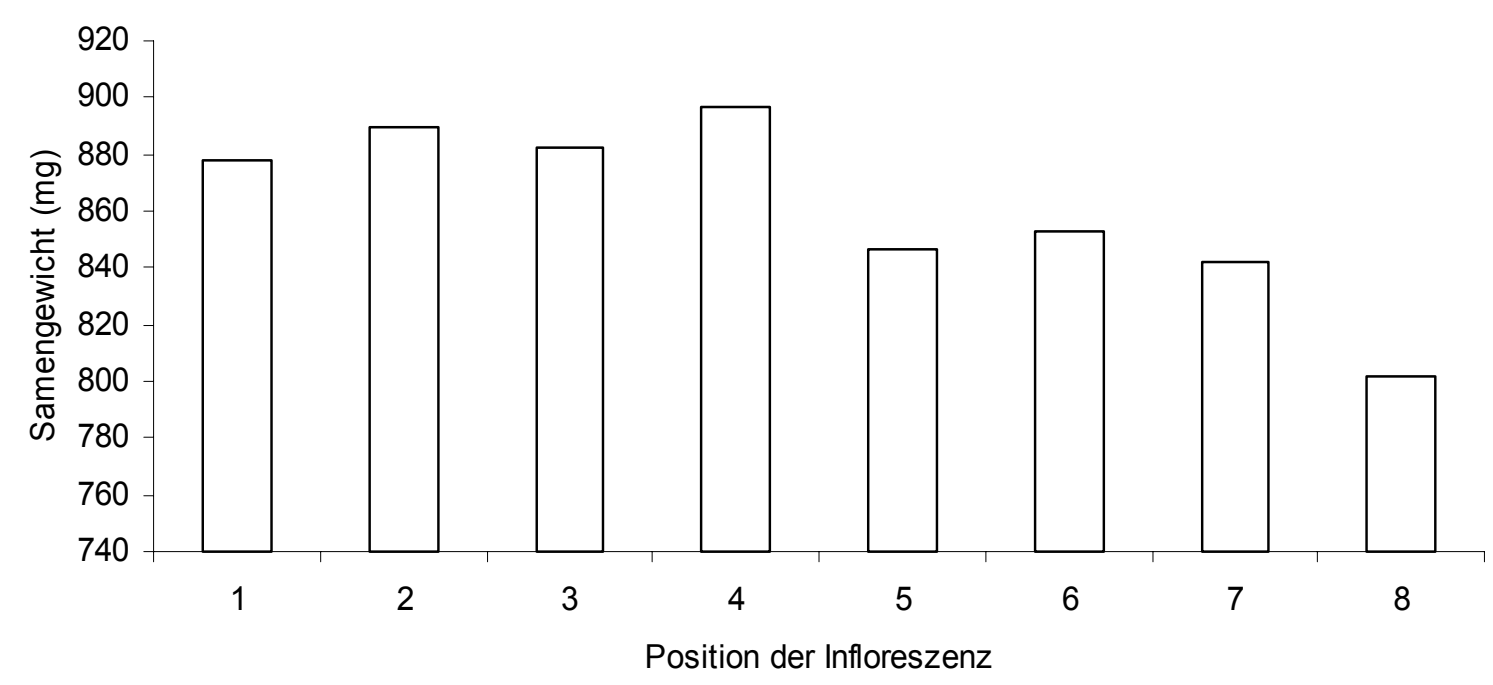

Abbildung 8: Mittleres Samengewicht [mg] in Abhängigkeit von der Position der Infloreszenz auf der Mutterpflanze. Mittel über Genotypen

Die Ergebnisse lassen darauf schließen, dass die Verteilung der Ressourcen innerhalb einer Pflanze nicht gleichmäßig ist, sondern positionsabhängig variiert.

\subsection{Experiment 1: Diallelanalyse}

\subsubsection{Freilandversuche}

Im Experiment 1 wurden insgesamt 19080 Samen untersucht, davon waren 7846 Samen fremdbefruchtet und 11234 Samen selbstbefruchtet. Die mittlere Anzahl Samen pro Pflanze betrug 20,58. Durchschnittlich wuchsen auf einer Pflanze 7,21 Hülsen, es wurden im Mittel 3,38 Kreuzungshülsen (darin $\mathrm{F}_{1}$-Samen und Rückkreuzungssamen) und 3,92 Selbstungshülsen (darin homozygote Samen und $\mathrm{F}_{2^{-}}$ Samen) pro Pflanze produziert und untersucht. In den Hülsen wuchsen im Mittel 3,10 Samen, wobei Kreuzungshülsen im Mittel 2,90 Samen enthielten und Selbstungshülsen durchschnittlich mit 3,20 Samen besetzt waren.

Die Diallelanalyse zeigt für das Merkmal Samengewicht hoch signifikante Additivund Dominanzvarianzen, sowie einen hoch signifikanten Einfluß des Zytoplasmas und der maternalen Additivvarianz (siehe Tab.12). Eine Standardabweichung der Dominanzeffekte betrug $44 \mathrm{mg}$ und umfasste damit eine Größe, die $26 \%$ der Größe einer Standardabweichung (171 mg) der Additivvarianz ausmachte. 
Tabelle 12: Komponenten der genetischen Varianz der Diallelanalyse und deren Standardfehler [mg]

\begin{tabular}{lrr}
\hline Varianzkomponente & Schätzwert & Standardfehler \\
\hline Additiv & $29.127^{* *}$ & 3.158 \\
Dominanz & $1.958^{* *}$ & 295 \\
Zytoplasmatisch & $119^{* *}$ & 15 \\
Maternal Additiv & $11.971^{* *}$ & 1.258 \\
Maternal Dominanz & $0^{\text {NS }}$ & 0
\end{tabular}

NS, ${ }^{* *}$ : nicht signifikant, signifikant bei $\alpha=1 \%$

Die Elternmittelheterosis einer konkreten reziproken Kreuzungsrichtung für die $\mathrm{F}_{1}$ Generation $\left[\mathrm{H}\left(\mathrm{F}_{1}\right)\right]$ ist nach Zhu (1997) definiert als:

$H\left(F_{1}\right)=D_{i j}-1 / 2\left(D_{i i}+D_{j j}\right)+1 / 2\left(C_{i}-C_{j}\right)+2\left[D m_{i j}-1 / 2\left(D m_{i j}+D m_{j j}\right)\right]$

Das vorgestellte Modell bezieht sich auf die Heterosis der $F_{1}$ unter Betrachtung nur einer der beiden reziproken Kreuzungsrichtungen, wobei anders als in Tabelle 13 Gleichungen [1] und [2] zur Schätzung der gesamte Datensatz und nicht nur die Generationen $P$ und $F_{1}$ benutzt wird (Chen und Zhu, 2003). Wird die Heterosis über die beiden Reziproken in $F_{1}$ gemittelt zeigt sich, dass der zytoplasmatische Effekt, ebenso wie der maternale Dominanzeffekt, ihren Einfluß verlieren (siehe Tab.13, Gleichung [3]). Da die einzelnen Reziproken in den für diese Arbeit relevanten Untersuchungen weniger von Bedeutung sind, wurde das oben beschriebene Modell gekürzt auf:

$H\left(F_{1}\right)=D_{i j}-\left(D_{i i}+D_{j j} / 2\right)$

Die vorgestellte Formel findet sich auch in Tabelle 13 Gleichung [3]. 
Tabelle 13: Zerlegung des genotypischen Wertes und Darstellung der Heterosis in Experiment 1, in Anlehnung an Zhu and Weir (1994)

\begin{tabular}{|c|c|c|c|c|c|c|c|c|c|c|c|c|c|}
\hline \multirow{3}{*}{$\begin{array}{c}\text { Samen- } \\
\text { generation }\end{array}$} & & \multicolumn{12}{|c|}{ Genetische Effekte und ihre Koeffizienten } \\
\hline & & \multicolumn{5}{|c|}{ Direkte Effekte } & \multicolumn{2}{|c|}{$\begin{array}{l}\text { Zytoplasmati- } \\
\text { sche Effekte }\end{array}$} & \multicolumn{5}{|c|}{ Maternale Effekte } \\
\hline & & $A_{i}$ & $A_{j}$ & $D_{i j}$ & $\mathrm{D}_{\mathrm{ii}}$ & $\mathrm{D}_{\mathrm{jj}}$ & $\mathrm{C}_{\mathrm{i}}$ & $\mathrm{C}_{\mathrm{j}}$ & $\mathrm{Am}_{\mathrm{i}}$ & $A m_{j}$ & $\mathrm{Dm}_{\mathrm{ij}}$ & $D m_{i i}$ & $D m_{j j}$ \\
\hline P Mittel & & 1 & 1 & & 0,5 & 0,5 & 0,5 & 0,5 & 1 & 1 & & 0,5 & 0,5 \\
\hline$F_{1}$ Mittel & & 1 & 1 & 1 & & & 0,5 & 0,5 & 1 & 1 & & 0,5 & 0,5 \\
\hline $\mathrm{F}_{2}$ Mittel & & 1 & 1 & 0,5 & 0,25 & 0,25 & 0,5 & 0,5 & 1 & 1 & 1 & & \\
\hline BC Mittel & & 1 & 1 & 0,5 & 0,25 & 0,25 & 1 & & 1 & 1 & 1 & & \\
\hline RBC Mittel & & 1 & 1 & 0,5 & 0,25 & 0,25 & 0,5 & 0,5 & 1 & 1 & 1 & & \\
\hline \multicolumn{14}{|c|}{ Heterosis } \\
\hline $\begin{array}{l}F_{1}(\mathrm{PixPj}) \\
\text { - P Mittel }\end{array}$ & [2] & & & 1 & $-0,5$ & $-0,5$ & 0,5 & $-0,5$ & 1 & -1 & & 0,5 & $-0,5$ \\
\hline $\begin{array}{l}F_{1}\left(P_{j} \times P_{i}\right) \\
\text { - P Mittel }\end{array}$ & [2] & & & 1 & $-0,5$ & $-0,5$ & $-0,5$ & 0,5 & -1 & 1 & & $-0,5$ & 0,5 \\
\hline $\begin{array}{l}F_{1} \text { Mittel } \\
\text { - P Mittel }\end{array}$ & [3] & & & 1 & $-0,5$ & $-0,5$ & & & & & & & \\
\hline
\end{tabular}

Für die analysierten Kreuzungen ergab sich in jedem Fall eine positive Heterosis, da die Samen mit keiner oder halber Inzucht schwerer waren als die vergleichbaren vollständig ingezüchteten Samen (siehe Tab.14).

Tabelle 14: Heterosis $(\mathrm{H})$ der Kreuzungen des Diallels in $\mathrm{mg}$ und in Prozent über das Elternmittel

\begin{tabular}{llrc}
\hline Elternkombination & Kreuzung & $\mathrm{H}(\mathrm{mg})$ & $\begin{array}{c}\% \text { über } \\
\text { Elternmittel }\end{array}$ \\
\hline $2 \times 3$ & HP58 x HP69 & $193,27^{* *}$ & 18,44 \\
$1 \times 2$ & Hedin/2 x HP58 & $142,26^{* *}$ & 14,77 \\
$2 \times 4$ & HP58 x Gobo-il1 & $148,83^{* *}$ & 14,55 \\
$3 \times 4$ & HP69 x Gobo-il1 & $36,62^{* *}$ & 5,17 \\
$1 \times 3$ & Hedin/2 x HP69 & $3,48^{* *}$ & 0,53 \\
$1 \times 4$ & Hedin/2 x Gobo-il1 & $2,24^{* *}$ & 0,36 \\
\hline
\end{tabular}

**: signifikant bei $\alpha=1 \%$

Ein Vergleich zwischen den reziproken Kreuzungen zeigt eine deutlich höhere Heterosis für das Samengewicht wenn der jeweils größersamige elterliche Genotyp als Mutter eingesetzt wurde (siehe Abb.9). 


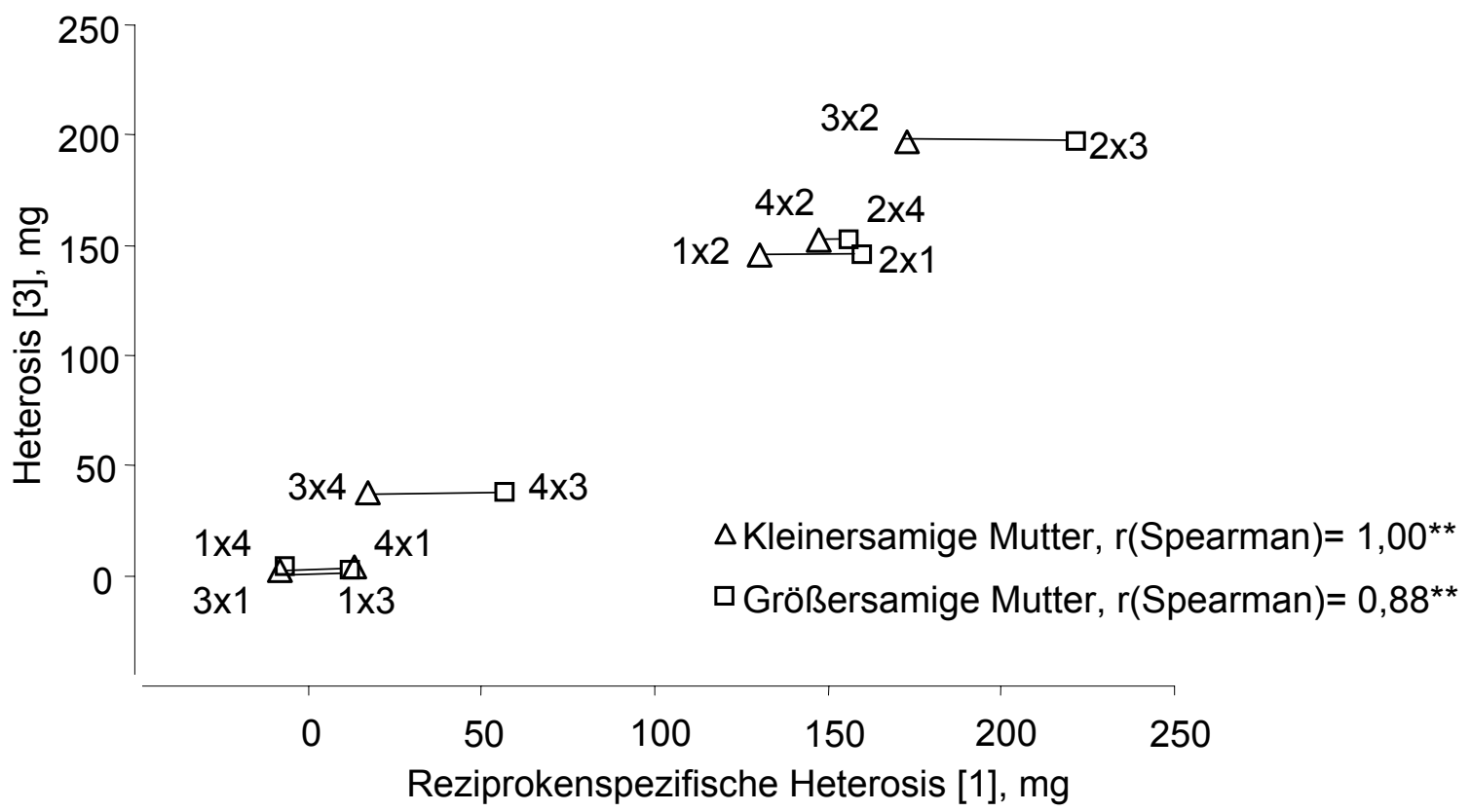

Abbildung 9: Heterosis im Vergleich über die reziproken Kreuzungsrichtungen und die Samengröße der jeweiligen Mutter, Heterosisgleichungen [1] und [3] siehe Tab.13

Auch in Abbildung 10 wird deutlich, dass die Kreuzungen mit den größersamigen Eltern höhere Gewichte aufweisen, die Samengewichte zwischen den reziproken Kreuzungen sind desto unterschiedlicher, je mehr die Eltern selbst verschieden sind.

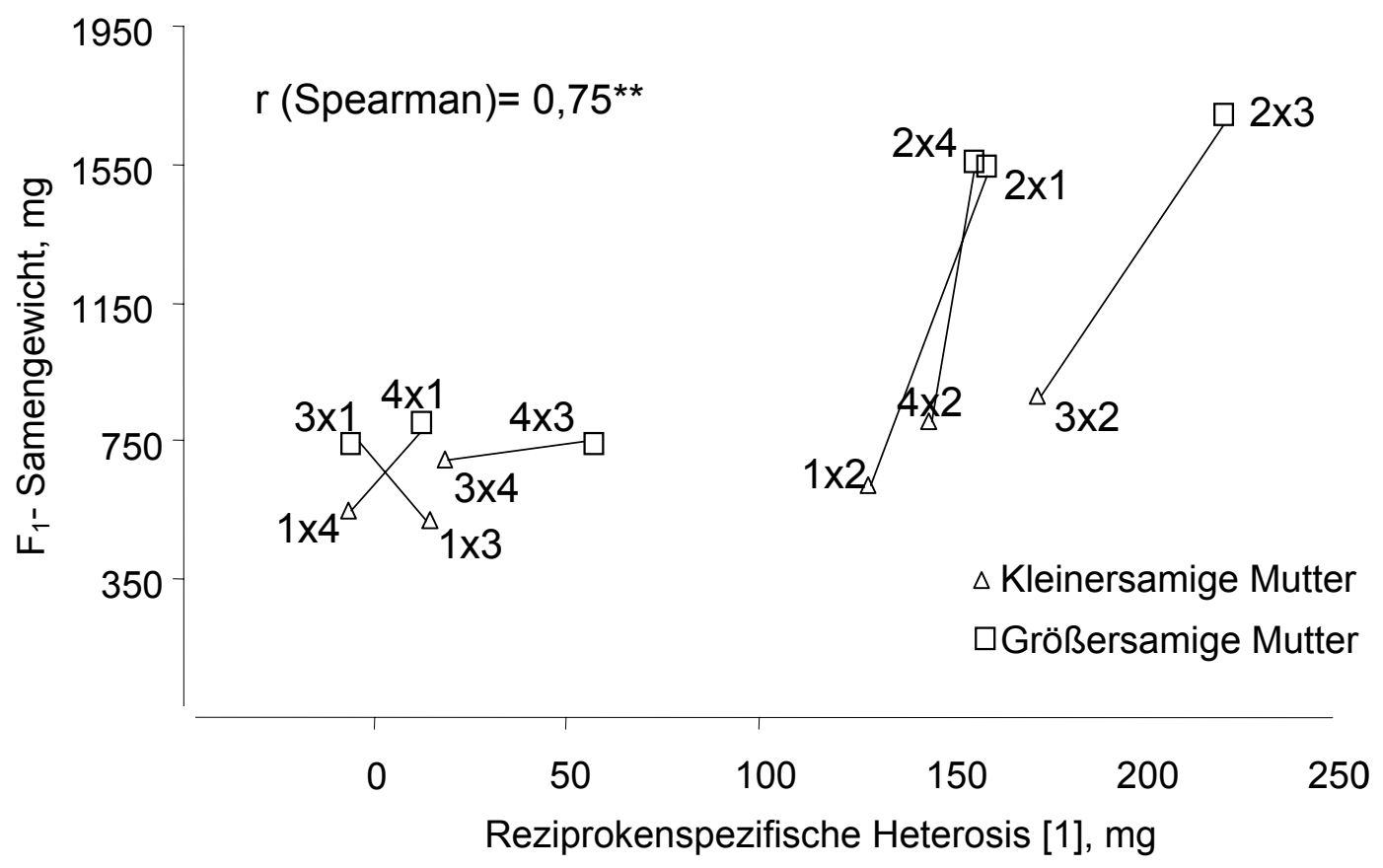

Abbildung 10: Reziprokenspezifische Heterosis der einzelnen Kreuzungen des Diallels in Abhängigkeit von dem $F_{1}$ Samengewicht, Heterosisgleichungen [1] und [3], siehe Tab.13 
Die signifikante Rangkorrelation von $0,75(P=0,01)$ deutet an, dass die Heterosis einen wichtigen Einfluß auf die Samengewichte in $F_{1}$ hat.

\subsubsection{Biomasseversuche}

Die Diallelanalyse ergibt für das Merkmal Biomasse hoch signifikante Additiv- und Dominanzvarianzen, sowie einen hoch signifikanten Einfluß des Zytoplasmas und der maternalen Dominanzvarianz. Eine Standardabweichung der Dominanzeffekte betrug 594 mg und umfasste damit eine Größe, die 56\% der Größe einer Standardabweichung (1054 mg) der Additivvarianz ausmachte. Für das Samengewicht zeigt sich kein signifikanter Einfluß der maternalen Additivvarianz auf die Biomasseproduktion (siehe Tab.15).

Tabelle 15: Genetische Varianzen der Biomasseversuche, deren Standardfehler und Signifikanzen [mg]

\begin{tabular}{lrr}
\hline Varianzkomponente & Schätzwert & Standardfehler \\
\hline Additiv & $1.111 .720^{* *}$ & 64.571 \\
Dominanz & $353.043^{* *}$ & 25.503 \\
Zytoplasmatisch & $107.693^{* *}$ & 8.088 \\
Maternal Additiv & $0^{\mathrm{NS}}$ & 0 \\
Maternal Dominanz & $871.260^{* *}$ & 38.828
\end{tabular}

NS, ${ }^{* *}$ :nicht signifikant, signifikant bei $\alpha=1 \%$

Es zeigt sich in allen Kreuzungen eine hoch signifikante Heterosis für das Merkmal Biomasse, welche positiv aber nicht signifikant korreliert mit der Samenheterosis (siehe Tab.16).

Tabelle 16: Vergleich der Heterosis $(\mathrm{H})$ der Samengewichte und der Biomasse der Kreuzungen des Diallels [mg]

\begin{tabular}{llcr}
\hline Elternkombination & Kreuzung & $\begin{array}{c}\text { H Samengewicht } \\
(\mathrm{mg})\end{array}$ & $\begin{array}{c}\text { H Biomasse } \\
(\mathrm{mg})\end{array}$ \\
\hline $2 \times 3$ & HP58 x HP69 & $193,27^{* *}$ & $2272,44^{* *}$ \\
$2 \times 4$ & HP58 x Gobo-il1 & $148,83^{* *}$ & $2468,85^{* *}$ \\
$1 \times 2$ & Hedin/2 x HP58 & $142,26^{* *}$ & $851,28^{* *}$ \\
$3 \times 4$ & $36,62^{* *}$ & $1913,13^{* *}$ \\
$1 \times 3$ & $3,48^{* *}$ & $-249,70^{* *}$ \\
$1 \times 4$ & HP69 x Gobo-il1 & $2,24^{* *}$ & $901,82^{* *}$ \\
\hline & Hedin/2 x HP69 & r (Spearman) $=0,65^{\text {NS }}$ \\
\hline
\end{tabular}

NS, ${ }^{* *}$ :nicht signifikant, signifikant bei $\alpha=1 \%$ 
Der Wassergehalt in der Biomasse lag im Mittel über alle untersuchten Genotypen bei $93 \%$ und zeigte eine geringe Variation (Variationskoeffizient $=0,0043 \%$ ) zwischen den Genotypen.

\subsection{Experiment 2: Konkurrenz}

Im Experiment 2 wurden insgesamt 11610 Samen untersucht, darunter waren 4767 fremdbefruchtete und 6841 selbstbefruchtete Samen. Auf den Pflanzen wuchsen im Mittel 17,43 Samen in 6,22 Hülsen mit einer mittleren Anzahl von 2,77 Samen pro Hülse. Die fremdbefruchteten Hülsen enthielten im Mittel 2,60 Samen, während in den selbstbefruchteten Hülsen durchschnittlich 2,90 Samen wuchsen. Die Bestäubung mit Pollenmischung in Konkurrenzsituation 2 führte für den Muttergenotyp Gloria/5 in allen drei Versuchsjahren zu einer Fremdbefruchtungsrate von $52 \%$, für den Muttergenotyp MarisBead-il1 lag die Fremdbefruchtungsrate zwischen 37\% im Jahr 2006 und 49\% in 2004 mit einem Mittelwert von 44\%.

Die Varianzanalyse des Experimentes 2 ergab hoch signifikante Unterschiede zwischen den Konkurrenzsituationen und den Behandlungen, demnach zeigten sich deutliche Unterschiede im Samengewicht der fremd- vs. selbstbefruchteten Samen (siehe Tab.17).

Tabelle 17: Auszug aus der Varianzanalyse des Experimentes 2. Merkmal: Samengewicht [mg]

\begin{tabular}{ccrrrr}
\hline Varianzursache & FG & \multicolumn{1}{c}{ MQ } & Var.kp. & F-Wert & GD $(0,05)$ \\
\hline Isolierhaus (I) & 4 & $516.580,98$ & $10.584,88$ & $60,73^{* *}$ & 39,15 \\
Mutter(M) & 1 & $14.996,49$ & 54,08 & $1,76^{\mathrm{NS}}$ & 24,76 \\
Vater(V) & 1 & 124,01 & $-69,86$ & $0,01^{\mathrm{NS}}$ & 24,76 \\
Mutter x Isolierhaus & 4 & $57.524,62$ & $2.042,41$ & $6,76^{* *}$ & 55,37 \\
Vater x Isolierhaus & 4 & 2289,19 & 118,14 & $0,27^{\mathrm{NS}}$ & 55,37 \\
Fehler 1 & 21 & $8.506,88$ & $1.114,86$ & $4,68^{* *}$ & 48,58 \\
Konkurrenzsituation (K) & 2 & $44.831,05$ & 537,67 & $24,66^{* *}$ & 13,30 \\
Behandlung (B) & 1 & $209.201,09$ & $1.728,19$ & $115,09^{* *}$ & 10,86 \\
B x K & 2 & $11.435,57$ & 240,45 & $6,29^{* *}$ & 18,82 \\
K x M & 2 & $23.341,28$ & 538,09 & $12,84^{* *}$ & 18,82 \\
K x V & 2 & 3600,07 & 44,56 & $1,98^{\mathrm{NS}}$ & 18,82 \\
K x I & 8 & $4.912,99$ & 193,45 & $2,70^{* *}$ & 29,75 \\
Fehler 2 & 174 & $1.817,73$ & $1.817,73$ & & \\
\hline
\end{tabular}

NS, ${ }^{* *}$ :nicht signifikant, signifikant bei $\alpha=1 \%$ 
Bei der Analyse der oben beschriebenen Heterosis (siehe Kap.3.1.1) wird das Mehrgewicht des Hybridsamens in Bezug auf das Elternmittel berechnet. Die Untersuchung der reziproken Kreuzungsrichtung überwindet dabei die Diskrepanz zwischen den Gewichten der elterlichen Selbstungssamen; immerhin wuchsen die jeweiligen väterlichen Selbstungssamen nicht gemeinsam mit den analysierten fremd- und selbstbefruchteten Samen auf der gleichen Pflanze. Da in Experiment 2 keine reziproken Kreuzungen untersucht wurden, kann keine Heterosis - wie in Kapitel 3.1.1 beschrieben - berechnet werden, es lässt sich vielmehr nur die Hybridüberlegenheit bezogen auf die mütterlichen Samengewichte $(\mathrm{Hy})$ analysieren (siehe Tab.18). Eine Mutterlinie wurde jeweils mit zwei Vatergenotypen bestäubt, sodass zwei Väter als neue Komponente in das genetische Modell eingeführt wurden. Die zytoplasmatischen und maternalen Effekte entfallen, da keine reziprokenspezifische Betrachtung möglich ist.

Tabelle 18: Zerlegung des genotypischen Wertes und Darstellung der Hybridüberlegenheit bezogen auf die Mutter (Hy) in Experiment 2, in Anlehnung an Zhu (1997)

Direkte genetische Effekte und ihre Koeffizienten

\begin{tabular}{ccccccccc}
\hline Samengeneration & $A_{i}$ & $A_{j}$ & $A_{k}$ & $D_{i i}$ & $D_{j j}$ & $D_{k k}$ & $D_{i j}$ & $D_{i k}$ \\
\hline$P_{i}$ Mutter & 2 & & & 1 & & & & \\
$P_{j}$ Vater1 & & 2 & & & 1 & & & \\
$P_{k}$ Vater2 & & & 2 & & & 1 & & \\
$F_{1}\left(P_{i} \times P_{j}\right)$ & 1 & 1 & & & & & 1 \\
$F_{1}\left(P_{i} \times P_{k}\right)$ & 1 & & 1 & & & 1 & \\
\hline \\
\hline$F_{1}\left(P_{i} \times P_{j}\right)-P_{i}[4]$
\end{tabular}

In Konkurrenzsituation 2 (fremd- und selbstbefruchtete Samen wuchsen gemeinsam in einer Hülse) waren die Samengewichte über beide Behandlungen und beide Mutter- und Vatergenotypen am größten (siehe Tab.19 und Tab.20), während die Unterschiede im Samengewicht der fremd- und selbstbefruchteten Samen in Konkurrenzsituation 3 (fremd- und selbstbefruchtete Samen wuchsen auf getrennten Pflanzen) am größten waren (siehe Tab.19). Wenn fremd- und selbstbefruchtete Samen gemeinsam auf einer Pflanze wuchsen (Konkurrenzsituation 1 
und 2) war der Unterschied im Samengewicht geringer, als wenn die Samen auf getrennten Pflanzen wuchsen (Konkurrenzsituation 3, siehe Tab. 19).

Tabelle 19: Mittlere Samengewichte [mg] in den Konkurrenzsituationen und Behandlungen im Mittel über Mutter- und Vatergenotypen

\begin{tabular}{cccc}
\hline \multirow{2}{*}{ Konkurrenzsituation $^{\mathrm{a}}$} & \multicolumn{2}{c}{ Behandlung } & \multirow{2}{*}{ Mittel } \\
\cline { 2 - 3 } & Kreuzung & Selbstung & \\
\hline 1 & 668,04 & 620,68 & 644,36 \\
2 & 701,50 & 658,27 & 679,89 \\
3 & 678,30 & 591,74 & 635,02 \\
\hline Mittel & 682,61 & 623,57 & 653,09 \\
\hline
\end{tabular}

GD $(0,05)$ für Behandlung x Konkurrenzsituationskombination: 18,82

${ }^{a}$ Konkurrenzsituation 1: Fremd- und selbstbefruchtete Samen wuchsen gemeinsam auf einer Pflanze in abwechselnder Reihenfolge am Nodium. K.2: Fremd- und selbstbefruchtete Samen wuchsen gemeinsam in einer Hülse. K.3: Fremd- und selbstbefruchtete Samen wuchsen auf getrennten Pflanzen

Die Überlegenheit der Hybridsamen über die Selbstungssamen (Hy, \%) zeigt sich in Konkurrenzsituation 3 am größten (siehe Tab.20).

Tabelle 20: Mittlere Samengewichte [mg] und Hybridüberlegenheit $(\mathrm{Hy}, \%$ nach Gleichung [4], Tab.18), realisiert auf den Muttergenotypen, in Abhängigkeit von Konkurrenzsituation, Vatergenotyp und Behandlung

\begin{tabular}{|c|c|c|c|c|c|c|c|c|}
\hline \multirow{4}{*}{$\begin{array}{l}\text { Mutter- } \\
\text { genotyp }\end{array}$} & \multirow{4}{*}{ Behandlung } & \multicolumn{6}{|c|}{ Vatergenotyp } & \multirow{4}{*}{ Mittel } \\
\hline & & \multicolumn{3}{|c|}{ Hedin/2, minor } & \multicolumn{3}{|c|}{ L2(MxCE), major } & \\
\hline & & \multicolumn{6}{|c|}{ Konkurrenzsituationa } & \\
\hline & & 1 & 2 & 3 & 1 & 2 & 3 & \\
\hline \multirow{4}{*}{ Gloria/5 } & Kreuzung & 667,25 & 702,60 & 680,33 & 678.98 & 740,90 & 646,98 & 686,17 \\
\hline & Selbstung & 621,32 & 686,10 & 568,44 & 653,28 & 677,11 & 599,66 & 634,32 \\
\hline & \multicolumn{8}{|c|}{ Hy [4] (\%) } \\
\hline & & 7,39 & 2,40 & 19,68 & 3,93 & 9,42 & 7,89 & \\
\hline MarisBead- & Kreuzung & 672,95 & 669,00 & 697,90 & 643,98 & 693,51 & 687,99 & 677,55 \\
\hline \multirow[t]{2}{*}{ il1 } & Selbstung & 622,40 & 628,71 & 611,45 & 585,73 & 641,17 & 592,52 & 613,66 \\
\hline & \multicolumn{8}{|c|}{$\mathrm{Hy}[4](\%)$} \\
\hline & & 8,12 & 6,41 & 14,14 & 9,94 & 8,06 & 16,11 & \\
\hline
\end{tabular}

GD $(0,05)$ für Konkurrenz x Behandlung x Mutterkombination: 26,23

${ }^{a}$ Konkurrenzsituation 1: Fremd- und selbstbefruchtete Samen wuchsen gemeinsam auf einer Pflanze in abwechselnder Reihenfolge am Nodium. K.2: Fremd- und selbstbefruchtete Samen wuchsen gemeinsam in einer Hülse. K.3: Fremd- und selbstbefruchtete Samen wuchsen auf getrennten Pflanzen 
Die beiden Vatergenotypen unterschieden sich in ihrem Einfluß auf das Samengewicht nicht, weder in den verschiedenen Konkurrenzsituationen (siehe Tab.20), noch in den unterschiedlichen Behandlungen (siehe Tab.21).

Tabelle 21: Mittlere Samengewichte [mg] über Vatergenotypen und Behandlungen im Mittel über beide Muttergenotypen

\begin{tabular}{cccc}
\hline \multirow{2}{*}{ Vatergenotyp } & \multicolumn{2}{c}{ Behandlung } & Mittel \\
\cline { 2 - 3 } & Kreuzung & $\begin{array}{c}\text { Selbstung der } \\
\text { Mütter }\end{array}$ & \\
\hline Hedin/2 (minor) & 681,67 & 623,07 & 652,37 \\
L2 (MxCE) (major) & 683,56 & 624,06 & 653,81 \\
\hline Mittel & 682,61 & 623,57 & 653,09 \\
\hline
\end{tabular}

GD $(0,05)$ für Behandlung $x$ Vatergenotypkombination: 15,36

\subsection{Experiment 3: Trockenstress}

Die Fremdbefruchtungsrate lag im Mittel über alle Genotypen und Jahre bei 42\% und schwankte je nach Muttergenotyp zwischen 38\% für Gobo-il1 und 45\% für MarisBead-il1. Die Stressvarianten beeinflussten die Fremdbefruchtungsrate kaum, im Trockenstress lag die Fremdbefruchtungsrate bei 40\%, ohne Trockenstress bei 37\% im Mittel über Jahre und Genotypen. Es wurden durchschnittlich 119 Einzelpflanzen pro Mutter und Jahr geerntet, die mittlere Anzahl Samen pro Pflanze lag bei 40. Das mittlere Samengewicht lag bei 460,34 mg, mit Minimum 270,72 mg und Maximum 789,68 mg.

Die Samengewichte der fremdbefruchteten Samen waren in allen drei Versuchsjahren höher als die der selbstbefruchteten Samen, es zeigte sich somit eine klare Überlegenheit der Hybridsamen über die mütterlichen Selbstungssamen (siehe Tab.22). 
Tabelle 22: Mittlere Samengewichte [mg] der fremd- und selbstbefruchteten Samen des Experimentes 3 und Hybridüberlegenheiten (Hy, \%) in Abhängigkeit von Jahr und Stressvariante. Mittel über Kreuzungen und Varianten

\begin{tabular}{|c|c|c|c|c|c|}
\hline \multirow{2}{*}{ Behandlung } & \multirow{2}{*}{ Stressvariante } & \multicolumn{3}{|c|}{ Jahre } & \multirow{2}{*}{ Mittel } \\
\hline & & 2004 & 2005 & 2006 & \\
\hline \multirow{2}{*}{ Kreuzung (K) } & $\begin{array}{c}\text { Ohne Trocken- } \\
\text { stress }\end{array}$ & & 604,99 & 344,44 & 484,15 \\
\hline & Trockenstress & 439,74 & 508,96 & 404,66 & 451,12 \\
\hline \multirow{2}{*}{ Selbstung (S) } & $\begin{array}{c}\text { Ohne Trocken- } \\
\text { stress }\end{array}$ & 476,77 & 572,60 & 322,46 & 457,28 \\
\hline & Trockenstress & 406,56 & 477,36 & 381,39 & 421,77 \\
\hline \multicolumn{2}{|c|}{ Hy (\%) ohne Trockenstress } & 5,50 & 5,66 & 6,82 & 5,99 \\
\hline \multicolumn{2}{|c|}{ Hy (\%) Trockenstress } & 8,16 & 6,62 & 6,10 & 6,96 \\
\hline
\end{tabular}

Auch im Mittel über beide Stressvarianten zeigte sich eine deutliche Hybridüberlegenheit der fremdbefruchteten Samen über die mütterlichen Selbstungssamen, es zeigte sich eine leichte Erhöhung der Differenz von fremd- und selbstbefruchteten Samen, wenn die Mutterpflanze unter Trockenstress gewachsen ist (siehe Tab.22).

Die Samengewichte der drei Muttergenotypen lagen zwischen 510,84 mg für Gobo-il1 und 410,57 mg für Gloria/5 im Mittel über Jahre, Vatergenotypen, Stressvarianten und Varianten. Der Trockenstress führte für alle Muttergenotypen zu einer Reduktion des mittleren Samengewichtes. Mit 17,72\% Samengewichtsreduktion zeigte Gloria/5 die geringste Toleranz gegenüber Trockenstress. Die Muttergenotypen MarisBead-il1 und Gobo-il1 reagierten mit 10,98\% und 5,79\% ebenfalls deutlich auf den Trockenstress.

Die Ertragsreduktion hat zu einer deutlichen Erhöhung der Samengewichte geführt, wobei sich kein deutlicher Einfluß der Variante auf die Hybridüberlegenheit zeigte (siehe Tab.23). 
Tabelle 23: Mittlere Samengewichte [mg] der fremd- und selbstbefruchteten Samen des Experimentes 3 in Abhängigkeit von der Variante, Mittel über Kreuzungen, Jahre und Stressvarianten

\begin{tabular}{|c|c|c|c|}
\hline \multirow[b]{2}{*}{ Behandlung } & \multicolumn{2}{|c|}{ Variante } & \multirow[b]{2}{*}{ Mittel } \\
\hline & $\begin{array}{l}\text { Ohne Ertragsreduk- } \\
\text { tion }\end{array}$ & Ertragsreduktion & \\
\hline $\begin{array}{l}\text { Kreuzung } \\
(\mathrm{K})\end{array}$ & 440,32 & 508,79 & 474,56 \\
\hline $\begin{array}{c}\text { Selbstung } \\
(\mathrm{S})\end{array}$ & 413,84 & 478,43 & 446,13 \\
\hline
\end{tabular}

GD $(0,05)$ für den Vergleich von Varianten- und Behandlungskombinationen: 8,79

Die Ergebnisse der Varianzanalyse zeigen signifikante $(P=0,01)$ Unterschiede zwischen den Behandlungen, die Hybridüberlegenheit ist auch in diesem Experiment deutlich nachweisbar (siehe Tab. 24).

Tabelle 24: Auszug aus der Varianzanalyse des Experimentes 3. Merkmal: Samengewicht [mg]

\begin{tabular}{ccrrrr}
\hline Varianzursache & FG & \multicolumn{1}{c}{ MQ } & Var.kp. & F-Wert & GD $(0,05)$ \\
\hline Jahre (J) & 2 & 303546,00 & 6189,05 & $46,90^{* *}$ & 40,18 \\
Stressvariante (S) & 1 & 82254,92 & 1083,13 & $19,27^{* *}$ & 21,84 \\
Variante (V) & 1 & 159342,83 & 2153,79 & $37,32^{* *}$ & 21,84 \\
Mutter (M) & 2 & 120667,05 & 2424,95 & $28,26^{* *}$ & 26,75 \\
S x J & 2 & 45945,90 & 1736,51 & $10,76^{* *}$ & 37,83 \\
V x J & 2 & 55647,54 & 2140,75 & $13,03^{* *}$ & 37,83 \\
Fehler 1 & 53 & 4269,61 & 1962,27 & $12,37^{*}$ & 37,28 \\
Behandlung (B) & 1 & 29086,38 & 399,18 & $84,29^{* *}$ & 6,21 \\
B x J & 2 & 272,87 & $-3,01$ & $0,79^{\text {NS }}$ & 10,76 \\
B x S & 1 & 30,91 & $-8,73$ & $0,09^{\text {NS }}$ & 8,79 \\
B x V & 1 & 135,77 & $-5,81$ & $0,39^{\text {NS }}$ & 8,79 \\
B x M & 2 & 2443,33 & 87,43 & $7,08^{* *}$ & 10,76 \\
Fehler 2 & 52 & 345,07 & 345,07 & &
\end{tabular}

NS, ${ }^{*},{ }^{* *}$ :nicht signifikant, signifikant bei $\alpha=5 \%, 1 \%$

Auch die Samengewichte der drei Muttergenotypen zwischen den drei Versuchsjahren unterschieden sich signifikant $(P=0,01)$. Ebenso hatte die Ertrags- 
normierung einen signifikanten Einfluß $(P=0,01)$ auf die mittleren Samengewichte. Die Behandlungen und die Stressvarianten interagierten nicht, so zeigte sich kein statistisch erhöhter Kontrast im Samengewicht von fremd- vs. selbstbefruchteten Samen in der einen oder anderen Stressvariante (siehe Tab.24).

\subsection{Experiment 4: Natürliche Befruchtung}

Es wurden jeweils fünf Pflanzen einer Wiederholung und Mutter x Bestäuberkombination untersucht, die durchschnittliche Samenzahl pro Mutterpflanze lag bei 57 und schwankte zwischen 25 Samen pro Pflanze für L2(MxCE) und 74 Samen pro Pflanze bei Hedin/2. Insgesamt sind pro Muttergenotyp zwischen 862 und 10058 Samen in die Ergebnisse eingegangen. Bei zwei der fünf Muttergenotypen (Goboil1 und Gloria/5) wurde anhand von Kotyledonen- bzw. Blütenfarbe zwischen fremd- und selbstbefruchteten Samen unterschieden. Für die restlichen Mutter $\mathrm{x}$ Bestäuberkombinationen wurde die Detektierung von fremd- vs. selbstbefruchteten Samen mittels Diskriminanzanalyse durchgeführt, basierend auf Spektraldaten. Die Ergebnisse der Diskriminanzanalyse wurden anhand der ermittelten Fremdbefruchtungsrate in ihrer Zuverlässigkeit bewertet, wobei alle Elternkombinationen, die bei der Mutter zu einer angeblichen Fremdbefruchtungsrate unter $25 \%$ und über $75 \%$ führen (in Anlehnung an das natürliche Bestäubungsverhalten der Ackerbohne) als Fehlinterpretationen eingeschätzt wurden. Basierend auf diesem Plausibilitätskriterium hat die Diskriminanzanalyse mit Ausnahme von acht Mutter x Bestäuber x Jahreskombinationen plausible Ergebnisse erbracht. Die Anzahl fehlender Werte (die entstehen, wenn das Spektrum eines jeweiligen Samens nicht eindeutig zu einer der beiden Gruppen, nämlich fremd- oder selbstbefruchteter Same, zuzuordnen war), lag je nach Kreuzung zwischen 6,40\% und 13,67\% mit einem Mittelwert von 10,12\%. Die ermittelte Fremdbefruchtungsrate schwankte zwischen $38 \%$ und $56 \%$ und lag im Mittel bei $47 \%$.

Die fünf Muttergenotypen zeigten teilweise deutliche Unterschiede im mittleren Samengewicht in Abhängigkeit vom Bestäubergenotyp (siehe Tab. 25). 
Tabelle 25: Mittlere Samengewichte [mg] der fremdbefruchteten Samen über die Mutter- und Vatergenotypen des Experimentes 4, Mittelwerte über Jahre

\begin{tabular}{|c|c|c|c|c|c|}
\hline \multirow{2}{*}{ Muttergenotyp } & \multicolumn{4}{|c|}{ Bestäuber } & \multirow{2}{*}{ Mittel } \\
\hline & HP58 & HP69 & Maya/2 & Merkur/2 & \\
\hline L2(MxCE) & 939,43 & 780,15 & 1 & 840,85 & 853,48 \\
\hline Gloria/5 & 370,23 & 356,11 & 357,06 & 348,26 & 444,98 \\
\hline Gobo-il1 & 374,68 & 388,94 & 402,99 & 412,00 & 394,65 \\
\hline Troy/1 & 365,22 & 400,80 & 416,10 & 379,02 & 390,29 \\
\hline Hedin/2 & l & I & 269,33 & 280,01 & 274,67 \\
\hline \multicolumn{6}{|c|}{ Mittel } \\
\hline & 512,39 & 481,50 & 361,37 & 452,03 & \\
\hline \multicolumn{6}{|c|}{ GD $(0,05)$ für den Vergleich von Bestäubern: 32,99 } \\
\hline
\end{tabular}

Für die auswertbaren Muttergenotypen konnte im Mittel über alle Väter eine positive Hybridüberlegenheit nachgewiesen werden, womit sich das Mehrgewicht der fremdbefruchteten Samen über die selbstbefruchteten auch unter offener Bestäubungssituation bestätigt hat (siehe Tab. 26).

Tabelle 26: Mittlere Samengewichte [mg] der Muttergenotypen über beide Behandlungen und Hybridüberlegenheit ( $\mathrm{Hy}, \%)$, Mittel über Väter und Jahre

\begin{tabular}{ccccc}
\hline \multirow{2}{*}{ Muttergenotyp } & \multicolumn{2}{c}{ Behandlung } & \multirow{2}{*}{ Mittel } & Hy (\%) \\
\cline { 2 - 3 } & Kreuzung & Selbstung & & \\
\hline L2(MxCE) & 853,48 & 843,85 & 848,66 & 1,14 \\
Gloria/5 & 357,91 & 351,97 & 354,94 & 1,69 \\
Gobo-il1 & 394,65 & 371,33 & 382,99 & 6,28 \\
Hedin/2* & $/$ & $/$ & $/$ & $/$ \\
Troy/1 & 390,29 & 339,27 & 364,78 & 15,04 \\
\hline \multicolumn{5}{c}{ Mittel } \\
\hline
\end{tabular}

GD $(0,05)$ für den Vergleich von Behandlungen

L2(MxCE): 60,31; Gloria/5: 5,07; Gobo-il1: 5,07; Troy/1: 14,28

* Werte für Hedin/2 fehlen 
Die Hybridüberlegenheiten schwanken je nach Kreuzung zwischen $-4,22 \%$ und 18,16\%, wobei die größten Hybridüberlegenheiten beim Muttergenotyp Troy/1 zu finden sind (siehe Abb.11). Für die Vatergenotypen kann sich kein klarer Trend feststellen lassen, allerdings war bei zwei der Kreuzungen mit höchster Hybridüberlegenheit der Vatergenotyp HP58 beteiligt.

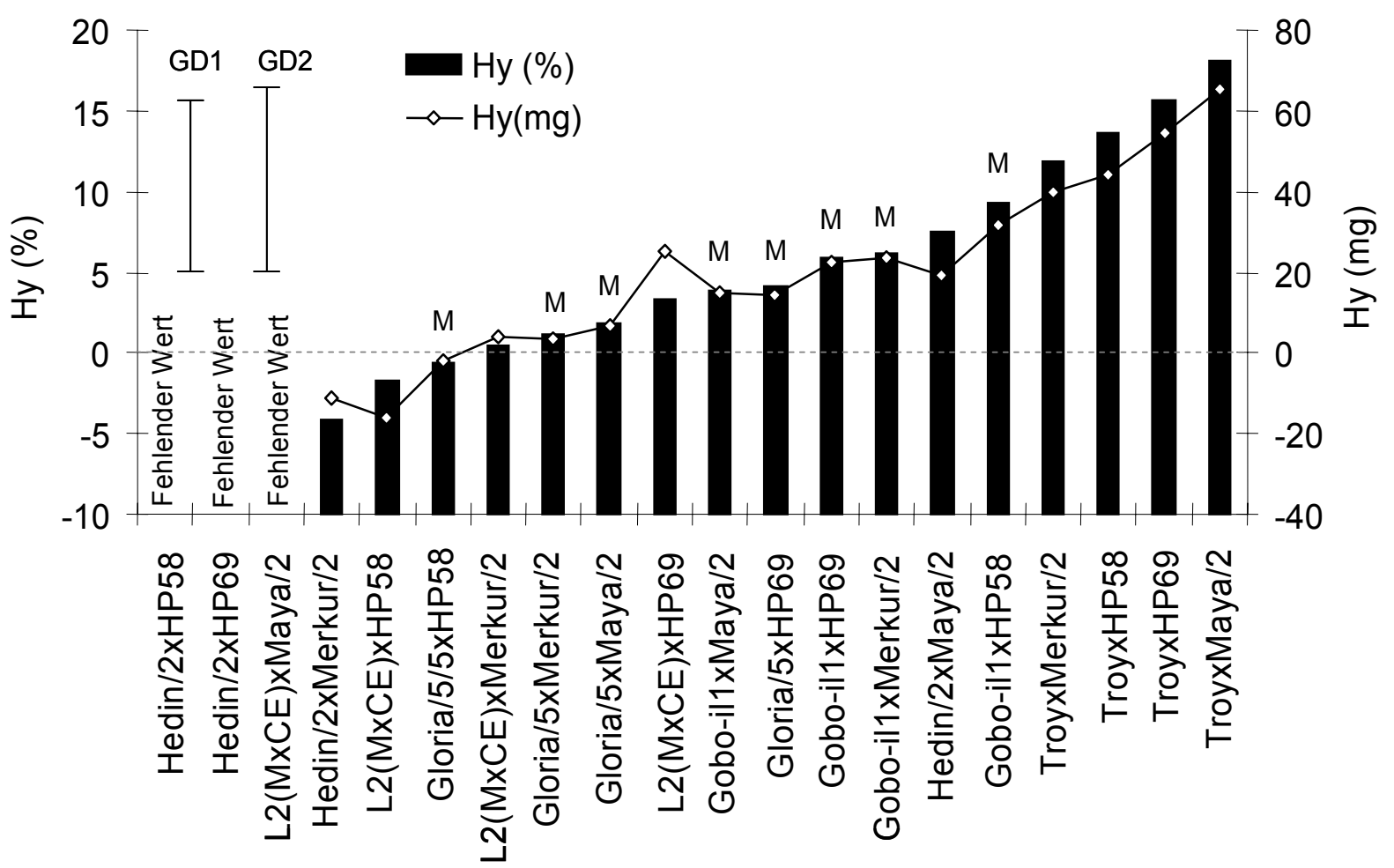

Abbildung 11: Hybridüberlegenheit $(\mathrm{Hy}, \%$ und $\mathrm{mg}$ ) der fremdbefruchteten Samen über die mütterlichen Selbstungssamen in den Kreuzungen des Experimentes 4. GD1: Grenzdifferenz $(0,05)$ für $\mathrm{Hy}(\mathrm{mg})$ der Kreuzungen mit Gobo-il1 und Gloria/5. GD2: Grenzdifferenz $(0,05)$ für Hy $(\mathrm{mg})$ der Kreuzungen mit Troy/1. M= Klassifizierung wurde mit morphologischen Markern durchgeführt.

Aufgrund mangelnder Orthogonalität der Daten konnte keine kombinierte Varianzanalyse aller Mutter $x$ Bestäuberkombinationen über drei Jahre durchgeführt werden. Die Daten wurden getrennt nach Muttergenotypen analysiert.

Für den Muttergenotyp L2(MxCE) konnten keine signifikanten Unterschiede im Samengewicht von fremd- und selbstbefruchteten Samen nachgewiesen werden, die Vatergenotypen unterschieden sich aber signifikant $(P=0,05)$ in ihrem Einfluß auf das Samengewicht der Kreuzungssamen voneinander (siehe Tab.27). Eine Varianzanalyse über mehrere Versuchsjahre war nach unseren Kriterien mit der NIRS-basierten Klassifikation zwischen fremd- und selbstbefruchteten Samen 
nicht möglich, es konnten ausschließlich Daten aus dem Jahr 2005 analysiert werden.

Tabelle 27: Auszug aus der Varianzanalyse des Genotyps L2 (MxCE) im Experiment 4

\begin{tabular}{ccrrrr}
\hline Varianzursache & FG & \multicolumn{1}{c}{ MQ } & Var.kp. & F-Wert & GD $(0,05)$ \\
\hline Wiederholungen (W) & 1 & 4475,53 & 472,64 & $2,73^{\mathrm{NS}}$ & 100,59 \\
Vater (V) & 2 & 33350,78 & 7927,77 & $20,34^{*}$ & 123,20 \\
W x V & 2 & 1639,71 & 281,04 & $1,52^{\mathrm{NS}}$ & 104,47 \\
Behandlung (B) & 1 & 278,27 & $-133,23$ & $0,26^{\mathrm{NS}}$ & 60,31 \\
B x V & 2 & 512,10 & $-282,76$ & $0,48^{\mathrm{NS}}$ & 104,47 \\
Fehler & 3 & 1077,63 & 1077,63 & &
\end{tabular}

NS, *:nicht signifikant, signifikant bei $\alpha=5 \%$

Die Varianzanalyse für die Muttergenotypen Gloria/5 und Gobo-il1 hat hoch signifikante Unterschiede zwischen den Behandlungen ergeben; die fremdbefruchteten Samen waren schwerer als die selbstbefruchteten. Auch die Muttergenotypen und die Jahre verursachten signifikante Effekte auf die Samengröße (siehe Tab. 28).

Tabelle 28: Auszug aus der Varianzanalyse der Genotypen Gloria/5 und Gobo-il1 im Experiment 4

\begin{tabular}{ccrrrr}
\hline Varianzursache & FG & \multicolumn{1}{c}{ MQ } & Var.kp. & F-Wert & GD (0,05) \\
\hline Jahre (J) & 2 & 5556,80 & 100,31 & $7,49^{*}$ & 13,60 \\
Vater(V) & 3 & 1112,77 & $-92,35$ & $0,25^{\mathrm{NS}}$ & 32,99 \\
V xJ & 6 & 6015,27 & 131,48 & $1,36^{\mathrm{NS}}$ & 57,13 \\
Mutter(M) & 1 & 28324,34 & 366,82 & $14,81^{* *}$ & 15,21 \\
V x M & 3 & 7511,82 & 311,04 & $3,93^{*}$ & 30,41 \\
M x J & 2 & 19377,11 & 727,67 & $10,13^{* *}$ & 26,34 \\
Behandlung (B) & 1 & 7712,92 & 103,95 & $33,72^{* *}$ & 5,07 \\
B x V & 3 & 73,34 & $-8,63$ & $0,32^{\mathrm{NS}}$ & 10,14 \\
B x M & 1 & 2716,98 & 69,12 & $11,88^{* *}$ & 7,17 \\
B x J & 2 & 349,57 & 5,04 & $1,53^{\mathrm{NS}}$ & 8,78 \\
Fehler & 48 & 228,71 & 228,71 & &
\end{tabular}

NS, ${ }^{*},{ }^{* *}$ :nicht signifikant, signifikant bei $\alpha=5 \%, 1 \%$ 
Die Varianzanalyse für den Muttergenotyp Troy/1 ergab hoch signifikante Unterschiede im Samengewicht der fremd- vs. selbstbefruchteten Samen. Hier fanden sich auch signifikante Unterschiede zwischen den Jahren, die Vatergenotypen unterschieden sich in ihrem Einfluß auf das Samengewicht der Kreuzungssamen nicht signifikant voneinander (siehe Tab.29).

Tabelle 29: Auszug aus der Varianzanalyse des Genotyps Troy/1 im Experiment 4

\begin{tabular}{ccrrrr}
\hline Varianzursache & FG & \multicolumn{1}{c}{ MQ } & Var.kp. & F-Wert & GD (0,05) \\
\hline Jahre (J) & 1 & 60557,79 & 2515,28 & $317,09^{* *}$ & 11,08 \\
Vater (V) & 3 & 3687,98 & 179,76 & $2,41^{\text {NS }}$ & 34,80 \\
V x J & 3 & 4802,45 & 545,26 & $3,14+$ & 49,22 \\
Behandlung (B) & 1 & 31239,23 & 1278,93 & $57,34^{* *}$ & 14,28 \\
B x V & 3 & 389,23 & $-25,85$ & $0,72 N S$ & 28,57 \\
B x J & 1 & 2303,38 & 146,55 & $4,23+$ & 20,20 \\
Fehler & 28 & 544,82 & 544,82 & &
\end{tabular}

$\mathrm{NS},+,{ }^{* *}$ :nicht signifikant, signifikant bei $\alpha=10 \%, 1 \%$

Für den Muttergenotyp Hedin/2 lagen unter Anwendung des Plausibilitätskriteriums nur unorthogonale Daten zweier Mutter x Bestäuberkombinationen vor; es wurde keine Varianzanalyse durchgeführt.

\subsection{Experiment 5: CMS Versuch}

Durchschnittlich wurden 30 Pflanzen pro Reihe geerntet. Die mittlere Anzahl Hülsen pro Pflanze betrug 16,83, es wurden durchschnittlich 46,51 Samen pro Pflanze geerntet. Im Mittel über alle Genotypen, Behandlungen und Jahre hatten die Pflanzen einen Einzelpflanzenertrag von $16,31 \mathrm{~g}$, mit einem mittleren Tausendkorngewicht von 409,09 g.

Die Varianzanalyse des Experimentes 5 zeigt keine signifikanten Unterschiede in den Einzelpflanzenerträgen der CMS-Mütter über die Behandlungen (siehe Tab. 30), die Einzelpflanzenerträge in Behandlung 1 (Mutterpflanzen wuchsen umgeben von ihrem isogenen Bestäuber, entsprechend einer Selbstbefruchtung) waren statistisch gleich mit denen in Behandlung 2 (Mutterpflanzen wuchsen umgeben von einem unverwandten Bestäuber, entsprechend einer Fremdbefruchtung). Der Einzelpflanzenertrag von rein fremdbefruchteten Mutterpflanzen war nicht höher 
als der rein selbstbefruchteter Mutterpflanzen. Die drei CMS- Muttergenotypen zeigten hoch signifikante Unterschiede für alle untersuchten Merkmale.

Tabelle 30: Auszüge aus der Varianzanalyse des Experimentes 5

\begin{tabular}{crrrrr}
\hline & & \multicolumn{5}{c}{ Mittelquadrate } \\
\cline { 3 - 6 } Varianzursache & FG & $\begin{array}{c}\text { Ertrag } \\
{[\mathrm{g}]}\end{array}$ & $\begin{array}{c}\text { Samen } \\
\text { pro Pflanze }\end{array}$ & $\begin{array}{c}\text { Hülsen pro } \\
\text { Pflanze }\end{array}$ & \multicolumn{1}{c}{ TKG } \\
\hline Jahre(J) & 1 & $47,54^{* *}$ & $591,41^{* *}$ & $63,06^{* *}$ & $2233,37^{\mathrm{NS}}$ \\
Wiederholung/Jahre & 4 & $3,20^{\mathrm{NS}}$ & $7,36^{\mathrm{NS}}$ & $0,95^{\mathrm{NS}}$ & $774,08^{\mathrm{NS}}$ \\
Mutter (M) & 2 & $784,33^{* *}$ & $17614,74^{* *}$ & $1423,00^{* *}$ & $858925,56^{* *}$ \\
Behandlung (B) & 1 & $2,60^{\mathrm{NS}}$ & $0,70^{\mathrm{NS}}$ & $0,70^{\mathrm{NS}}$ & $399,00^{\mathrm{NS}}$ \\
Behandlung x Mutter & 2 & $8,83^{\mathrm{NS}}$ & $48,65^{\mathrm{NS}}$ & $2,35^{\mathrm{NS}}$ & $4,96^{\mathrm{NS}}$ \\
Mutter x Jahre & 2 & $46,67^{*}$ & $1020,50^{* *}$ & $55,71^{*}$ & $4607,40^{\mathrm{NS}}$ \\
Behandlung x Jahre & 1 & $1,38^{\mathrm{NS}}$ & $64,85^{\mathrm{NS}}$ & $10,09^{\mathrm{NS}}$ & $1425,09^{\mathrm{NS}}$ \\
B x M x J & 2 & $3,19+$ & $137,54^{* *}$ & $7,86^{* *}$ & $1213,36+$ \\
Fehler & 16 & $9,24^{\mathrm{NS}}$ & $117,19^{\mathrm{NS}}$ & $12,56^{\mathrm{NS}}$ & $2469,77^{\mathrm{NS}}$ \\
\hline
\end{tabular}

${ }^{a}$ Behandlung 1: CMS-Mutter umgeben von isogenem Bestäuber, Behandlung 2: CMS-Mutter umgeben von unverwandtem Bestäuber. NS, $+,{ }^{*},{ }^{* *}$ :nicht signifikant, signifikant bei $\alpha=10 \%, 5 \%, 1 \%$

Die CMS- Muttergenotypen zeigten generell ein geringes Ertragsniveau, besonders die Genotypen CMS199 und CMS350 waren in ihrem Ertrag, wie in der Anzahl Samen und Hülsen pro Pflanze schwach (siehe Tab. 31 und Tab. 32).

Tabelle 31: Einzelpflanzenertrag [g] der Muttergenotypen in Abhängigkeit von der Behandlung

\begin{tabular}{cccc}
\hline Muttergenotyp & \multicolumn{2}{c}{ Behandlung } & Mittel \\
\cline { 2 - 3 } & $\begin{array}{c}\text { Isogener } \\
\text { Bestäuber }\end{array}$ & $\begin{array}{c}\text { Unverwandter } \\
\text { Bestäuber }\end{array}$ & \\
\hline CMS 199 & 11,63 & 12,42 & 12,02 \\
CMS 350 & 14,91 & 13,28 & 14,10 \\
$\mathrm{~F}_{1}$ (CMS199xHF22) & 22,95 & 22,65 & 22,80 \\
\hline & \multicolumn{3}{c}{ Mittel } \\
\cline { 2 - 3 } & 16,50 & 16,12 & 16,31 \\
\hline
\end{tabular}

GD $(0,05)$ Mutter x Behandlungskombination: 2,63 
Für die Anzahl Samen pro Pflanze und Anzahl Hülsen pro Pflanze zeigen sich keine deutlichen Unterschiede zwischen den Behandlungen (siehe Tab. 32).

Tabelle 32: Anzahl Samen pro Pflanze und Anzahl Hülsen pro Pflanze in Abhängigkeit von Muttergenotyp und Behandlung

\begin{tabular}{|c|c|c|c|c|c|c|}
\hline \multirow[b]{2}{*}{ Muttergenotyp } & \multicolumn{2}{|c|}{ Anzahl Samen/Pflanze } & \multirow[b]{2}{*}{ Mittel } & \multicolumn{2}{|c|}{ Anzahl Hülsen/Pflanze } & \multirow[b]{2}{*}{ Mittel } \\
\hline & $\begin{array}{c}\text { Isogener } \\
\text { Bestäu- } \\
\text { ber }\end{array}$ & $\begin{array}{c}\text { Unverwandter } \\
\text { Bestäuber }\end{array}$ & & $\begin{array}{l}\text { Isogener } \\
\text { Bestäuber }\end{array}$ & $\begin{array}{c}\text { Unverwandter } \\
\text { Bestäuber }\end{array}$ & \\
\hline CMS 199 & 39,60 & 42,83 & 41,21 & 16,02 & 16,54 & 16,28 \\
\hline CMS 350 & 23,67 & 21,26 & 22,46 & 9,64 & 9,20 & 9,42 \\
\hline \multirow[t]{3}{*}{$\mathrm{F}_{1}(\mathrm{CMS199xHF22)}$} & 75,98 & 75,74 & 75,86 & 25,12 & 24,46 & 24,79 \\
\hline & \multicolumn{6}{|c|}{ Mittel } \\
\hline & 46,41 & 46,51 & 46,51 & 16,93 & 16,73 & 16,83 \\
\hline \multicolumn{7}{|c|}{ GD $(0,05)$ für Mutter x Behandlungskombination } \\
\hline & \multicolumn{2}{|c|}{9,37} & \multicolumn{4}{|c|}{3,07} \\
\hline
\end{tabular}

Auch das Tausendkorngewicht der Muttergenotypen unterscheidet sich kaum zwischen den Behandlungen (siehe Tab. 33).

Tabelle 33: Tausendkorngewicht [mg] der Muttergenotypen in Abhängigkeit von der Behandlung

\begin{tabular}{|c|c|c|c|}
\hline \multirow[b]{2}{*}{ Muttergenotyp } & \multicolumn{2}{|c|}{ Behandlung } & \multirow[b]{2}{*}{ Mittel } \\
\hline & $\begin{array}{l}\text { Isogener } \\
\text { Bestäuber }\end{array}$ & $\begin{array}{c}\text { Unverwandter } \\
\text { Bestäuber }\end{array}$ & \\
\hline CMS 199 & 300,14 & 295,79 & 297,96 \\
\hline CMS 350 & 630,39 & 624,65 & 627,52 \\
\hline \multirow[t]{2}{*}{$\mathrm{F}_{1}(\mathrm{CMS} 199 \mathrm{xHF} 22)$} & 303,79 & 299,76 & 301,78 \\
\hline & \multicolumn{2}{|c|}{ Mittel } & \\
\hline
\end{tabular}

GD $(0,05)$ Mutter x Behandlungskombination: 43,01 


\section{Diskussion}

\subsection{Methodenkritik}

\subsubsection{Pflanzenmaterial}

Für die Untersuchung der Samenheterosis wurden 17 Genotypen verschiedener Herkunft und Verwandtschaftsbeziehungen verwendet. Darunter befanden sich einige Inzuchtlinien, die aus auf dem Markt erhältlichen Sorten hervorgegangen sind. Die Samengrößen variierten zwischen einem Tausendkorngewicht von $300 \mathrm{~g}$ und 1500g. Um den Einfluß der Samengröße- bestimmenden Gene auf die Samenheterosis analysieren zu können, war in Vorarbeiten die Kreuzung von Hedin/2 (minor, TKG ca. 350g) aus Schwäbisch-Hall mit Pietranera (major, TKG ca. $1800 \mathrm{~g}$ ), einer großsamigen sizilianischen Ackerbohne durchgeführt worden. Die daraus hervorgegangenen Nachkommen waren in Generation $F_{2}$ auf Samengröße selektiert worden, der jeweils kleinste und größte $\mathrm{F}_{2}$-Same war bis zur Generation $F_{13}$ ingezüchtet worden, um die daraus resultierende kleinsamige Linie HP69 und großsamige Linie HP58 als nah verwandte Genotypen (Vollgeschwister) mit unterschiedlicher Samengröße für die vorliegenden Arbeit verwenden zu können. Die genetischen Ähnlichkeiten der betroffenen Genotypen wurden von Zeid et al. (2003) untersucht. Pietranera konnte nach Analyse mit 477 polymorphen AFLPFragmenten eng zu Polycarpe geklustert werden. Beide Linien gehören zur Varietät major und sind Gemüsebohnentypen aus dem mediterranen Raum. Die Ähnlichkeit war 0,672. Hedin wurde direkt zum kleinsamigen, österreichischen Genotyp Kornberger Kleinkörnige geklustert. Beide Genotypen gehören der Varietät minor an und stammen aus Deutschland bzw. Österreich. Die Ähnlichkeit betrug 0,741. Polycarpe und Pietranera zeigten zu Hedin und Kornberger Kleinkörnige mit 0,590 eine geringe Ähnlichkeit, das war weniger als die durchschnittliche Ähnlichkeit von 8 mediterranen Ackerbohnen als Gruppe zu 40 europäischen minorAckerbohnen als Gruppe, diese Ähnlichkeit lag bei 0,642. Es ist demzufolge durchaus möglich, dass wegen großer Distanz zwischen Hedin/2 und Pietranera aus dieser Kreuzung Linien entstehen, die eine deutliche genetische Distanz zu Hedin/2 aufweisen. Diese Distanz dieser Linien zum eigenen Muttergenotyp ist eventuell nicht wesentlich kleiner als ihre Distanz zu anderen Genotypen des europäischen minor- Genpools, wie das in Experiment 1 im Fall von Gobo-il1 wäre. Hedin hatte zu Gobo (in diese Linie ist nicht die grüne Kotyledonenfarbe einge- 
kreuzt) eine relativ hohe Ähnlichkeit von 0,674, obwohl die beiden Linien nicht direkt verwandt sind. Die genetische Ähnlichkeit zwischen den Linien HP58 und HP69 ist den Ergebnissen zu Folge nicht unbedingt deutlich höher als ihre Ähnlichkeit zu anderen untersuchten Genotypen. Das würde erlauben, dass die Kreuzung dieser beiden Geschwisterlinien trotz ihrer Verwandtschaft eine hohe Samenheterosis aufweist.

Drei der 17 Genotypen ließen eine morphologische Differenzierung von fremd- vs. selbstbefruchteten Samen durch grüne Kotyledonenfarbe des Samens oder Fehlen des schwarzen Punktes am Nektarium der Jungpflanze zu (siehe Kap. 2.1). Die grüne Kotyledonenfarbe wurde von Duc et al. (1999) an einem chinesischen Ackerbohnengenotyp beschrieben. Ein monogen, rezessiv vererbter Defekt im Chlorophyllabbau des reifenden Samens führt zu der veränderten Farbe des Kotyledonengewebes (beschrieben bei Thomas et al., 1996). Dieses Samenmerkmal lässt in den vorliegenden Experimenten eine Erkennung des Inzuchtstatus des Samens bei Reife direkt auf der Mutterlinie zu. In Vorarbeiten war das Merkmal in die Elitelinien Gobo und MarisBead eingekreuzt worden. Um einen möglichen direkten Einfluß der Kotyledonenfarbe auf das Samengewicht zu untersuchen, wurden in den Jahren 2004 bis 2006 Samengewichte von grünen und gelben im Isolierhaus gewachsenen $\mathrm{BC}_{2} \mathrm{~F}_{2}$ - Samen der Genotypen MarisBead-il1 und Gobo-il1 gewogen. Im Jahr 2004 und 2005 wurden pro Genotyp drei Reihen mit jeweils acht Pflanzen pro Reihe im Isolierhaus angebaut, in 2006 wurden pro Genotyp acht Reihen mit jeweils acht Pflanzen pro Reihe im Isolierhaus angebaut. Die Pflanzen wurden nicht in ihrer Ertragsstruktur normiert, alle Blüten wurden manuell selbstbefruchtet. Die Samen einer Mutterpflanze waren in der gleichen Generation und segregierten auf derselben Pflanze für das Merkmal Kotyledonenfarbe, sodass ein Heterosis- unabhängiger Vergleich der Samengewichte von Samen mit grünen und gelben Kotyledonen möglich war. Die geernteten Samen wurden einzeln gewogen, anschließend wurde die Samenschale angeschnitten, um die Kotyledonenfarbe zu ermitteln. Die Ergebnisse haben keine signifikanten Unterschiede (Varianzanalyse nicht gezeigt) im Samengewicht der grünen und gelben Samen ergeben. Die mittleren Samengewichte der auf Gobo-il1 geernteten Samen mit grüner Kotyledonenfarbe lagen bei 568,81 mg, die Samen mit gelben Kotyledonen wogen im Mittel 560,46 mg. Die Samengewichte der auf MarisBead-il1 geernteten grünen Samen lagen bei 380,26 mg, die Samen mit gelber Kotyledonenfarbe wo- 
gen im Mittel 381,12 mg. Eine Veränderung des Samengewichtes aufgrund der Kotyledonenfarbe ist den Ergebnissen zu Folge auszuschließen.

Generell lässt sich anmerken, dass sich das für diese Arbeit eingesetzte Saatgut der Linien MarisBead-il1 und Gobo-il1 in der Rückkreuzungsgeneration 2 befand und daraus resultierend der Inzuchtstatus der selbstbefruchteten Samen nur 0,875 betrug, während bei hoch ingezüchteten $\left(F_{>12}\right)$ Linien von einem Inzuchtkoeffizienten von 1,00 auszugehen ist. Der Vergleich von Selbstungssamen und Hybridsamen auf den Mutterpflanzen MarisBead-il1 und Gobo-il1 ist also ein Vergleich von Samen mit Inzuchtkoeffizienten $F=0,875$ zu $F=0,00$, während Selbstungssamen und Hybridsamen auf hoch ingezüchteten Linien (z.B. HP69) einen Vergleich im Inzuchtkoeffizienten $F=1,00$ und $F=0,00$ zulassen. Die Heterosis, die sich für diese beiden Linien ergeben hat, ist demnach leicht unterschätzt, allerdings wurden die Linien in den drei Versuchsjahren weiter ingezüchtet, sodass eine abnehmende Unterschätzung der Heterosis stattgefunden hat. Weitere Generationen reiner Selbstung als Vorarbeit zu dieser Arbeit zur Erhöhung des Inzuchtkoeffizienten der Linien MarisBead-il1 und Gobo-il1 hätten die Diskrepanz der Inzuchtkoeffizienten der benutzten Elternlinien überwunden.

\subsubsection{Ertragsphysiologische Studien}

Die ertragsphysiologischen Untersuchungen haben gezeigt, dass sich die Samengewichte in Abhängigkeit von der Position der Infloreszenz auf der Pflanze verändern; sie nahmen ab, je höher die Hülse auf der Pflanze gewachsen war. Diese Einflußgröße auf das Samengewicht kann in den vorliegenden Experimenten vernachlässigt werden, da fremd- und selbstbefruchtete Samen, wenn sie gemeinsam auf einer Pflanze wuchsen, in gleichmäßiger Verteilung wuchsen, entweder abwechselnd nach Infloreszenz oder gemeinsam innerhalb einer Infloreszenz (Hülse). Eine systematische Veränderung der mittleren Samengewichte von fremd- oder selbstbefruchteten Samen durch die Position der Infloreszenz auf der Pflanze kann ausgeschlossen werden.

Die Samenpositionen innerhalb einer Hülse zeigten sich für alle untersuchten Genotypen nicht signifikant unterschiedlich, sodass hier ebenfalls kein Einfluß auf das Samengewicht vorherrschte.

Im Experiment 1 der vorliegenden Arbeit hat sich eine geringere Anzahl fremdbefruchteter Hülsen pro Pflanze als selbstbefruchteter Hülsen pro Pflanze im Mittel 
über alle Versuchsjahre und Genotypen ergeben. Dieser Unterschied dürfte ohne Einfluß auf das Samengewicht sein, da sich lediglich der Stichprobenumfang und damit der Standardfehler zwischen fremd- und selbstbefruchteten Hülsen unterscheiden. Die geringere Anzahl fremdbefruchteter Hülsen pro Pflanze im Vergleich zu selbstbefruchteten wird die Schätzgenauigkeit der Gewichte der fremdbefruchteten Samen verringern, aber nicht zu einer systematischen Veränderung der Samengewichte führen. Gleiches gilt für die Anzahl fremdbefruchteter- und selbstbefruchteter Samen pro Pflanze.

Für die Experimente 1 und 2 hat sich im Durchschnitt über alle Versuchsjahre und Genotypen eine höhere Anzahl Samen pro Hülse im Falle der selbstbefruchteten Hülsen ergeben, während die fremdbefruchteten Hülsen in beiden Experimenten mit weniger Samen besetzt waren (2,9 fremdbefruchtete Samen pro Hülse gegenüber 3,2 selbstbefruchtete Samen pro Hülse für Experiment1; Experiment 2 mit einem Verhältnis von 2,6 zu 2,9). Dieser Effekt scheint eine Wirkung der manuellen Fremdbestäubung zu sein und führt wohl nicht systematisch zu einer Veränderung der Samengewichte von Hybrid- und Selbstungssamen, da die Varianzanalyse für das Merkmal Anzahl Samen pro Hülse keine nennenswerten und auch keine signifikanten Unterschiede zwischen Samengewichten in zwei- bis viersamig besetzten Hülsen ergeben hat (siehe Abb. 6). Eine merkliche Erhöhung des Samengewichtes von fremdbefruchteten Samen aufgrund geringerer Samenzahl pro Hülse kann nach diesen Befunden ausgeschlossen werden. Beim Genotyp HP58 finden sich allerdings aufgrund seiner Großsamigkeit häufiger auch einsamige Hülsen, deren Auftreten einen Effekt auf die Samengröße haben dürfte (siehe Abb. 6). Solche einsamigen Hülsen traten hier aber unabhängig von der Behandlung Kreuzung oder Selbstung auf. Ein Einfluß der Anzahl Samen pro Hülse auf den Samengewichtsunterschied von fremd- und selbstbefruchteten Samen konnte auch hier ausgeschlossen werden. Da auch die Rückkreuzungssamen manuell fremdbefruchtet und die $\mathrm{F}_{2}$-Samen durch Selbstbefruchtung hergestellt wurden, beide aber den gleichen Inzuchtkoeffizienten haben, würde zusätzlich hierdurch bei der Schätzung der Heterosis ein etwaiger systematischer Effekt auf das Samengewicht vermindert. Diese Erwägungen sind bei den Experimenten 3 und 4, wo ebenfalls Hybridüberlegenheit nachgewiesen wurde, gegenstandslos, da dort sowohl Selbstung als auch Kreuzung über die natürliche Fortpflanzung mit bestäubenden Insekten ausgelöst wurde. 


\subsubsection{Nah-Infrarot-Reflexions-Spektroskopie (NIRS)}

Die Identifizierung von fremd- vs. selbstbefruchteten Samen der in offener Bestäubungssituation gewachsenen Samen wurde für einige Elternkombinationen anhand morphologischer Merkmale (Kotyledonenfarbe und Blütenfarbe) durchgeführt. Bei anderen Kombinationen von Genotypen, bei denen keine morphologischen Merkmale zur Differenzierung zur Verfügung standen, wurden die Samen mit Hilfe einer Diskriminanzanalyse, basierend auf Nah-Infrarot-ReflexionsSpektroskopie (NIRS) gemessenen Spektraldaten, als fremd- oder selbstbefruchtet eingestuft. Die Zuteilung zu einer der beiden Gruppen (fremd- oder selbstbefruchtet) geschieht nach Berechnung eines Ähnlichkeitswertes eines jeden Spektrums zu den Referenzproben (im vorliegenden Fall waren das von Hand fremdund selbstbefruchtete Samen der jeweiligen Elternkombination). Dabei werden die kompletten Spektraldaten des jeweiligen Samens mit denen der Referenzprobe verglichen. Es wird unterstellt, dass der mütterliche Selbstungssame sich in mindestens einer NIRS- relevanten Inhaltsstoffkomponente deutlich von dem auf ihr gewachsenen Kreuzungssamen unterscheidet und eine Gruppierung dadurch möglich wird. In Anlehnung an Abel and Link (2004) wurde ein Spektrum (ein Same) bei einem Ähnlichkeitswert über 1,55 zur Gruppe der Selbstungssamen oder zur Gruppe der Kreuzungssamen zugeordnet.

Der Erfolg der Gruppierung wurde in der vorliegenden Arbeit anhand der ermittelten Fremdbefruchtungsrate auf Plausibilität geprüft, dabei wurden alle Elternkombinationen mit angeblichen Fremdbefruchtungsraten zwischen 25\% und 75\% (in Anlehnung an das natürliche Bestäubungsverhalten der Ackerbohne) als plausibel eingestuft.

Es war nicht für alle Elternkombinationen eine plausible Trennung zwischen fremd- und selbstbefruchteten Samen möglich. Insbesondere die Trennung zwischen den Selbstungssamen der Mutterlinie Hedin/2 und den auf ihr gewachsenen mit HP69 und HP58 bestäubten Hybridsamen war nicht möglich. Die Diskriminanzanalyse hat fast alle Samen dieser Elternkombination (80\% im Fall von HP58, 100\% im Fall von HP69) als fremdbefruchtet klassifiziert. Eine mögliche Ursache dafür kann sein, dass die drei Linien miteinander verwandt sind und sich daher die fremd- und selbstbefruchteten Samen in ihren Inhaltsstoffen nicht deutlich genug unterscheiden. Allerdings schlug auch die Trennung zwischen Samen des Mutter- 
genotyps L2(MxCE) und $F_{1}[\mathrm{~L} 2(\mathrm{MxCE}) \times$ Maya/2] fehl, die Diskriminanzanalyse erbrachte eine angebliche Fremdbefruchtungsrate von $9 \%$.

Die mittlere Fremdbefruchtungsrate der nach Diskriminanzanalyse als plausibel eingestufen Kreuzungen lag bei 53\% und entspricht damit den Angaben in der Literatur (Link et al., 1994). Die Hybridüberlegenheiten im Experiment 4 variierten zwischen $-4,22 \%$ und 18,16\% Mehrgewicht des fremdbefruchteten Samens über seine mütterlichen Selbstungssamen. Dieses Ergebnis kann als Indiz für die erfolgreiche Klassifizierung zwischen fremd- und selbstbefruchteten Samen durch die Diskriminanzanalyse gewertet werden, da bei rein zufälliger Einsortierung von Samen in angeblich geselbstet und angeblich fremdbefruchtet keine Überlegenheit der fremdbefruchteten Samen über die selbstbefruchteten Samen im Samengewicht zu erwarten gewesen wäre. Als weiteres Argument zugunsten einer überwiegend korrekten Differenzierung zwischen fremd- und selbstbefruchteten Samen kann angeführt werden, dass die Hybridüberlegenheiten der Kreuzungen mit den Muttergenotypen Gloria/5 und Gobo-il1, bei denen die Klassifizierung unzweifelhaft mittels morphologischer Marker durchgeführt wurde, mit 1,68\% Hybridüberlegenheit für Gloria/5 im Mittel über alle Väter und 6,28\% Hybridüberlegenheit für Gobo-il1 im Mittel über alle Väter, sich unspektakulär in die Ergebnisse der anderen durch Diskriminanzanalyse untersuchten Kreuzungen eingliedern (siehe Abb. 11).

Abschließend lässt sich sagen, dass die Diskriminanzanalyse auf Basis von Spektraldaten als Methode zur Differenzierung zwischen fremd- und selbstbefruchteten Samen in den vorliegenden Experimenten für viele Kreuzungen offensichtlich erfolgreich war, aber nicht bei allen Kreuzungen eine zuverlässige Trennung zwischen fremd- und selbstbefruchteten Samen vorgenommen werden konnte. Diese Methode ist den Ergebnissen zu Folge nicht für alle Elternkombinationen einsetzbar und die Kontrollmöglichkeiten sind begrenzt. Als alternative Methode, oder zumindest als Erfolgskontrolle der Diskriminanzanalyse, hätte sich der Einsatz molekularer Marker zur Klassifizierung von fremd- vs. selbstbefruchteten Samen aus offenen Bestäubungsverhältnissen angeboten; letztere wurden von Gasim (2003) für diesen Zweck bei Vicia faba eingesetzt. 


\subsection{Samenheterosis}

Für alle durchgeführten Experimente mit Ausnahme des Experimentes 5 hat sich die Hypothese bestätigt, dass fremdbefruchtete Samen größer werden als selbstbefruchtete. Dabei schwanken die prozentualen Überlegenheiten im Samengewicht der Hybridsamen über die Selbstungssamen je nach Elternkombination zwischen -4,22\% und 19,68\% beträchtlich. In Experiment 1 der vorliegenden Arbeit konnte bestätigt werden, dass selbstverständlich maternale Effekte das Samengewicht hoch signifikant beeinflussen, dass aber auch der Samengenotyp sowohl über direkte Additiveffekte, als auch über direkte Dominanzeffekte einen hoch signifikanten und bedeutenden Einfluß auf sein eigenes Samengewicht hat. Es wurde für das genetische Individuum „Same“ signifikante Heterosis für sein eigenes Gewicht bei Reife nachgewiesen (siehe Tab. 12).

Das Gewicht eines Samens wird in zweierlei Hinsicht beeinflusst: Der Same wächst auf seiner Mutterpflanze, deren Genotyp die Versorgung des Samens mit Assimilaten und Phytohormonen steuert und damit auch die Größe der auf ihr wachsenden Samen beeinflusst. Zusätzlich hat der Same aber auch seinen eigenen Genotyp, dieser kann mehr oder weniger verschieden vom mütterlichen Genotyp sein. Er nimmt Einfluß auf sein eigenes Samengewicht. Die Abtrennung dieser beiden Einflußgrößen voneinander lässt sich durch Vergleich von fremd- und selbstbefruchteten Samen in beiden reziproken Kreuzungsrichtungen anstellen (Davies, 1975; Melchinger et al., 1984; Dani and Kohel, 1989).

Die Untersuchung von Samen aus beiden reziproken Kreuzungsrichtungen bringt zusätzlich noch weitere Vorteile mit sich. Der Vergleich des $F_{1}$-Samengewichtes mit dem mittleren Samengewicht der Eltern birgt bei Betrachtung nur einer reziproken Kreuzungsrichtung eine Gefahr: Der vergleichbare mütterliche Selbstungssame wächst gemeinsam mit dem $\mathrm{F}_{1}$-Samen auf einer Pflanze, der väterliche Selbstungssame muß aber zwangsläufig auf einer anderen Pflanze wachsen. Gerade weil das Samengewicht stark durch den maternalen Genotyp beeinflusst wird, ist der Bezug des $\mathrm{F}_{1}$-Samengewichtes auf die mütterlichen und väterlichen Selbstungssamengewichte ungenügend. In diesem Fall kann das $F_{1^{-}}$ Samengewicht ausschließlich auf das mütterliche Selbstungssamengewicht bezogen werden und daraus folgend wird bei Betrachtung nur einer reziproken Kreuzungsrichtung in der vorliegenden Arbeit nicht die Heterosis des Samengewichtes $(\mathrm{H})$, sondern vielmehr die Hybridüberlegenheit bezogen auf das mütterliche 
Selbstungssamengewicht (Hy) studiert. Die Untersuchung beider reziproker Kreuzungsrichtungen, wie in Experiment 1 vorgestellt, überwindet hingegen die Diskrepanz zwischen den elterlichen Samengewichten, indem der maternale Einfluß geschätzt, berücksichtigt und durch Mittelwertsbildung eliminiert wird. Die Schätzung der genetischen Effekte mit ihrem Einfluß auf das Samengewicht wird durch die Untersuchung verschiedener Samengenerationen möglich (siehe Tab. 34).

Tabelle 34: Reziprokendifferenzen in verschiedenen Generationen (Melchinger et al., 1984)

\begin{tabular}{cccc}
\hline \multirow{2}{*}{ Generation } & Reziprokendifferenz* & \multicolumn{2}{c}{ Reziprokendifferenz beeinflusst durch } \\
\cline { 3 - 4 } & AxB $-\mathrm{BxA}$ & Maternale Effekte & $\begin{array}{c}\text { Zytoplasmatische } \\
\text { Effekte }\end{array}$ \\
\hline $\mathrm{F}_{1}$ & $(\mathrm{AxB})^{\mathrm{s}}-(\mathrm{BxA})^{\mathrm{s}}$ & Kaum & $\mathrm{Ja}$ \\
$\mathrm{F}_{2}$ & $\mathrm{Ax}(\mathrm{AxB})-(\mathrm{AxB}) \times \mathrm{J}$ & $\mathrm{Ja}$ & $\mathrm{Ja}$ \\
$\mathrm{BC}$ & $\mathrm{Nein}$
\end{tabular}

${ }^{*} \mathrm{AxB}$ bezeichnet die Leistung der $\mathrm{F}_{1}$-Kreuzung zwischen Linie $\mathrm{A}$ (Mutter) und Linie $B$; $(A x B)^{s}$ symbolisiert die Leistung der daraus durch Selbstung entstandenen $F_{2^{-}}$ Kreuzung.

Verschiedene Studien deuten an, dass der Einfluß des maternalen Genotyps und des Samengenotyps je nach Merkmal variiert. So kann Davies (1975) durch Untersuchungen von reziproken Kreuzungen an Erbsen einen großen maternalen Einfluß auf die Merkmale Samengewicht und Kotyledonen- Zellzahlen nachweisen, reziproke $F_{1}$-Genotypen einer Kreuzung großsamiger x kleinsamiger Erbsen haben in $\mathrm{F}_{1}$, trotz gleichen Genotyps, unterschiedliche Phänotypen gezeigt. Die $F_{1}$-Samen, die auf der kleinersamigen Mutter gewachsen waren, zeigten ein deutlich geringeres Samengewicht und deutlich weniger Zellzahlen in den Kotyledonen als vergleichbare $F_{1}$-Samen der reziproken Kreuzungsrichtung, die auf der großsamigeren Mutter gewachsen waren. Zusätzlich untersuchte er die Zellgewichte in den Kotyledonen und fand, dass dieses Merkmal hauptsächlich vom eigenen Genotyp des Samens determiniert wird. Unabhängig vom mütterlichen Genotyp waren die Zellgewichte der $\mathrm{F}_{1}$-Samen sehr ähnlich. Er beschreibt den maternalen Einfluß als extrinsische Kontrolle eines Merkmals, während der samengenotypische Einfluß auf ein Merkmal als intrinsische Kontrolle beschrieben wird. Diese beiden regulatorischen Größen unterscheiden sich in verschiedenen Merkmalen und beschreiben eine größere oder geringere Ähnlichkeit des $\mathrm{F}_{1}$-Samens zum dazugehörigen mütterlichen Genotyp. Auch Grotehusmann und Röbbelen (1985) 
untersuchten Nachkommen 17 reziproker Kreuzungskombinationen an Ackerbohnen und fanden einen Entwicklungsvorteil bei Pflanzen einer reziproken Kreuzungsrichtung, die aus den jeweils größeren Samen erwachsen sind, obwohl diese genetisch identisch mit den Pflanzen der kleinsamigeren reziproken Kreuzungsrichtung waren. Sie konnten zusätzlich eine Ertragserhöhung in Abhängigkeit von der Größe der ausgesäten Samen nachweisen. Die Ergebnisse unterstreichen den starken maternalen Einfluß auf die Samen bzw. Pflanzen. Dani und Kohel (1989) untersuchten an vier Baumwolllinien und deren Reziproken in den Samengenerationen $\mathrm{P}, \mathrm{F}_{1}, \mathrm{~F}_{2}, \mathrm{BC}_{1}$ und $\mathrm{BC}_{2}$ maternale und samengenotypische Effekte auf die Merkmale Samengewicht und Ölgehalt des Samens. Sie fanden für beide Merkmale signifikante heterotische Effekte. Auch diese Autoren konnten für das Samengewicht durch maternale Effekte bedingte Unterschiede zwischen Samen aus reziproken $F_{1}-K r e u z u n g e n$ finden. Die Autoren fanden ebenfalls signifikante Additiveffekte für das Samengewicht, was sich auch in anderen Studien gezeigt hat (Suso and Cubero, 1986; Lemontey, 1999).

Duc et al. (2001) konnten signifikant höhere Samengewichte von Hybridsamen über Selbstungssamen bei Ackerbohnen nachweisen und fanden eine hoch positive Korrelation zwischen dem Samengewicht und der Kotyledonenzellzahl. Dieser Zusammenhang konnte auch von Lemontey (1999) an Erbsen festgestellt werden. Ebenso findet Davies (1977) die erhöhte Zellzahl in den Kotyledonen verschiedener Genotypen der Familie Vicia als Ursache für das höhere Samengewicht und führt zusätzlich ein erhöhtes Zellvolumen an. Darüber hinaus konnte er einen Zusammenhang zwischen Zellgröße und DNA-Gehalt in der Zelle feststellen, der zu größeren Samen führen kann. Die physiologischen Ursachen für die Erhöhung des Samengewichtes von Hybridsamen gegenüber Selbstungssamen wurden in der vorliegenden Arbeit nicht studiert, die Kotyledonenzellzahl wäre aber auch für das untersuchte Material ein interessantes Merkmal. Duc et al. (2001) beschreiben die erhöhten Kotyledonenzellzahlen und das daraus resultierende erhöhte Samengewicht des Hybridsamens im Vergleich zum Selbstungssamen als Xenie, da die Reaktion des Samengewichtes auf den Einfluß des Pollens zurückzuführen ist. Die Definition von Xenien wurde durch Focke (1881) geprägt und beschreibt den Effekt des Pollens auf den Samen oder die Frucht. Tschermark (1932) schreibt dazu: „Unter echten Xenien versteht man die Äußerungen einer selbständigen, nicht von der Mutterpflanze abhängigen Vererbungsweise bestimmter Eigenschaf- 
ten der Samen im Gefolge von Fremdbestäubung. Dieselben benehmen sich dabei nicht wie bloße Teile der Mutterpflanze, sondern wie selbständige Individuen. Die betreffenden Sameneigenschaften verhalten sich bereits wie vegetative Merkmale der aus den Samen hervorgehenden nächsten Pflanzengeneration..." Es wird zwischen Samenxenien und Fruchtstandxenien unterschieden (Tschermark, 1932). Unter den Samenxenien finden sich Farbxenien, wie die von Duc et al. (1999) an Ackerbohnen beschriebene grüne Kotyledonenfarbe, Formxenien, wie die von Mendel gefundenen runden und runzligen Erbsensamen, Chemoxenien und Größenxenien. Letztere beschreiben Erhöhungen in Größe und Gewicht des Samens als Effekt der väterlichen Gene auf den Samen. Bei der Gewichtserhöhung des Samens nach Fremdbefruchtung ist nicht zwangsläufig von einer echten Größenxenie auszugehen, wenn die Veränderung des Samens nicht weiter vererbt wird, weil von einer heterotischen Wirkung, induziert durch den fremden Pollen, ausgegangen werden kann. Die Heterosis (Heterozygotie) als Ursache einer Veränderung des Samengewichtes wird in der Literatur als falsche Xenie beschrieben (Tschermark, 1932).

\subsection{Heterosis der Biomasse}

Die Korrelation zwischen der Samenheterosis und der Heterosis für Biomasse, gemessen an der Jungpflanze, ergab für die sechs untersuchten Kreuzungen des Experimentes 1 in der vorliegenden Arbeit eine positive Rangkorrelation von $r=$ 0,65, welche auf jeweils einen Heterosiswert der sechs Elternkombinationen zurückgeht. Diese Korrelation ist mit vier Freiheitsgraden nicht signifikant von Null verschieden. Wird die Korrelation basierend auf der reziprokenspezifischen Heterosis, also mit jeweils zwei Werten pro Elternkombination errechnet, dann zeigt sich mit den 10 Freiheitsgraden eine hoch signifikante Rangkorrelation $(r=0,76$, $P=0,01)$ zwischen der Samenheterosis und der Heterosis für Biomasse (siehe Abb.12). Diese Feststellung führt dazu, die Korrelation zwischen der Samenheterosis und der Heterosis der Biomasse als abgesichert zu sehen. Die mittlere Heterosis der Biomasse zwischen unverwandten Eltern betrug 4895,48 mg, zwischen verwandten Eltern ergab sich im Mittel 3463,24 mg Heterosis. Daraus wird deutlich, dass die Heterosis der Biomasse für Kreuzungen zwischen unverwandten Eltern höher ist und damit den bekannten Grundsätzen der klassischen Heterosis folgt. Die Heterosis für Samengewichte verhält sich hier gegensätzlich; mit 62,56 
mg mittlerer Heterosis zwischen unverwandten Eltern und im Mittel 113,00 mg Heterosis bei Kreuzungen verwandter Eltern ist die Samenheterosis für verwandte Kreuzungskombinationen deutlich höher. Die hier vorliegende Verwandtschaft der Eltern scheint für die Ausprägung der Samenheterosis - im Gegensatz zur Heterosis der Biomasse - nicht von vorrangiger Bedeutung zu sein.

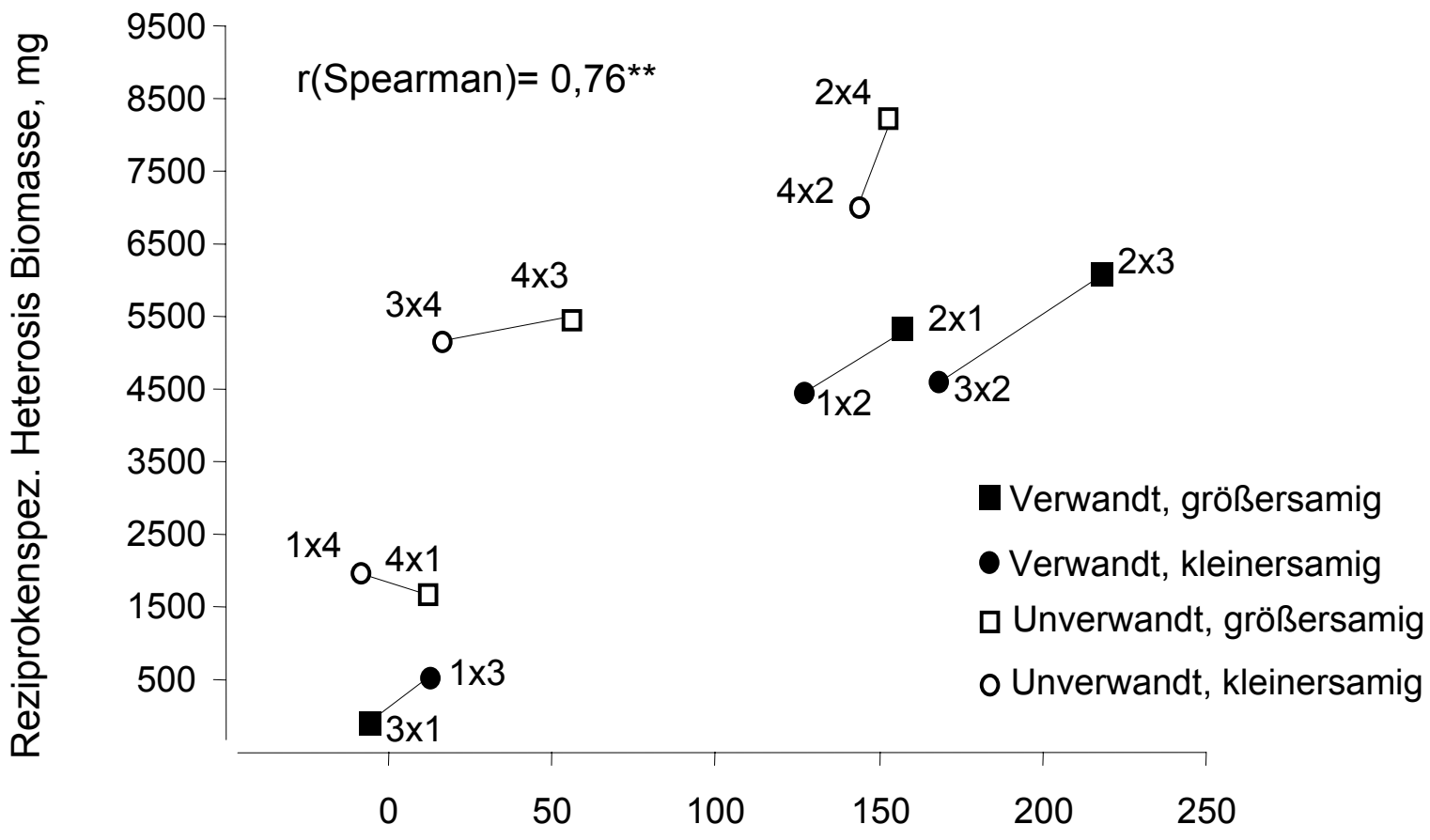

Reziprokenspez. Samenheterosis, mg

Abbildung 12:Vergleich der reziprokenspezifischen Heterosis $(H,[1]$ siehe Tab.13) der Samengewichte und der Biomasse der Kreuzungen des Diallels in Experiment 1 in Abhängigkeit von der mütterlichen Samengröße und Verwandtschaft zwischen den Kreuzungseltern [mg]

In ähnlichen Untersuchungen fanden Duc et al. (2001) an drei Ackerbohnengenotypen der Generationen $\mathrm{P}$ und $\mathrm{F}_{1}$ identische Rangfolgen für Samengewichte und Biomasseproduktionen von Hybrid- vs. Selbstungssamen und folgern daraus, dass die gewichtmäßige Überlegenheit der Hybridsamen über die Selbstungssamen ein früher Ausdruck von Heterosis ist. In Anlehnung an diese und die hier vorgestellten Ergebnisse wäre es praktisch möglich, durch Auswahl der schwereren Samen während der Saatgutvermehrung die Heterosis der späteren Population zu steigern. Bond und Pope (1984, in Duc et a., 2001) fanden heraus, dass es in Winterackerbohnen- Populationen durch Selektion großer Samen zu Ertragserhöhungen in der Population kam, was außer dem üblichen, bekannten Effekt des Herkunftswertes von Saatgut auch auf dem hier studierten Effekt beruhen kann. 
Ein Vergleich der Ergebnisse zur Heterosis der Biomasse und des Samengewichtes zeigt, dass die maternale Dominanzvarianz ohne signifikanten Einfluß auf das Samengewicht war (siehe Tab. 12) wohingegen die Biomasseproduktion der Pflanzen signifikant durch die maternale Dominanzvarianz beeinflusst war (siehe Tab. 15). Den Ergebnissen zu Folge konnte kein signifikant höheres reifes Samengewicht beobachtet werden, wenn die Samen auf Hybridpflanzen gewachsen waren, als wenn sie auf ingezüchteten Mutterpflanzen wuchsen. Die Reduktion auf acht Hülsen pro Pflanze scheint demnach zu einer ausreichenden Assimilatversorgung der Samen geführt zu haben, die unabhängig vom mütterlichen Inzuchtstatus war. Der signifikante Einfluß der maternalen Dominanzvarianz auf die Biomasseproduktion deutet allerdings an, dass Samen die auf Hybridpflanzen gewachsen waren eine deutlich höhere oberirdische Biomasseproduktion zeigten, als vergleichbare Samen die auf ingezüchteten Mutterpflanzen wuchsen. Der Inzuchtstatus der Mutterpflanze hat demnach Einfluß auf den Samen, mögliche Unterschiede in der stofflichen Zusammensetzung des Samens könnten hier eine Erklärung bringen.

\subsection{Konkurrenz um Ressourcen}

Eine zu untersuchende Hypothese war, ob der Kontrast im Samengewicht von Hybridsamen zum Samengewicht der Selbstungssamen größer ist, wenn die Mutterpflanze unter Stress wächst, wenn also Konkurrenz um Ressourcen unter den Samen herrscht. In zwei Experimenten wurde die Einwirkung verschiedener Stress- bzw. Konkurrenzsituationen auf die Hybridüberlegenheit studiert. In Experiment 2 steht die Konkurrenz um mütterliche Ressourcen zwischen den fremd- und selbstbefruchteten Samen im Fokus. Dabei ist davon auszugehen, dass die Samen insgesamt ausreichend mit Ressourcen versorgt waren, da alle Mutterpflanzen in ihrer Ertragsstruktur auf acht Hülsen begrenzt wurden. Daher kann ein möglicher Kontrast im Samengewicht einzig durch Unterschiede in der Aneignung dieser Ressourcen zwischen fremd- und selbstbefruchteten Samen bestehen. Die drei Konkurrenzsituationen führten in allen Mutter x Vaterkombinationen zu einer positiven Hybridüberlegenheit des fremdbefruchteten Samens über das Samengewicht seines mütterlichen Selbstungssamens. Es ergaben sich signifikante $(P=0,01)$ Unterschiede für die Behandlung, die Hybridüberlegenheit war statistisch signifikant. Auch die drei Konkurrenzsituationen unterschieden sich 
signifikant $(P=0,01)$ voneinander, wobei Konkurrenzsituation 3 , fremd- und selbstbefruchtete Samen wachsen auf getrennten Pflanzen, mit Abstand zu der größten Hybridüberlegenheit führte. Entgegen der Hypothese haben die Konkurrenzsituationen, in denen fremd- und selbstbefruchtete Samen gemeinsam auf einer Pflanze wuchsen im Vergleich zu der Konkurrenzsituation, in der sie auf getrennten Pflanzen wuchsen, geringere Hybridüberlegenheiten induziert. Die geringste Hybridüberlegenheit wurde in Konkurrenzsituation 2, fremd- und selbstbefruchtete Samen wachsen gemeinsam in der Hülse, beobachtet. Diese hätte hypothesengemäß am größten sein sollen, da die Konkurrenz zwischen fremd- und selbstbefruchteten Samen hier am dichtesten ist.

Davies (1975) beschreibt an Erbsen, dass heterozygote Samen eine stärkere Assimilataneignung zeigen gegenüber auf der gleichen Mutterpflanze wachsenden homozygoten Samen. Untersucht wurden die Merkmale Kotyledonenzellzahl und Samengewicht. Er weist zusätzlich darauf hin, dass Sink- Source Interaktionen auftreten können, Genotypen sich in ihrer Aneignung und Bereitstellung von Ressourcen also unterscheiden und in verschiedenen Kombinationen ergänzen können. Auch Drayner (1959) vermutet, dass fremdbefruchtete Samen in Konkurrenzsituationen den selbstbefruchteten überlegen sind. In dieser Arbeit führte das Vorhandensein von Hybrid- und Selbstungssamen auf einer Pflanze zu einer niedrigeren Hybridüberlegenheit, als wenn sie- wie in Konkurrenzsituation 3- auf getrennten Pflanzen wuchsen. Ein Grund für die große Differenz von fremd- und selbstbefruchteten Samengewichten in Konkurrenzsituation 3 könnte sein, dass die rein selbstbefruchteten Pflanzen mehr und dadurch kleinere Samen pro Pflanze produziert haben als die rein fremdbefruchteten Pflanzen, was an der manuellen Bestäubung der fremdbefruchteten Pflanzen liegen mag. Diese Deutung dürfte auf die Mutter Gloria/5 zutreffen, auf den rein selbstbefruchteten Pflanzen wuchsen im Mittel 23,13 Samen, während auf den rein fremdbefruchteten Pflanzen im Mittel 12,16 Samen wuchsen. Für den Muttergenotyp MarisBead-il1 ist der Fall nicht ganz so deutlich: Mit 23,15 Samen pro Pflanze auf den rein selbstbefruchteten Pflanzen und 16,78 Samen auf rein fremdbefruchteten Pflanzen ist die Differenz in der Anzahl Samen pro Pflanze in Konkurrenzsituation 3 auch vorhanden, aber nicht so groß wie die bei dem Muttergenotyp Gloria/5. Die geringere Anzahl Samen pro Pflanze kann die große Hybridüberlegenheit von bis zu 19,68 \% in Konkurrenzsituation 3 erklären. Eine weitere mögliche Erklärung könnte aber auch 
sein, dass bei gemeinsamem Vorhandensein von Hybrid- und Selbstungssamen auf einer Pflanze, die höhere Assimilataneignung der Hybridsamen, wie sie von Davies (1975) beschrieben wurde, auch für die Selbstungssamen einen Vorteil bringt und damit auch die Selbstungssamengewichte erhöht werden. Dadurch ergäbe sich ein geringerer Schätzwert für die Heterosis in Konkurrenzsituation 1 und 2 im Vergleich zur Konkurrenzsituation 3, wo die Selbstungssamen alleine wachsen. Dieser Ansatz setzt voraus, dass die gesamte Menge an von der Mutterpflanze in Anspruch genommenen Ressourcen bei Anwesenheit von Hybridsamen größer ist, als wenn ausschließlich selbstbefruchtete Samen auf ihr wachsen. Das Ziel des Experimentes 3 war, durch terminalen Trockenstress die Ressourcenversorgung der Pflanzen einzuschränken und damit eine Stresssituation für die Samen zu erzeugen. Im Vergleich zum Experiment 2 ist hier von einer eingeschränkten Versorgung der Mutterpflanzen und der Samen auszugehen. Kontraste im Samengewicht zwischen fremd- und selbstbefruchteten Samen können hier durch Unterschiede in der jeweiligen Assimilataneignung der Samen und zusätzlich durch selektives, Stress- induziertes Verhalten der Mutterpflanzen hervorgerufen werden. Innerhalb des Experimentes 3 wurde zusätzlich getestet, welchen Effekt Ertragsnormierungen auf die Hybridüberlegenheit haben.

Die Ergebnisse zeigen auch für diesen Versuch signifikante $(P=0,01)$ Hybridüberlegenheit über die mütterlichen Selbstungssamen. Die Hybridüberlegenheit der unter Trockenstress gewachsenen Pflanzen war im Mittel über alle Versuchsjahre nicht signifikant höher als die von Pflanzen, die ohne Trockenstress gewachsenen waren (siehe Tab. 24). Die Hypothese, der Kontrast im Samengewicht von fremdvs. selbstbefruchteten Samen wäre stärker unter Trockenstress, hat sich damit nicht bestätigt. Die in der Literatur vorherrschende Meinung steht hier nicht im Einklang mit den vorliegenden Ergebnissen.

So untersuchten Duc and Rowland (1990) Konkurrenzeffekte zwischen fremd- und selbstbefruchteten Samen an zwei Ackerbohnenlinien an offen abgeblühten Pflanzen. Sie fanden heraus, dass zwischen den sich entwickelnden Embryonen Konkurrenz um Assimilate besteht und die Hybridsamen einen wettbewerblichen Vorteil haben. Dieser Vorteil liegt aber nicht in der Befruchtung an sich, es konnte kein Vorzug des fremden Pollens bei Befruchtung festgestellt werden. Vielmehr kommt es zu einer späteren Selektion unter den befruchteten Eizellen. Bookman (1983) konnte nachweisen, dass der Muttergenotyp von Asclepias bei Angebot verschie- 
dener Pollenspender auswählt, welche Hülsen ausgebildet werden. Zusätzlich fand sie, dass die ausgewählten Pollenspender zu einem höheren Samengewicht und einer besseren Wüchsigkeit im Nachbau führten, was die Autorin darauf schließen lässt, dass Pollenspender unterschiedlich geeignet sind, die maternalen Ressourcen zu nutzen. Diese Ergebnisse würden eine mütterliche Selektion zwischen Pollenspendern unterstützen, die gegebenenfalls unter Stress verändert wäre. In dem vorliegenden Experiment wurden die von der Mutterpflanze selektierten Pollenspender nicht kontrolliert, es wäre den Ergebnissen zu Folge aber durchaus möglich, dass eine mütterliche Selektion stattgefunden hat, der eigene Pollen wurde aber nachweislich nicht weniger bevorzugt als der fremde Pollen, da sich keine Unterschiede in der Fremdbefruchtungsrate zwischen in Trockenstress gewachsenen Pflanzen (40\% Fremdbefruchtung) und ohne Trockenstress gewachsenen Pflanzen (37\% Fremdbefruchtung) ergeben haben. Dieses Ergebnis steht in gewissem Kontrast zu den Untersuchungen von Mc Vetty and NugentRigby (1984, in Duc and Rowland, 1990), die eine signifikant höhere Fremdbefruchtungsrate bei Ackerbohnen im heißen und trockenen Jahr 1980 in Manitoba feststellten, als im folgenden, vergleichsweise kühlen und feuchten Jahr, und damit eine Erhöhung der Fremdbefruchtungsrate unter Stress vermuten. Duc and Rowland (1990) fanden eine signifikant $(P=0,01)$ höhere Anzahl von Hybridsamen in den oberen Abschnitten der Infloreszenz. Dies erklärten die Autoren mit einem möglichen Vorteil für die Hybridsamen in Stresssituationen, der erst in der Entwicklung der oberen Hülsen einer Infloreszenz zur Geltung kommt, weil die Konkurrenz um Assimilate dann größer ist. Das gefundene Mehrgewicht der Hybridsamen über die Selbstungssamen war bei ihren Untersuchungen nicht signifikant. Überträgt man die Ergebnisse auf die vorliegende Arbeit, so wäre möglicherweise auch hier mit einer Erhöhung der Fremdbefruchtungsrate in der Trockenstressvariante im Vergleich zur Variante ohne Trockenstress zu rechnen gewesen, was aber nicht der Fall war. Allerdings stellen die Trockenstresshäuser keine natürliche Umwelt da, aufgrund der Bedachung mit wasserabweisender Folie ist innerhalb der Häuser ein verändertes Klima vorzufinden, was das Verhalten der bestäubenden Insekten beeinflussen kann. Auch unterscheiden sich die klimatischen Bedingungen in den Stressvarianten, so ist mit einer deutlich höheren Luftfeuchtigkeit und größeren Pflanzen in der bewässerten Variante zu rechnen. Diese umweltbedingten Unterschiede können Einfluß auf die Fremdbefruchtungsrate haben und 
den erwarteten Unterschied im Samengewicht von fremd- und selbstbefruchteten Samen überdecken.

Es hat sich in dem vorliegenden Experiment weder eine signifikante Erhöhung der Hybridüberlegenheit ergeben, noch wurde im Trockenstress eine höhere Fremdbefruchtungsrate beobachtet als in der bewässerten Variante. Die Stresssituation zeigte keinen signifikanten Einfluß auf die Hybridüberlegenheit.

\subsection{Verwandtschaft und Samengröße}

Es konnte keine Reduktion der Samenheterosis in Kreuzungen von verwandten $(f=0,5)$ Genotypen im Vergleich zu Kreuzungen unverwandter Genotypen nachgewiesen werden. Vielmehr führten in zwei Experimenten die Kreuzungen verwandter Genotypen zu besonders großen Hybridüberlegenheiten und Samenheterosis. So zeigt im Experiment 1 die Kreuzung der verwandten Linien HP58 und HP69 sogar die höchste Samenheterosis. Das könnte einerseits daran liegen, dass die beiden Linien, wie in Kapitel 4.1 beschrieben, vermutlich keine deutlich höhere genetische Ähnlichkeit zueinander aufweisen, als zu andern unverwandten Linien und andererseits daran, dass sie sich in ihrer Samengröße (und demnach den entsprechenden Allelen) sehr unterscheiden. Allerdings hat sich auch im Experiment 4 für die Kreuzung Troy/1 x Maya/2, deren Verwandtschaftskoeffizient ebenfalls $\mathrm{f}=0,5$ beträgt (Troy war Muttergenotyp für die Linie Maya) mit 18,16\% eine sehr hohe Hybridüberlegenheit ergeben (siehe Abb.11). Auf den ersten Blick zeigte sich in der vorliegenden Arbeit kein ungünstiger Einfluß von einer gewissen Verwandtschaft $(f=0,5)$ auf die Samenheterosis. Dieses Ergebnis widerspricht der im Kapitel 4.3 getroffenen Annahme, dass die Samenheterosis eine frühe Ausprägung der klassischen Heterosis an Pflanzen sei. Die Kontraste im Verwandtschaftsgrad der untersuchten Linien sind zwar relativ sicher, nicht sicher sind aber die Kontraste der jeweiligen genetischen Ähnlichkeit. Außerdem werden in der vorliegenden Arbeit nur zwei Fälle, $f=0,5$ und $f=0,0$ studiert, sodass über mögliche Unterschiede in der genetischen Basis der Samenheterosis und der klassischen Heterosis hier keine abschließenden Folgerungen zu ziehen sind. Es scheint, als könnte die Samenheterosis überwiegend eine frühzeitige Expression der Heterosis im klassischen Sinne sein, sich aber andererseits auch genetisch von ihr unterscheiden. Diese Ergebnisse könnten in detaillierten Studien auf der 
Basis von Distanzanalysen zum Einfluß der Verwandtschaft auf die Samenheterosis geprüft werden, um hier sichere Aussagen treffen zu können.

Unter den untersuchten Genotypen befanden sich zwei sehr großsamige Linien, HP58 und L2(MxCE). Beide Linien wurden sowohl als Vater und auch als Mutterpflanzen in offener und kontrollierter Bestäubungssituation eingesetzt. Die Ergebnisse zum Effekt der Samengröße auf die Hybridüberlegenheit bzw. die Samenheterosis sind etwas widersprüchlich. Die Linie HP58 führt in Experiment 1 in allen Kreuzungskombinationen, sowohl als Mutter als auch als Vater eingesetzt, zu einer hohen Samenheterosis. Auch unter natürlicher Bestäubung im Experiment 4 war HP58 Vater in zwei der fünf Kreuzungen mit den höchsten Hybridüberlegenheiten (siehe Abb. 11). Für den Genotyp L2(MxCE) ist die Situation anders: in kontrollierter Bestäubungssituation im Experiment 2 induziert der großsamige Vater keine höhere Hybridüberlegenheiten im Vergleich zum kleinsamigen Bestäubergenotyp Hedin/2 (siehe Tab. 17 und 20). Und auch unter natürlicher Bestäubung im Experiment 4 zeigt sich keine signifikante Hybridüberlegenheit wenn L2(MxCE) als Muttergenotyp eingesetzt wurde (siehe Tab. 27).

Die Frage des Einflusses von Samengröße und genetischer Distanz der Eltern auf die resultierende Samenheterosis soll am Beispiel des Experimentes 1 diskutiert werden, da in diesem Experiment vier Linien verschiedener Samengrößen und Verwandtschaftsgrade untersucht wurden. Die Hybridsamen der verschiedenen Elternkombinationen können sich sowohl in ihrer Heterozygotie für SamengrößenAllele als auch in dem Inzuchtkoeffizienten ihres Restgenoms unterscheiden (siehe Tab. 35). Ursprünglich war beabsichtigt, die beschriebenen Kontraste durch die Auswahl der untersuchten Linien aufzubauen und zu studieren, die Ergebnisse lassen nun aber Zweifel zu, ob das Restgenom von HP58 tatsächlich ähnlicher dem von HP69 und dem von Hedin/2 ist (siehe Kap. 4.1.1) und ob die Kontraste dadurch eindeutig darstellbar sind. 
Tabelle 35: Beabsichtigte genetische Ähnlichkeiten der Eltern für Samengröße und Restgenom des Experimentes 1

\begin{tabular}{cccccc}
\hline \multirow{2}{*}{ Genotyp } & $\begin{array}{c}\text { Genetisch } \\
\text { ähnlich in }\end{array}$ & Hedin/2 & HP58 & HP69 & Gobo-il1 \\
\hline \multirow{2}{*}{ Hedin/2 } & Samengröße & $/$ & Nein & Ja & Ja \\
& Restgenom & $/$ & Ja & Ja & Nein \\
\hline \multirow{2}{*}{ HP58 } & Samengröße & $/$ & Nein & Nein \\
& Restgenom & $/$ & Ja & Nein \\
\hline \multirow{2}{*}{ HP69 } & Samengröße & & $/$ & Ja \\
& Restgenom & & $/$ & Nein \\
\hline \multirow{2}{*}{ Gobo-il1 } & Samengröße & & & & $/$ \\
& Restgenom & & & & I \\
\hline
\end{tabular}

Die Gene für Samengröße in der Kreuzung von Hedin/2 und HP69 können keine große Samenheterosis induzieren, weil beide Genotypen phänotypisch ähnliche Samengrößen haben und die Allele für kleine Samen, aufgrund der Entstehung der Linie HP69, abstammungsgleich sind. Die kleinsamige Linie HP69, die aus der Kreuzung von Hedin (minor) und Pietranera (major) hervorgegangen ist, wird ihre samengrößenbestimmenden Allele hauptsächlich von ihrem kleinsamigen Muttergenotyp Hedin/2 geerbt haben, während die großsamige Linie HP58, die aus derselben Kreuzung hervorgegangen ist, in ihren samengrößenbestimmenden Allelen hauptsächlich ähnlich zur großsamigen Vaterlinie Pietranera sein wird. Die Gene für Samengröße sind demnach in der Kreuzung von Hedin/2 mit HP58 verschieden (heterozygot) und können Heterosis induzieren. Die Linie Gobo-il1 ist genetisch unverwandt zu allen anderen untersuchten Linien und zeigt daher wohl zu allen Linien keine Ähnlichkeit im Restgenom. Wenn die Samenheterosis maßgeblich und eindeutig durch die Heterozygotie des Restgenoms bestimmt wäre, könnte für die Kreuzungen mit der Linie Gobo-il1 im Mittel über alle Kreuzungen die höchste Samenheterosis erwartet werden. Dies ist nicht der Fall. Im Mittel über alle Kreuzungen zeigten die Kreuzungen mit HP58 die größte Samenheterosis. Diese Linie führt in allen Kreuzungskombinationen zu Heterozygotie für Samengröße, weil die drei anderen Linien zu ihr phänotypisch und genotypisch in der Samengröße verschieden sind. Erwartungsgemäß würde die Kreuzung von HP58 mit Gobo-il1 zu der größten Samenheterosis führen, da in diesem Fall sowohl die Samengröße als auch das Restgenom unterschiedlich zueinander sind. Diese Kreuzung führte mit $14,55 \%$ tatsächlich zu einer sehr hohen Samenheterosis, aber 
nicht zur höchsten. Allerdings führte diese Kreuzung zu der höchsten Heterosis für Biomasse (siehe Abb.12, Kapitel 4.3), was die These unterstützt, dass im Gegensatz zur Heterosis der Biomasse, die Samenheterosis scheinbar weniger abhängig von der Heterozygotie des Restgenomes ist und die Heterozygotie der samengrößenbestimmenden Gene von vorrangiger Bedeutung für die Ausprägung der Samenheterosis ist.

Es findet sich im Experiment 1 ein deutlicher Zusammenhang zwischen mütterlicher Samengröße und Samenheterosis. Je größer die mütterlichen Samen der jeweiligen Kreuzung waren, desto mehr Samenheterosis konnte für diese Kreuzung beobachtet werden, was auf dem höheren Niveau durch das höhere Samengewicht beruhen kann.

\subsection{Ertragswirkung}

Im Experiment 5 zeigten sich keine signifikanten Unterschiede im Einzelpflanzenertrag von mit isogenem Pollen bestäubten CMS- Mutterpflanzen (im Sinne einer Selbstbefruchtung) im Vergleich zu Erträgen der mit genetisch fremden Pollen bestäubten CMS- Mutterpflanzen (im Sinne einer Fremdbefruchtung). Auch die Anzahl Samen pro Pflanze, Anzahl Hülsen pro Pflanze und insbesondere das Tausendkorngewicht unterschieden sich nicht signifikant zwischen den beiden Behandlungen. Es ist für dieses Experiment demnach keine Hybridüberlegenheit der fremdbefruchteten Samen über die selbstbefruchteten Samen im TKG gefunden worden und deswegen bleibt unklar, ob der Einzelpflanzenertrag möglicherweise angestiegen wäre, wenn die übliche Samenheterosis aufgetreten wäre. Generell lässt sich anmerken, dass die eingesetzten CMS- Linien möglicherweise für diese Untersuchungen wenig geeignet waren, einerseits weil sie in Einzelpflanzenertrag, Tausendkorngewicht und Anzahl Samen und Hülsen pro Pflanze im Vergleich zu den sonst üblichen Ackerbohnenlinien deutlich unterlegen sind; andererseits mag die Sterilität der CMS- Mutterlinien zu einem untypischen Verhalten der Bestäuberinsekten und zu Veränderungen in physiologischen Prozessen führen, die in den anderen Experimenten nicht auftraten. Immerhin wird in den Experimenten 4 und 5 unterstellt, dass die Bestäuberinsekten die hauptsächliche Pollenfracht aus der unmittelbaren Umgebung gesammelt haben, was zwar der Erfahrung entspricht (Link and v. Kittlitz, 1989) aber nicht unbedingt für die Verhältnisse des Experimentes 5 gelten muß. 


\subsection{Schlußbetrachtung}

In der vorliegenden Arbeit konnte mehrfach die Hypothese 1 (siehe Kap. 1.3), dass heterozygote Samen in ihrem Samengewicht den homozygoten Samen überlegen sind, bestätigt werden. Es wurde Heterosis für das Samengewicht von bis über $18 \%$ nachgewiesen. Auch konnte gezeigt werden, dass der Samen selber einen signifikanten Einfluß auf sein eigenes Gewicht nimmt, sodass auch Hypothese 2 in der vorliegenden Arbeit bestätigt werden konnte. Hypothese 3, die genomweite Heterozygotie des Samens ist entscheidend für den heterotischen Effekt auf seine Größe konnte nicht bestätigt werden; die Ergebnisse zum Einfluß der verwandtschaftlichen Beziehung der Eltern auf die Samenheterosis waren überraschend, es konnten keine abschließenden Schlüsse gezogen werden. In der vorliegenden Arbeit hat sich eine deutliche, hoch signifikante Korrelation zwischen der Samenheterosis und der Heterosis der Biomasse ergeben, womit sich die Hypothese 4 zunächst als bestätigt erwiesen hat. Wegen der überraschenden Befunde zu Hypothese 3 bleibt aber wohl ein gewisser Unterschied, der nach den gesammelten Befunden zwischen der Genetik der Heterosis des Samens und der Heterosis einer Jungpflanze vorliegt. Direkte Konkurrenz zwischen heterozygoten und homozygoten Samen um mütterliche Ressourcen hat in den vorliegenden Untersuchungen, entgegen der Hypothese 5, nicht zu einer Erhöhung der Hybridüberlegenheit geführt. Ebenso konnte keine Erhöhung der Hybridüberlegenheit nachgewiesen werden wenn die Mutterpflanze unter Trockenstress gewachsen war. Hypothese 6, dass unter abiotischem Stress der Kontrast im Samengewicht zwischen heterozygoten und homozygoten Samen größer ist, hat sich hier nicht bestätigt. Auch Hypothese 7, dass der Einzelpflanzenertrag größer ist wenn die auf der Pflanze gewachsenen Samen heterozygot sind, hat sich hier nicht bewahrheitet, sollte aber an anderem Material weiter geprüft werden.

Die Ackerbohne hat sich für die Untersuchung der Samenheterosis aufgrund ihrer großen Samen und des geringen Anteils an Endosperm (durchgehende Diploidie des Samens) als besonders geeignet erwiesen. Weitere Grundlagen der Samenheterosis sollten in Folgearbeiten studiert werden. So bleibt unbeantwortet, welche Gene für die Ausprägung der Samenheterosis relevant sind, und inwieweit diese deckungsgleich sind mit den (ebenfalls noch überwiegend unbekannten) Genen, die die klassische Heterosis der $\mathrm{F}_{1}$-Pflanze induzieren. 
Es sollen zukünftig Untersuchungen zur mRNA- Expression durchgeführt werden. Dabei sollen durch den Einsatz von Microarrays mögliche Unterschiede zwischen Hybrid- und Selbstungssamen auf mRNA- Ebene studiert werden. Auch für entwicklungsstadien- spezifische Studien ist das untersuchte Material geeignet, um möglicherweise auftretende Unterschiede in Wachstum und Zusammensetzung zwischen Hybrid- und Selbstungssamen zu untersuchen.

Für die Heterosisforschung zeigen die vorliegenden Ergebnisse, dass Heterosis nicht erst an der $F_{1}$-Pflanze, sondern früher, nämlich bereits am $F_{1}$-Samen auftritt, und dass die Samenheterosis einerseits deutlich korreliert mit der Heterosis von Jungpflanzen, also wohl insgesamt mit Heterosis auf Pflanzenebene, sich aber die Erwartung von geringerer Heterosis bei Kreuzung zwischen verwandten Linien hier in zwei Fällen nicht bewahrheitet hat. Hohe Heterozygotie derjenigen Gene, die elterliche Unterschiede der Samengröße bewirken, führte hier überwiegend zu hoher Samenheterosis. Dieser Beitrag zur Beschreibung der Samenheterosis und zur Aufklärung der genetischen Mechanismen, die ihr zugrunde liegen, sollte durch weitere Studien erweitert und vertieft werden. 


\section{Zusammenfassung}

Heterosis, die Mehrleistung der Hybride über das Mittel ihrer homozygoten Eltern, ist ein viel untersuchtes genetisches Phänomen, das bis heute in seinen Ursachen und Wirkmechanismen noch nicht vollständig verstanden ist. Die klassische Untersuchung der Heterosis wird an Merkmalen der Pflanze, wie dem Biomasseoder Korn- Ertrag und dem Tausendkorngewicht durchgeführt. In der vorliegenden Arbeit wurde studiert, ob schon auf der Ebene des Samens als genetischem Individuum Heterosis ausgeprägt wird. Ziel der Untersuchungen war, mögliche Unterschiede im reifen Samengewicht von heterozygoten und homozygoten Samen zu finden. Außerdem sollte der Einfluß von elterlicher Verwandtschaft, elterlicher Samengröße und von verschiedenen Stresssituationen auf diese Samenheterosis analysiert werden und eine mögliche Verbindung zwischen der Samenheterosis und der klassischen Heterosis untersucht werden. Darüber hinaus sollten Effekte des Inzuchtstatus der Samen auf den Samenertrag ihrer Mutterpflanze untersucht werden.

In drei Versuchsjahren wurden insgesamt 17 Ackerbohnenlinien (Vicia faba) verschiedener Verwandtschaftsbeziehungen und Samengrößen in fünf Experimenten im Freiland, in offener und kontrollierter Bestäubungssituation, getestet. Zusätzlich wurde ein Experiment zur Verbindung zwischen Samenheterosis und klassischer Heterosis im Gewächshaus durchgeführt. Die Differenzierung zwischen fremdund selbstbefruchteten Samen geschah entweder durch Handkreuzungen in sog. Freiland-Isolierhäusern, oder es wurden in offener Bestäubungssituation morphologische Marker zur Klassifizierung eingesetzt. Ferner wurde erprobt, inwiefern fremd- und selbstbefruchtete Samen aus offener Bestäubungssituation mittels Nah-Infrarot-Reflexions-Spektrometrie (NIRS) zu differenzieren sind. Durch Einsatz eines speziellen Kreuzungsschemas konnte die Samenheterosis beider reziproker Kreuzungsrichtungen in verschiedenen Samengenerationen geschätzt werden und eine biometrische Trennung der maternalen von den sameneigenen genetischen Effekten vorgenommen werden.

Die Ergebnisse zeigen eine deutliche Überlegenheit des Samengewichtes von Hybridsamen über entsprechend vergleichbare ingezüchtete Samen; es konnte somit Heterosis für das Merkmal Samengewicht signifikant nachgewiesen werden, sie lag je nach Kreuzung zwischen 0,36\% und 18,44\% Mehrgewicht des Hybridsamens über dem homozygoten Elternwert. Die Untersuchung beider reziproker 
Kreuzungsrichtungen hat ergeben, dass das Samengewicht signifikant $(P=0,01)$ beeinflusst war durch maternal additive und zytoplasmatische Effekte, sowie durch sameneigene Dominanz- und Additiveffekte. Direkte Konkurrenz um mütterliche Ressourcen führte zu keiner Erhöhung der Hybridüberlegenheit, ebenso konnte keine höhere Überlegenheit der Hybridsamengewichte über die der Selbstungssamen nachgewiesen werden, wenn die Pflanze unter abiotischem Stress (Trockenheit) wuchs. Es wurde deutlich höhere Heterosis gefunden, wenn der Vergleich zwischen den Samengenerationen auf einem hohen Niveau der Samengröße stattfand, als wenn es sich um kleine Samen handelte. Die Ergebnisse zeigen tendenziell eine Erhöhung der Samenheterosis, wenn Heterozygotie für die elterliche Samengröße vorliegt, während keinerlei Hinweis auf geringere Heterosis bei Verwandtschaft der Eltern ( $f=0,5$; Geschwister-Linien bzw. Elter-Nachkomme) nachgewiesen werden konnte. Dieses steht im Widerspruch zu klassischen Befunden der Heterosisforschung. Es konnte eine signifikante Korrelation $(r=0,76$, $P=0,01)$ zwischen der Heterosis der Samen und der Heterosis der Biomasse von (aus diesen Samen erwachsenen) Jungpflanzen nachgewiesen werden, woraus gefolgert wurde, dass die Samenheterosis dennoch, zumindest teilweise, ähnlichen genetischen Grundsätzen folgt wie die klassische Heterosis.

Die Ergebnisse der vorliegenden Arbeit zeigen, dass Heterosis schon im frühen Entwicklungsstadium der Pflanze, am Samen, signifikant, bedeutend und mit großer Variation ausgeprägt ist. Es konnte abgeleitet werden, dass besonders die Heterozygotie für Allele, die die Samengröße der Eltern stark verschieden ausfallen lässt, in einem Samen dessen eigene Heterosis verursacht oder zumindest wesentlich bestimmt. 


\section{Summary}

Heterosis, defined as the surplus performance of the hybrid over the mean of its parents, is a well analysed phenomenon, and still since today its causes and modes of action are not yet fully understood. Classical studies on heterosis are carried out on traits of plants such as biomass, grain yield and thousand seed weight. In the present study it was analyzed whether heterosis is already expressed at the level of the seed, which is a genetic individual on its own. The objective of the present analyses was to detect potential differences for mature seed weight of heterozygous and homozygous seeds. In addition, the analyses focussed on the impact of parental relationship, parental seed size and of different types of stress on this seed heterosis. A potential connection between seed heterosis and classical heterosis should be uncovered. Furthermore, potential effects of the inbreeding status of the seeds on the seed yield of their seed parent plants were to be studied.

A number of 17 faba bean (Vicia faba) lines with different genetic relationships and seed sizes were used. Five experiments were carried out, in open field, either in open or in controlled pollination. In addition, an experiment in the greenhouse was carried out on the connection between seed heterosis and classical heterosis.

The identification of cross- and self-fertilized seeds was possible either because of manual crossing in so-called open-field-isolation-cages, or, in case of open pollination in the field, morphological markers were applied. Furthermore a study was carried out on the usefulness of Near-Infrared-Reflectance-Spectrometry (NIRS) for determining cross- vs. self-fertilized seed. A specific mating scheme was applied to estimate seed heterosis of both reciprocal cross directions across several seed generations, and a biometrical separation of maternal from genuine seedcaused effects was made possible.

The results showed a marked superiority of the weight of hybrid seeds over corresponding inbred seed; significant heterosis for the trait seed weight could be evidenced, it depended on the actual cross and amounted to between $0.36 \%$ and $18.44 \%$ of weight increment of the hybrid seed over the homozygous parental value. The analysis of the two reciprocal cross directions showed that the seed weight was significantly $(P=0.01)$ influenced by maternal additive and cytoplasmic effects, and by dominance and additive effects of the seed itself. Direct competition for maternal resources did not lead to a larger hybrid superiority, as well as no 
larger superiority of hybrid seed over selfed seed was shown in cases of abiotic stress (drought) of the seed parent plants. Markedly larger heterosis was detected if large-seeded bean types were employed than if small-seeded beans were used. The results showed a trend towards higher seed heterosis if there was heterozygosity for the parental seed size, whereas there were no hints on smaller heterosis in case or parental relationship ( $f=0.5$; sibling lines and parent-offspring). This is in contradiction to classical findings of heterosis research. A significant correlation was detected $(r=0.76, P=0.01)$ between heterosis of seeds and heterosis for biomass of young plants grown from these seeds. The conclusion was that seed heterosis at least partially follows similar genetic principles as classical heterosis. The results of the present thesis show that heterosis is significantly and markedly expressed and shows large variation at a developmental stage of a plant as early as the stage 'seed'. Heterozygosity for alleles that make two inbred parents markedly different for seed size was concluded to cause or at least substantially influence the heterosis of a seed that harbours these alleles. 


\section{$7 \quad$ Literaturverzeichnis}

Abdelmula, A. A., W. Link, E. von Kittlitz and D. Stelling, 1999: Heterosis and inheritance of drought tolerance in faba bean, Vicia faba L.. Plant Breeding 118, 485-490.

Abel, S. and W. Link, 2004: High throughput identification of crossed vs. selfed seeds in Vicia faba based on NIRS. Tagungsband: Fifth European Conference on Grain Legumes. Editor AEP, Dijon, France, 120.

Becker, H., 1993: Pflanzenzüchtung. UTB Eugen Ulmer Verlag, Stuttgart.

Birchler, J. A., D. L. Auger and N. C. Riddle, 2003: In search of the molecular basis of heterosis. Plant Cell 15, 2236-2239.

Bond, D. A. and M. Pope, 1984: Effect of seed source on performance of faba bean varieties. In: Hebblethwaite. T. C. K. Dawkins, M. C. Heath and G. Lockwood: Vicia faba: Agronomy, Physiology and Breeding, Martinus Nijhoff/ Dr. W. Junk Publishers, Dordrecht, NL, 127-133.

Bookman, S. S., 1984: Evidence for selective fruit production in Asclepias. Evolution 38(1), 72-86.

Borisjuk, L., H. Rolletschek, R. Radchuk, W. Weschke, U. Wobus and H. Weber, 2003: Seed development and differentiation: a role for metabolic regulation. Plant Physiol. 132, 1169-1206.

Chen, G. and J. Zhu, 2003: QGAStation 1.0. Software for classical quantitative genetics. Developed by Guobo Chen and Jun Zhu. Institute of Bioinformatics, Zhejang University, China.

Dani, R. G. and R. J. Kohel, 1989: Maternal effects and generation mean analysis of seed- oil content in cotton (Gossypium hirsutum L.). Theor. Appl. Genet. 77, 569-575. 
Davies, D. R., 1975: Studies of seed development in Pisum sativum. Planta 124, 297-302.

Davies, D. R., 1977: DNA contents and cell number in relation to seed size in genus Vicia. Heredity 39(1), 153-163.

Drayner, J. M., 1959: Self- and cross- fertility in field beans (Vicia faba L.). J. Agric. Sci. 53, 387-403.

Duc, G. and G. G. Rowland, 1990: The effect of ovule position on the frequency of hybrid and inbred seed in faba bean. Can. J. Plant Sci. $70,79-82$.

Duc, G., F. Moussy, X. Zong and G. Ding, 1999: Single gene mutation for green cotyledons as a marker for the embryonic genotype in faba bean, Vicia faba. Plant Breeding 118, 577-578.

Duc, G., A. Moessner, F. Moussy and C. Mousset-Déclas, 2001: A xenia effect on number and volume of cotyledon cells and on seed weight in faba bean (Vicia faba L.). Euphytica 117, 169-174.

Focke, O. W., 1881: Die Pflanzenmischlinge. Bornträger, Berlin.

Fu, H. and H. K. Dooner, 2002: Intraspecific violation of genetic colinearity and its implications in maize. Proc. Natl. Acad. Sci. USA 99, 95739578.

Gallais, A., 1988: Heterosis: its genetic basis and its utilisation in plant breeding. Euphytica 39, 95-104.

Gasim, S. E., 2003: Winter-hardy faba bean: applied genetic research on the reproductive mode of the european gene pool. Cuvillier Göttingen. 
Grotehusmann, G. and G. Röbbelen, 1985: Effects of seed weight on the performance of Vicia faba (L.). J. Agronomy and Crop Science 155, 129-136.

Jacob, J. und E. J. Jäger, 1987: Botanik. Kapitel 5. UTB Gustav Fischer Verlag, Stuttgart.

Lemontey, C., C. Mousset- Déclas, N. Munier- Jolain and J. P. Boutin, 1999: Maternal genotype influences pea seed size by controlling both mitotic activity during early embryogenesis and final endoreduplication level and cotyledon- cell size in mature seed. Journal of Experimental Botany 51, 167-175.

Link, W., W. Ederer, P. Metz, H. Buiel and A.E: Melchinger, 1994: Genotypic and environmental variation for degree of cross- fertilization in faba bean. Crop Science 34, 960-964.

Link, W., W. Ederer, R.K. Gumber and A.E. Melchinger, 1997: Detection and characterization of two new CMS systems in faba bean (Vicia faba). Plant Breeding 116, 158-162.

Link, W. and E. von Kittlitz, 1989: Rate of cross-fertilization between single plants and between plots. FABIS Newsletter, 36-39.

Lippmann, Z. B. and D. Zamir, 2006: Heterosis: revisiting the magic. Trends in Genetics 23(2), 60-66.

Lüpken, T., 2006: Untersuchungen zur Trockenheitsresistenz von vier genetisch verschiedenen Gruppen von Ackerbohnen. Masterarbeit and der Georg- August- Universität Göttingen.

Mc Vetty, P. B. E. and J. Nugent- Rigby, 1984: Natural cross pollination of faba beans (Vicia faba L.) grown in Manitoba. Can. J. Plant Sci. 64, 43-46. 
Melchinger, A. E., H. H. Geiger und F. W. Schnell, 1984: Analyse von Reziprokendifferenzen in einer Versuchsserie mit Einfachhybriden und deren $\mathrm{F}_{2^{-}}$Nachkommenschaften bei Mais. Vortr. Pflanzenzüchtg. 5, 158-172.

Meyer, R. C., O. Törjék, M. Becher and T. Altmann, 2004: Heterosis of biomass production in Arabidopsis. Establishment during early development. Plant Physiology 134, 1813-1823.

Meyer, S., H. Pospisil, S. Scholten, 2006: Heterosis associated gene expression in maize embryos 6 days after fertilization exhibits additive, dominant and overdominant pattern. Plant Mol. Biol. 63(3), 381-391.

Reif, J. C., A. R. Hallauer and A. E. Melchinger, 2005: Heterosis and heterotic patterns in maize. Maydica 50, 215-223.

Schnell, F. W., 1982: A synoptic study of the methods and categories of plant breeding. Z. Pflanzenzüchtung 89, 1-18.

Searle, S. R., 1995: An overview of variance component estimation. Metrika 42, 215-230.

Shull, G. H., 1908: The composition of a field of maize. Am. Breed. Assoc. Rep. 5, 51-59.

Suso, M. J. and J. I. Cubero, 1986: Genetic changes under domestication in Vicia faba L. Theor. Appl. Genet. 72, 364-372.

Thomas, H., M. Schellenberg, F. Vicentini and Ph. Matile, 1996: Gregor Mendel's green and yellow pea seeds. Bot. Acta. 109, 3-4.

Tsaftaris, S. A., 1995: Molecular aspects of heterosis in plants. Physiol. Plant 94, 362-370. 
Tschermark, E., 1932: Bemerkungen über echte und falsche Größen- Xenien. Zeitschrift für Züchtung, Reihe A, Band 17, 447-450.

Utz, H. F. 1996: PLABSTAT. Ein Computerprogramm zur statistischen Analyse von pflanzenzüchterischen Experimenten. Institut für Pflanzenzüchtung, Saatgutforschung und Populationsgenetik der Universität Hohenheim

Uzarowska, A., B. Keller, H.-P. Piepho, G. Schwarz, C. Ingvardsen, G. Wenzel and T. Lübberstedt, 2006: Comparative expression profiling in meristems of inbred- hybrid triplets of maize based on morphological investigations of heterosis for plant height. Plant Mol. Biol. (2007) 63, 21-34.

Zeid, M., C. C. Schön and W. Link, 2003: Genetic diversity in recent elite faba bean lines using AFLP markers. Theor. Appl. Genet. 107, 1304-1314.

Zhu, J. and B. S. Weir, 1994: Analysis of cytoplasmic and maternal effects I. A genetic model for diploid plant seeds and animals. Theor. Appl. Genet. 89, 153-159.

Zhu, J., 1997: Analysis Methods for genetic models. Agricultural Publication House of China, Beijing.

Quellen im Internet:

http://www.wetterstation-goettingen.de. Abrufdatum : 19. Januar 2007

http://www.gseis.ucla.edu/courses/ed230bc1/cnotes1/interaction.html. Education 230 B/C. Linear statistical models. Abrufdatum: 07. März 2007 


\section{Lebenslauf}

\section{Persönliche Daten:}

Name: Dieckmann, geb. Voges

Vorname: Susanne

Anschrift: Calenberger Strasse 28, 30169 Hannover

Geburtstag: 07.04.1978

Geburtsort: Hannover

Staatsangehörigkeit: deutsch

Familienstand: verheiratet

\section{Schulische Ausbildung:}

1984 - 1988 Grundschule Wennigsen am Deister

1988 - 1990 Orientierungsstufe Wennigsen am Deister

1990 - 1994 Realschule Wennigsen am Deister

1994 - 1997 Oberstufe an der Integrierten Gesamtschule Hannover/ Mühlenberg, Abschluss: Abitur

\section{Praktikum:}

07/1997 - 08/1998 Landwirtschaftliches Praktikum

\section{Studium:}

10/1998 - 08/2003 Studium der Agrarwissenschaften an der Georg- AugustUniversität Göttingen, Abschluss: Master of Science

\section{Beruflicher Werdegang:}

01/2004 - 05/2007 Promotion im Department für Nutzpflanzenwissenschaften, DFG-Projekt: Genetische Analyse von Heterosis im jüngsten Stadium einer Pflanze, als Embryo, am Beispiel der Fababohne (Vicia faba L.) 
Danksagung

Mein größter Dank gilt Herrn Prof. Dr. Wolfgang Link für die Überlassung des Themas und die hervorragende wissenschaftliche Betreuung. Sein fachliches Interesse und persönliches Engagement haben mein wissenschaftliches Verständnis geprägt und erweitert.

Auch Herrn Prof. Dr. Bernward Märländer möchte ich für die Übernahme des Korreferats und seine damit verbundene Flexibilität herzlich danken.

Regina Martsch gilt mein besonderer Dank für ihre unendlichen Bemühungen und ihren unermüdlichen Einsatz auf dem Feld und im Gewächshaus. Auch an Silke Wedemeyer geht ein großer Dank für ihre Hilfe in meinem Projekt. Sie hat mir durch ihr großes Interesse viele Anregungen und Lösungen für die praktische und theoretische Arbeit gebracht. Weiterhin danke meinen lieben und fleißigen Helfern Ulrike Kierbaum, Nicole Ritgen- Homaryounfar, Antje Otten, Bianca Rimbach, Andrea Rode, Claudia Torborg, Linda Jansson, Manuela Nagel, Anna- Lena Flux und Iris Leineweber.

Für das Wiegen der einzelnen Bohnen im Winter und die vielen Handgriffe im Sommer danke ich ganz herzlich den Mitarbeiterinnen und Mitarbeitern der Abteilung Pflanzenzüchtung des Departments für Nutzpflanzenwissenschaften und hierbei ganz besonders Helmut Gehrke, Andreas Henn, Doris Freitag, Regina Rösler und Ingrid Funke.

Für die Bereitstellung des NIRS- Sondenaufsatzes und die Hilfe bei der Auswertung der Spektraldaten danke ich Herrn Martin Hellmann und der Firma VOSS $\mathrm{GmbH}$, Hamburg.

Dr. Hans Weber danke ich für das große Interesse und die produktiven Anregungen für meine Arbeit.

Margit Dylla danke ich ganz herzlich für die mühevollen Korrekturen.

Ich danke meinen lieben Kollegen Lamiae Ghaouti und Mustapha Arbaoui für ihre fachliche Hilfe und eine tolle gemeinsame Zeit.

Schließlich danke ich meiner kleinen und großen Familie für ihre grenzenlose Unterstützung.

Diese Arbeit wurde im Rahmen des Forschungsschwerpunktes „Heterosis bei Pflanzen" von der Deutschen Forschungsgemeinschaft (DFG) finanziert. 